\title{
Anais do I Simpósio Interligas de Pesquisa e Iniciação Científica
}

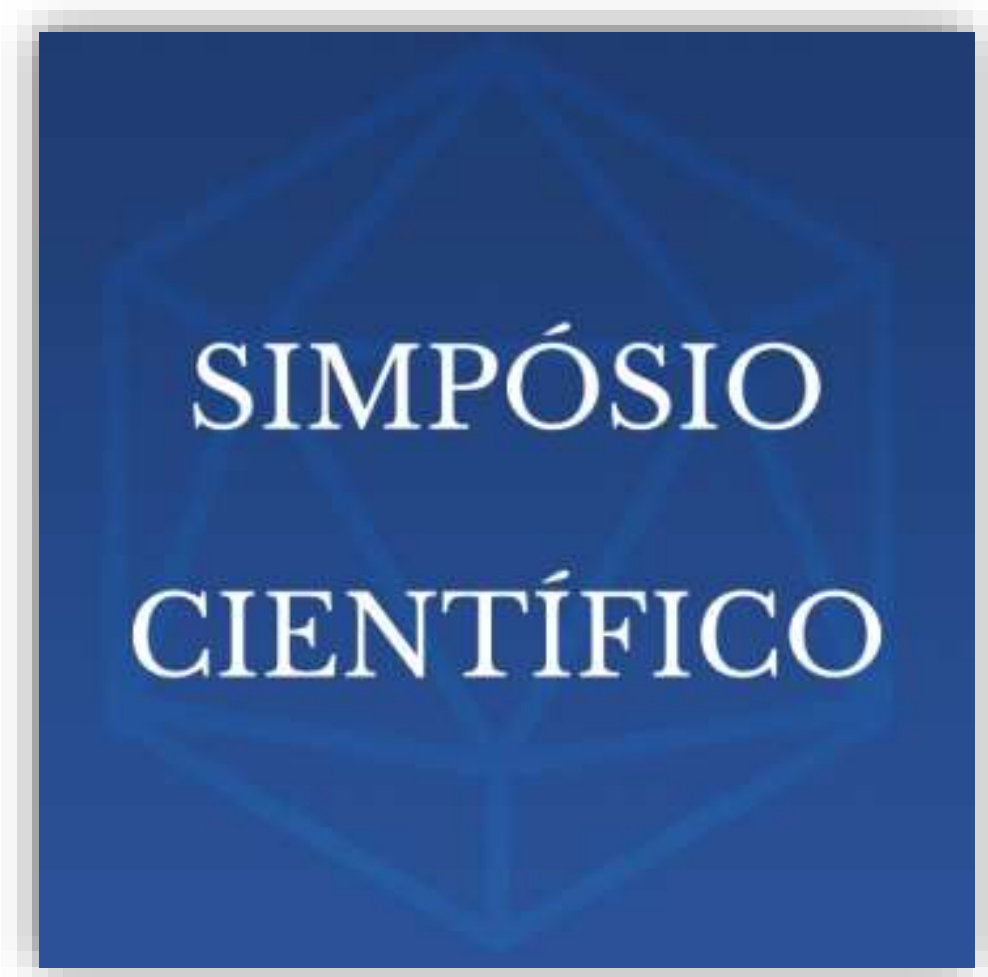

Apoio:

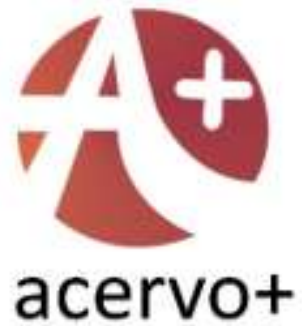

Eventos

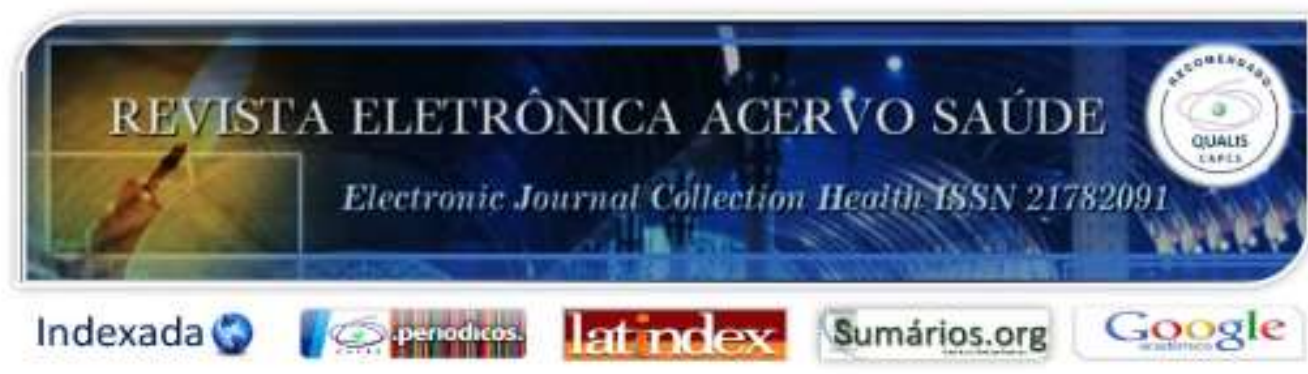




\section{SUMÁRIO}

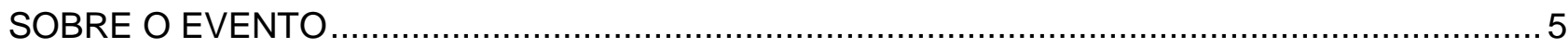

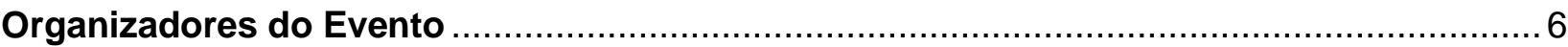

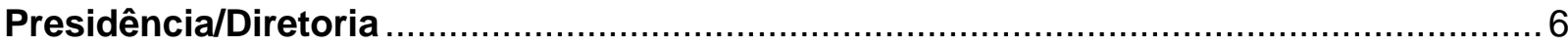

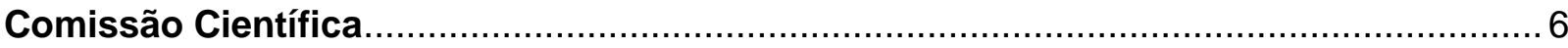

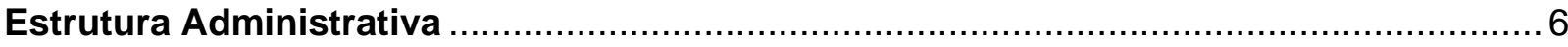

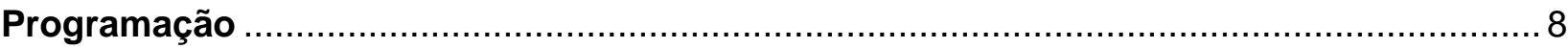

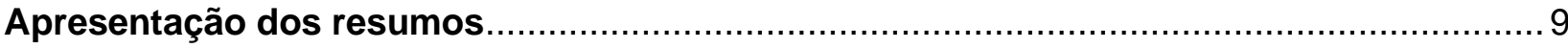

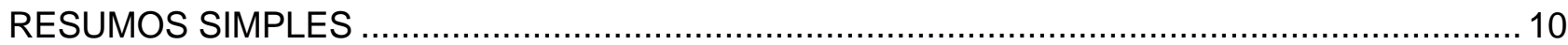

Síndrome dos Cabelos Impenteáveis: manifestação clínica, fisiopatologia e diagnóstico dessa rara patologia

Oxigenoterapia Hiperbárica como adjuvante no tratamento de feridas ................................. 13

Síndrome de Sjögren-Larsson: fatores genéticos, sintomas e tratamento .............................. 15

A rara Síndrome de Griscelli, uma breve revisão literária ................................................. 17

Uma breve revisão literária sobre Herpes Zoster na faixa pediátrica com ênfase para as

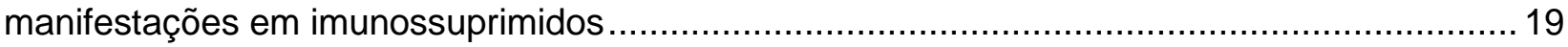

Relevância do psicólogo enquanto profissional na Atenção Básica .......................................21

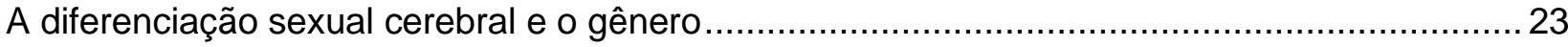

A doença de Crohn como fator de risco para câncer colorretal .............................................. 25

A importância da promoção em saúde para o acidente escorpiônico no Brasil ........................27

A influência da microbiota intestinal no desenvolvimento de transtornos mentais ................... 29

A influência dos maus-tratos na infância no desenvolvimento do Transtorno de Personalidade

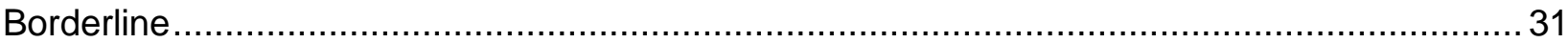

A negligência ao atendimento de dependentes químicos na Atenção Primária à Saúde e suas consequências

A terapia cognitivo comportamental por intermédio do telefone como tratamento da depressão na doença de Parkinson: uma revisão bibliográfica................................................................. 35

Aspectos nutricionais para o tratamento da doença de Crohn ............................................. 37

Ictiose Lamelar Congênita: uma revisão do impacto psicossocial na vida dos pacientes .......... 39

Infecção pelo HPV masculino relacionado ao câncer de pênis .............................................. 41

Mecanismo Neuroprotetor da Irisina aplicado a Doença de Alzheimer ................................... 43

Os componentes psicopatológicos que envolvem a doença do refluxo gastroesofágico ........... 45 
Uso do extrato de cannabis para tratamento de náuseas e vômitos induzidos por quimioterapia .47

Covid 19: dinâmica de transmissão e controle associado à vulnerabilidade ..... 49

Contribuições otorrinolaringológicas para a COVID-19 no Brasil ..... .51

Disfonia pós intubação orotraqueal . 53

Perspectiva otorrinolaringológica da doença do refluxo laringofaríngeo pediátrico 55

Hipertensão arterial e perda auditiva: uma revisão bibliográfica 57

Otorreia de tubo de timpanostomia: precauções com a água influenciam no tratamento? ....... 59

Vestibulopatias e suas interferências na qualidade de vida dos idosos 61

A moderna combinação analgésica para diminuir efeitos perioperatórios. 63

A eficiente troca de um anestésico de via inalatória para uso tópico no manejo da dor perioperatória.... 65

Violência obstétrica e o plano de parto como prevenção: revisão bibliográfica. 67

Transtornos mentais comuns em estudantes de medicina 69

Implicações psiquiátricas no profissional da saúde durante a pandemia da COVID-19..... 71

Dermatite atópica no cenário adolescente: $O$ aspecto biopsicossocial no contexto pandêmico. 73 Descumprimento do calendário vacinal infantil e a sua relação com a ineficácia no controle da pneumonia 75

Hidradenite supurativa: uma revisão acerca dos principais medicamentos utilizados no tratamento .77

Relação entre psoríase e doenças metabólicas: uma revisão . .79

Agulhamento cutâneo e peptídeos antimicrobianos: uma alternativa para o quelóide..... .81

Fraturas Vertebrais por Insuficiência em Idosos.... .83

Fatores de Risco Envolvidos no Desenvolvimento da Síndrome do Túnel do Carpo. .85

Entorse de tornozelo: mecanismo, diagnóstico e tratamento das lesões ligamentares .87

A importância do rastreio precoce da toxoplasmose congênita no teste do pézinho .89

Efeitos sistêmicos do uso de corticoides tópicos intranasais no tratamento da rinite: uma revisão bibliográfica.

Síndrome da Apnéia Obstrutiva do Sono (SAOS) em crianças: a importância do diagnóstico precoce perante suas possíveis complicações. .93

Zumbido e Saúde Mental: o desenvolvimento de desordens psicoemocionais e fisiológicas ....95

Síndrome de Ortner: Um desafio diagnóstico .................................................................... 97

Efeitos a longo prazo do uso profilático de azitromicina contra a Covid-19............................. 99

Sintomas otoneurológicos associados a clínica da Covid-19 ........................................... 101 
Aumento de preenchimentos faciais com Ácido Hialurônico: a importância do conhecimento do protocolo de prevenção e identificação de possíveis complicações. 103

O uso do ácido tranexâmico na abordagem inicial ao trauma. 105

Lúpus Eritematoso Sistêmico (LES): a importância da detecção precoce das possíveis complicações cardiovasculares desencadeadas pela síndrome 107

AGRADECIMENTOS 109 


\section{SOBRE O EVENTO}

O I Simpósio Interligas de Pesquisa e Iniciação Científica será um evento diferente do que vem sendo praticado na área e trará discussões da área científica no âmbito da Medicina. O evento tem como objetivo disseminar o conhecimento e aprimorar os saberes científicos para os acadêmicos de Medicina, fomentando assim a busca do conhecimento ao promover assuntos ligados à área médica. Diante de um cenário hostil, tornou-se fundamental enriquecer ainda mais a ciência da saúde, com trabalhos que visam esclarecer informações ainda não questionadas, prosperando assim o aprendizado.

O evento proporcionará aos acadêmicos palestras que aspiram desenvolver o seu potencial científico, assim como suas habilidades médicas. O I Simpósio Interligas de Pesquisa e Iniciação Científica é organizado por acadêmicos do Centro Universitário Atenas (UniAtenas, Paracatu) e Centro Universitário de Brasília (Uniceub), e acontecerá em ambiente virtual no dia 10 de fevereiro de 2021.

\section{EDUARDO HENRIQUE ANTUNES MANN}

Presidente da Comissão Organizadora do I Simpósio Interligas de Pesquisa e Iniciação Científica

SABRINA ALVES MAIA

Vice-presidente da Comissão Organizadora do I Simpósio Interligas de Pesquisa e Iniciação Científica

MARIANA DE PAULA FERREIRA

Diretora Científica do I Simpósio Interligas de Pesquisa e Iniciação Científica

CRISNA RODRIGUES PEREIRA

Orientadora do I Simpósio Interligas de Pesquisa e Iniciação Científica 


\title{
Organizadores do Evento
}

\author{
Presidência/Diretoria \\ Eduardo Henrique Antunes Mann - Presidente \\ Sabrina Alves Maia - Vice-Presidente
}

Comissão Científica

Orientadora do evento

Crisna Rodrigues Pereira

Diretora científica

Mariana de Paula Ferreira

Integrantes da comissão científica

Gabriela Teixeira Lima

Jassiara Soares da Silva

Guilherme Mendes Galvão

Gabriel Araújo Nascimento

João Lucas Pereira Mariano

Diogo Borges Ferreira

\section{Estrutura Administrativa}

Raquel de Oliveira Brito

Palestras

Pedro Eduardo Murad Porto

Palestras

Rafaela Borges Nogueira

Palestras 


\author{
Ize Amanda Pereira Marques \\ Palestras \\ Gabriel Meira Cardoso Pereira \\ Palestras \\ Maria Carolina Martins Caixêta \\ Palestras
}




\section{Programação}

\begin{tabular}{|c|c|c|}
\hline \multirow{2}{*}{ ATIVIDADE } & \multicolumn{2}{|c|}{ HORÁRIO } \\
\cline { 2 - 3 } & INÍCIO & TÉRMINO \\
\hline \multicolumn{2}{|c|}{$\mathbf{1 0 / 0 2 / 2 0 2 1}$} \\
\hline Cerimônia de Abertura & $18: 00$ & $18: 30$ \\
\hline Palestra 1 & $18: 30$ & $19: 20$ \\
\hline Palestra 2 & $19: 20$ & $20: 00$ \\
\hline Palestra 3 & & \\
\hline & $20: 00$ & $20: 40$ \\
\hline
\end{tabular}




\section{Apresentação dos resumos}

"O conhecimento é em si mesmo um poder".

Francis Bacon

A pesquisa científica na Medicina é importantíssima no desenvolvimento de um acadêmico. Através dela, o estudante pode aprender um contexto mais amplo da área médica, e até mesmo acrescentar pontos que não conseguem ser explicados em um ambiente de aprendizado convencional, podendo fornecer mais riqueza e versatilidades aos temas até então conhecidos. O I Simpósio Interligas de Pesquisa e Iniciação Científica consolidou esta árdua missão de disseminar o conhecimento científico através da promoção do aprendizado na área da saúde, assim como o incentivo à produção de trabalhos. O evento possibilitou a submissão, avaliação e apresentação de resumos simples na forma de revisões bibliográfica, estudos de caso, relatos de experiência e estudos originais. O evento teve como intuito incentivar estudantes de medicina de graduação a crescer no ambiente científico, apoiando-os na formulação de novas questões a serem resolvidas e estimulando etapas de pesquisa a fim de gerar novos conhecimentos ou fortalecer os anteriores, resultando assim na recepção de diversos resumos da ampla área médica. A comissão científica buscou os trabalhos que melhor contribuíssem para 0 meio científico, resultando na aprovação de 49 resumos simples que constam nestes anais.

Todos os trabalhos selecionados apresentam grande potencial de abertura de novas discussões, realizando a função principal da ciência: o aperfeiçoamento do conhecimento, possibilitando a substituição de conceitos anteriores por novos.

\section{EDUARDO HENRIQUE ANTUNES MANN}

Presidente da Comissão Organizadora do I Simpósio Interligas de Pesquisa e Iniciação Científica 


\section{RESUMOS SIMPLES}

Revisão Bibliográfica: 49 resumos 
RESUMO SIMPLES: Revisão Bibliográfica

Título: Síndrome dos Cabelos Impenteáveis: manifestação clínica, fisiopatologia e diagnóstico dessa rara patologia

Autor/coautores: Dyovana Rislley César Almeida, Giovana Junior Pires, Michelle Lorrane Bezerra Hipólito, Gabriela Teixeira Lima e Caroline Dias Simões.

Instituição: Centro Universitário Atenas (UniAtenas), Paracatu - MG.

Palavras-chave: Síndrome dos Cabelos Impenteáveis, Pili Trianguli et Canaliculi, Cheveux Incoiffables.

\section{INTRODUÇÃO}

A Síndrome dos Cabelos Impenteáveis (SCI) é uma incomum patologia caracterizada pela presença de cabelos de aspecto áspero, arrepiados, pouco maleáveis e de lento crescimento. Geralmente esta condição se inicia na primeira infância e tende a melhorar progressivamente ao longo dos anos (HSU CK, et al., 2017). É considerável apontar que, em geral, sobrancelhas, cílios e outros pelos do corpo são inalterados, afetando apenas o couro cabeludo. Não existe uma preferência por sexo instituída, uma vez que mulheres e homens são afetados na mesma proporção (RAMOT Y e ZLOTOGORSKI A, 2019).

\section{OBJETIVO}

Revisar a literatura científica a respeito dos aspectos gerais da $\mathrm{SCl}$, bem como suas possíveis causas, incidência e fisiopatologia. Objetiva-se também analisar possíveis linhas de tratamento que possam impactar positivamente na qualidade de vida dos pacientes portadores desta síndrome.

\section{MÉTODO}

Trata-se de uma revisão de literatura sistemática realizada a partir de busca nas bases de dados Google Acadêmico, PubMed e SciELO, com os descritores "síndrome dos cabelos impenteáveis", "pili canaliculi" e "uncombable hair syndrome". Foram incluídos artigos de revisão publicados de 2016 a 2020 em língua portuguesa e inglesa com acesso aberto. Excluíram-se artigos incompletos e que não tratassem do tema estudado.

\section{REVISÃO BIBLIOGRÁFICA}

O diagnóstico da $\mathrm{SCl}$ comumente é feito nos primeiros anos de vida associando à apresentação clínica e achados microscópicos, sendo a microscopia eletrônica de varredura o padrão ouro para a confirmação do diagnóstico clínico (CORTEZ AMS, et al., 2016).

Por um bom tempo desconhecia-se a causa da $\mathrm{SCl}$, sendo mencionada nos estudos como uma "herança genética autossômica". No entanto, um recente estudo de Ü. Basmanav et al., realizado no ano de 2016 acerca da causa desta síndrome, apresentou resultados que sua ocorrência seria devida mutações autossômicas dominantes e recessivas localizadas nos genes peptidilarginina desaminase, transglutaminase 3 e tricô-hialina, responsáveis pela formação e estruturação do eixo capilar (HSU CK, et al., 2017).

A ciência não traz um consenso sobre a etiologia e o tratamento específico para a $\mathrm{SCl}$, ficando a cargo do médico responsável escolher as condutas gerais e recomendar o acompanhamento psicológico devido as repercussões negativas na autoestima do paciente (BASMANAV F, et al., 2016).

\section{CONSIDERAÇÕES FINAIS}


Por ser uma patologia pouco conhecida pela humanidade, o diagnóstico da SCI torna-se mais difícil. Desta forma, faz-se de fundamental importância que mais estudos sejam realizados acerca desse tema a fim de conseguir ofertar uma conduta de melhor qualidade aos pacientes com portadores desta síndrome.

\section{REFERÊNCIAS}

1. BASMANAV F, et al. Mutations in Three Genes Encoding Proteins Involved in Hair Shaft Formation Cause Uncombable Hair Syndrome. The American Journal of Human Genetics, 2016; 99(6): 1292-1304.

2. CORTEZ ÁMS, et al. Síndrome de Pelo Impeinable. Dermatología Argentina, 2016; 21(3): 217-219.

3. HSU CHAO-KAI, et al. Congenital Anonychia and Uncombable Hair Syndrome: Coinheritance of Homozygous Mutations in RSPO4 and PADI3. The Journal of Investigative Dermatology, 2017; 137(5): 1176.

4. RAMOT Y, et al. Spontaneous Quick Resolution of Uncombable Hair Syndrome-Like Disease. Skin Appendage Disorders, 2019; 5(3): 162-164. 
RESUMO SIMPLES: Revisão Bibliográfica

Título: Oxigenoterapia Hiperbárica como adjuvante no tratamento de feridas

Autor/coautores: Maria Eugênia Costa Casagrande, Nicole Assis Valadares Tavares, Denise Abud de Castro, Gabriela Teixeira Lima e Rhuan de Santana Fernandes.

Instituição: Centro Universitário Atenas (UniAtenas), Paracatu - MG.

Palavras-chave: Cicatrização de Feridas, Oxigenação Hiperbárica, Terapia Biológica.

\section{INTRODUÇÃO}

A oxigenoterapia hiperbárica (OHB) baseia-se na aplicação de oxigênio puro em câmaras hiperbáricas mono ou multipaciente com pressão superior à atmosférica, objetivando hiperóxia e melhora nos processos de infecção e cicatrização (MARTINELLI B, et al., 2019). A terapêutica da OHB é usada como adjuvante principalmente em casos de úlcera em pé diabético, lesão de tecido por radiação e esmagamento, osteomielite crônica refratária e isquemia aguda (ANDRADE SM, et al., 2016).

\section{OBJETIVO}

Revisar a literatura científica a respeito da eficácia da oxigenoterapia hiperbárica no tratamento de feridas hipóxicas e expor os efeitos terapêuticos oriundos dessa terapia.

\section{MÉTODO}

Trata-se de uma revisão bibliográfica sistemática com base na análise de dados encontrados nas plataformas SciELO e LILACS, com os descritores "oxigenação hiperbárica", "terapia biológica" e "cicatrização de feridas". Foram incluídos artigos de revisão publicados de 2016 a 2020 em língua portuguesa com acesso aberto. Excluiu-se artigos incompletos e que não tratassem do tema estudado.

\section{REVISÃO BIBLIOGRÁFICA}

A OHB é usada como complemento a outras estratégias no tratamento de feridas hipóxicas por auxiliar no processo da cicatrização, que é dependente da replicação celular, da formação de uma nova matriz e da remoção do material necrosado, além do fornecimento de nutrientes e oxigênio para a área lesada (BRASIL, 2017). Outros efeitos terapêuticos consistem na proliferação de fibroblastos e de colágeno, na neovascularização, na atividade osteoclástica e osteoblástica e na ação antimicrobiana (MARTINELLI B, et al., 2019).

Ao entrar no organismo o oxigênio se transforma em radical livre que pode ser inibido pela enzima superóxido dismutase. Desse modo, a OHB aumenta essa enzima e diminui os radicais livres, retardando o envelhecimento celular (ANDRADE SM, et al., 2016).

O foco do oxigênio hiperbárico tem sido a úlcera do pé diabético, uma vez que se trata de uma complicação multifatorial em que o tratamento é muito expressivo na maioria dos fatores envolvidos (alteração da resposta inflamatória, ausência de perfusão tecidual e diminuição da angionêse, fatores que propiciam uma área isquêmica) (MARTINELLI B, et al., 2019).

\section{CONSIDERAÇÕES FINAIS}


O tratamento com OHB aumenta significativamente a chance de cura de feridas e diminui a prevalência de amputação em membros, principalmente na úlcera do pé diabético, quadro que a terapia de oxigênio tem apresentado resultados promissores. A resposta foi positiva nos pacientes que apresentaram melhora na perfusão tecidual, na produção de colágeno e na redução do edema, além da proliferação de fibroblastos, da neovascularização e da angiogênese.

\section{REFERÊNCIAS}

1. ANDRADE SM DE, SANTOS ICRV. Oxigenoterapia Hiperbárica para Tratamento de Feridas. Revista Gaúcha de Enfermagem, 2016; 37(2): e59257.

2. BRASIL. Manual do Ministério da Saúde. 2017. Disponível em:

https://saude.es.gov.br/Media/sesa/Consulta\%20P\%C3\%BAblica/Oxigenoterapia\%20Hiperb\%C3\%A1ric a/PROTOCOLO\%20DE\%20USO\%20DE\%20OXIGENOTERAPIA\%20HIPERB\%C3\%81RICA\%20DA\%2 OSESA-ES\%2025-08-2017.pdf. Acesso em: 04 de janeiro de 2021.

3. MARTINELLI B, et al. Alterações Cardiorrespiratórias de Pacientes Submetidos à Oxigenoterapia Hiperbárica. Revista da Escola de Enfermagem da Universidade de São Paulo, 2019; 53: e03469. 
RESUMO SIMPLES: Revisão Bibliográfica

Título: Síndrome de Sjögren-Larsson: fatores genéticos, sintomas e tratamento

Autor/coautores: Marina Rocha Arêdes, Eduardo Henrique Antunes Mann, Thaísa Munique Ferreira Costa de Oliveira, Gabriela Teixeira Lima e Maritha Araújo Prates.

Instituição: Centro Universitário Atenas (UniAtenas), Paracatu - MG.

Palavras-chave: Síndrome Sjögren-Larsson, Desordem Neurocutânea, Ictiose Congênita.

\section{INTRODUÇÃO}

A Síndrome de Sjögren-Larsson (SSL) é uma rara doença autossômica recessiva classicamente caracterizada por ictiose congênita, desenvolvimento de paraplegia ou tetraplegia e retardo mental (ROY U, et al., 2016). Caracteriza-se por um erro inato no metabolismo dos lipídios devido à deficiência da enzima aldeído graxo desidrogenase, desencadeado por um déficit na oxidação da cadeia longa dos ácidos graxos, e gerando depósito de metabólitos lipídicos nos tecidos (WEUSTENFELD M, et al., 2019).

\section{OBJETIVO}

Revisar a literatura científica a respeito da Síndrome de Sjögren-Larsson, a fim de tronar a doença mais conhecida no meio médico e, desta forma, auxiliar na identificação do diagnóstico e de promover o tratamento, objetivando aumentar a qualidade de vida dos portadores dessa rara síndrome.

\section{MÉTODO}

Trata-se de uma revisão bibliográfica sistemática com base na análise de dados encontrados nas plataformas PubMED e LILACS, com os descritores "Síndrome Sjögren-Larsson", "desordem neurocutânea" e "ictiose congênita". Foram incluídos artigos de revisão publicados de 2016 a 2020 em língua portuguesa e inglesa com acesso aberto. Excluiram-se artigos incompletos e que não tratassem do tema estudado.

\section{REVISÃO BIBLIOGRÁFICA}

Os pacientes com SLL apresentam uma mutação do gene ALDH3A2, que codifica a enzima aldeído graxo desidrogenase, levando a queda da quantidade dessa enzima e gerando um déficit na oxidação da cadeia longa dos ácidos graxos, produzindo depósito de metabólitos lipídicos nos tecidos (GARCíA-ORTIZ L, et al., 2018).

As manifestações dermatológicas podem ser observadas desde o nascimento. Inicialmente a pele pode apresentar-se áspera, seca e ter aspecto descamativo por defeito na queratina, possuindo coloração acastanhada. Normalmente as regiões periumbilical, pescoço e dobras estão afetados, enquanto a face é sempre poupada (WEUSTENFELD M, et al., 2019). A ictiose ocorre devido aos ácidos graxos acumulados na pele que levam a perda da barreira transepidérmica de água. Por outro lado, a deficiência da oxidação dos ácidos graxos gera atraso na mielinização e desmielinização das fibras nervosas, o que pode levar a um acometimento neurológico (ROY U, et al., 2016).

As opções terapêuticas para SSL estão limitadas ao tratamento sintomático de manifestações cutâneas e neurológicas (WEUSTENFELD M, et al., 2019).

\section{CONSIDERAÇÕES FINAIS}


Apesar de ser uma síndrome rara, é importante que todos os profissionais de saúde tenham conhecimento da SLL. Dessa forma, conclui-se que mais estudos precisam ser realizados para melhor elucidar e esclarecer essa patologia, uma vez que existem poucos trabalhos atuais sobre 0 assunto.

\section{REFERÊNCIAS}

1. GARCÍA-ORTIZ L, et al. Síndrome de Sjögren-Larsson: Reporte de Caso Pediátrico. Arch Argent Pediatr; 2018; 116(6): 773-777.

2. ROY U, et al. Sjögren-Larsson Syndrome: A Rare Disease Of The Skin and Central Nervous System. BMJ Case Rep; 2016.

3. WEUSTENFELD M, et al. Genotype and Phenotype Variability in Sjögren-Larsson Syndrome. Hum Mutat; 2019; 40(2): 177-186. 
RESUMO SIMPLES: Revisão Bibliográfica

Título: A rara Síndrome de Griscelli, uma breve revisão literária

Autor/coautores: Hellen Kristina Magalhães Brito, Raquel Cambraia Gomes de Melo, Yngrid Marques de Sousa, Gabriela Teixeira Lima e Victor Santana Correia Scalabrini.

Instituição: Centro Universitário Atenas (UniAtenas), Paracatu - MG.

Palavras-chave: Síndrome de Griscelli, Albinismo Parcial, Síndrome Hemofagocítica.

\section{INTRODUÇÃO}

A Síndrome de Griscelli (SG) foi descrita pela primeira vez em 1978 e pouco mais de 60 casos foram descritos na literatura, sendo a maioria lactantes e escolares, sobretudo em população turca e mediterrânea. A maior parte dos casos envolviam irmãos e/ou pais consanguíneos, propondo uma resposta autossômica recessiva (ALSUGAIR F, et al., 2020). Representa uma alteração no transporte de melanossomos com a presença de grandes grupos de grânulos de pigmento na haste capilar, resultando em uma cor cinza prateada, simultaneamente com graus variáveis de imunodeficiência e alta mortalidade (MORALES D e ZALDIVAR G, 2019).

\section{OBJETIVO}

Revisar a literatura científica a respeito da Síndrome de Griscelli, enfatizando sobre a importância do conhecimento sobre essa rara síndrome. Visa também promover o diagnóstico e o tratamento precoces, aumentando assim a sobrevida dos pacientes portadores dessa patologia.

\section{MÉTODO}

Trata-se de uma revisão bibliográfica sistemática com base em dados coletados nas plataformas SciELO, PubMED e LILACS, com os descritores "síndrome de griscelli"; "albinismo parcial" e "hemofagocítica". Foram incluídos artigos de revisão publicados de 2016 a 2020 em língua portuguesa com acesso aberto. Excluiu-se artigos incompletos e que não tratassem do tema estudado.

\section{REVISÃo BIBLIOGRÁFICA}

A SG foi classificada em três subtipos: Tipo 1 manifesta-se com hipomelanose e déficit neurológico primário. Provocada por mutação no gene MYO5A, caracteriza-se por cabelos grisalhos, atraso psicomotor grave e sério comprometimento neurológico primário. A Tipo 2 é provocada por mutação no gene RAB27A, manifestada com hipomelanose e deterioração imunológica grave, provocando suscetibilidade para infecções repetidas que resulta em uma condição de alta mortalidade. A Tipo 3 apresenta apenas manifestações cutâneas, limitada a defeitos de hipopigmentação (MORALES D e ZALDIVAR G, 2019).

O diagnóstico é realizado por meio dos sinais clínicos, achados microscópicos e evidências laboratoriais, como neutropenia, trombocitopenia, anemia recorrente ao aumento dos níveis de triglicerídeos e hipogamaglobulinemia (ALSUGAIR F, et al., 2020).

Possui um prognóstico severo e o tratamento varia de acordo com o tipo da condição. A melhor opção para o tratamento da SG Tipo 2 é o transplante de medula óssea que deve ser realizado o mais precocemente possível. A Tipo 1 não tem cura, e a Tipo 3 não precisa de tratamento (SAHU C, et al., 2017).

\section{CONSIDERAÇÕES FINAIS}


Há poucos estudos acerca de possíveis condutas e tratamentos eficazes. Torna-se assim de extrema relevância o debate sobre a patologia, possibilitando, dessa forma, interferir significativamente na sobrevida do paciente portador da Síndrome de Griscelli.

\section{REFERÊNCIAS}

1. ALSUGAIR F, et al. Neuroimaging Findings in Griscelli Syndrome: A Case Report and Review of the Literature. Radiology Case Reports, 2020; 15: 2339-2342.

2. MORALES D, ZALDIVAR G. Síndrome de Griscelli: Reporte de Caso. Acta Pediátrica Hondureña, 2019; 9(2): 943-947.

3. SAHU C, et al. Griscelli Syndrome: A Rare Disorder. Neurology India, Mumbai, 2017; 65(4): 869-870. 
RESUMO SIMPLES: Revisão Bibliográfica

Título: Uma breve revisão literária sobre Herpes Zoster na faixa pediátrica com ênfase para as manifestações em imunossuprimidos

Autor/coautores: Bruna Albernaz Costa Couto, Larissa Caroline Rodrigues, Nathália Vieira Tavares,

Gabriela Teixeira Lima e Tássia Viviane Cardoso de Souza.

Instituição: Centro Universitário Atenas (UniAtenas), Paracatu - MG.

Palavras-chave: Herpes Zoster, Criança, Imunocomprometido.

\section{INTRODUÇÃO}

Os herpesvírus humano apresentam transmissão por contato de fluidos corporais contaminados. A varicela e o herpes zoster representam duas manifestações clínicas da infecção pelo Vírus Varicela Zoster (VVZ) ou Herpes Zoster Vírus (HZV). O HZV resulta de reativação do VVZ, o qual permanece latente em gânglios da raiz dorsal de nervos sensoriais ou de nervos cranianos após a infecção primária pela varicela. $O$ herpes zoster é raro na idade pediátrica, sendo sua incidência aumentada com o avançar da idade e em estados de imunossupressão. (CARNEIRO FRO, et al., 2020).

\section{OBJETIVO}

Revisar a literatura científica a respeito da infecção pelo herpes zoster vírus na faixa pediátrica, enfatizando sua ocorrência para as crianças imunossuprimidas.

\section{MÉTODO}

Trata-se de uma revisão bibliográfica sistemática com base na análise de dados encontrados nas plataformas SciELO, PubMED e Google Acadêmico com os descritores "herpes zoster", "criança" e "imunocomprometido". Foram incluídos artigos de revisão publicados de 2016 a 2020 em língua portuguesa com acesso aberto. Foram excluídos artigos incompletos e que não tratassem do tema estudado.

\section{REVISÃO BIBLIOGRÁFICA}

O herpes zoster infantil é visto em indivíduos imunocomprometidos ou em crianças que contraíram varicela primária com menos de seis meses de vida. É caracterizado pela erupção eritema-vesicular habitualmente limitada a um único dermátomo, surgindo de um a sete dias após a manifestação de dor e hiperestesia localizada (CARRUSCA C, et al., 2016). O exantema geralmente regride ao final de três semanas e pode ser acompanhado de febre, prurido, irritabilidade, mal-estar geral, hipersensibilidade local, sensação de queimadura e adenopatias regionais (CARNEIRO FRO, et al., 2020). O diagnóstico é clínico através da análise das manifestações cutâneas e de sua localização acompanhando o dermátomo.

A terapêutica antiviral em crianças saudáveis deve limitar-se a situações específicas: quando se tem exantema moderado a grave, dor intensa e/ou envolvimento dos pares cranianos. O Aciclovir é o fármaco de escolha, recomendando-se a administração durante cinco a dez dias, ou até dois dias sem aparecimento de novas lesões cutâneas (BRASIL, 2019). O uso da vacina para profilaxia da varicela em crianças mais novas pode minimizar a ocorrência clínica da varicela e do herpes zoster.

\section{CONSIDERAÇÕES FINAIS}


O herpes zoster infantil é incomum de ocorrer em crianças previamente saudáveis, sendo mais presente em indivíduos imunossuprimidos. Quando presente na faixa pediátrica cursa habitualmente com menor gravidade que nos adultos. A identificação da doença e início precoce do seu tratamento é crucial para uma melhor resolução do quadro.

\section{REFERÊNCIAS}

1. BRASIL. Manual do Ministério de Saúde. 2019. Disponível em: http://antigo.saude.gov.br/saude-de-az/herpes-zoster. Acesso em: 13 de agosto de 2020.

2. CARNEIRO FRO, et al. Herpes Zoster como Sintoma Inicial da Infecção pelo HIV em Criança. Braz. J. Hea. Rev., Curitiba, 2020; 3(5): 11796-11803.

3. CARRUSCA C, et al. Herpes Zoster como Primeira Manifestação de Infecção por Vírus Varicela-Zoster numa Criança Saudável. Rev. Nascer e Crescer, 2016; 25(1): 38-41. 
RESUMO SIMPLES: Revisão Bibliográfica

Título: Relevância do psicólogo enquanto profissional na Atenção Básica

Autor/coautores: Carolina Lelis Neiva, Andressa Alves Guimarães, Matheus Gontijo Lima de Oliveira Santos, Rafaela Borges Nogueira, Talitha Araújo Velôso Faria.

Instituição: Centro Universitário Atenas, Paracatu - MG.

Palavras-chave: Atenção Primária à Saúde, Prática psicológica, Assistência à saúde.

\section{INTRODUÇÃO}

O paradigma do cuidado se incorporou aos direitos humanos e sociais para fortalecer o cuidado em saúde na Atenção Básica brasileira. Baseando-se na ampliação da estratégia de atenção aos indivíduos com transtornos mentais, o NASF (Núcleos de Apoio à Saúde da Família) implementa mudanças no modelo de assistência à saúde (OLIVEIRA IF, et al., 2017). Assim, apesar de o Sistema Único de Saúde (SUS) agregar os psicólogos nas políticas públicas de forma pioneira, a consolidação do papel desses profissionais no atual cenário de atenção psicossocial ainda se mostra deficiente (PERRELA AC, 2015).

\section{OBJETIVO}

Revisar a literatura científica sobre o processo, a importância e condições de inserção de profissionais psicólogos na Atenção Básica, analisando o papel do SUS e eficiência de suas estratégias.

\section{MÉTODO}

Trata-se de uma revisão bibliográfica integrativa, com referências publicadas entre 2015 e 2019. Utilizouse descritores padronizados pela BIREME para a pesquisa nas plataformas: Google Scholar e Scielo, sendo considerados critérios de inclusão: dados coerentes com o tema; publicações entre 2015 e 2020. De exclusão: publicações desatualizadas ou/e generalistas.

\section{REVISÃO BIBLIOGRÁFICA}

Diante da consciência da necessidade do cuidado do sofrimento mental, foi ampliada a participação de profissionais nas equipes de atenção primária por meio do NASF, sendo um deles o psicólogo. Contudo, tal contexto mostra-se desafiante, tanto pela recente instituição desse serviço quanto pela necessidade do trabalho multiprofissional, indo de encontro ao modelo individualista por muitos anos empregado (VASCONCELOS FG e ALESSIO RLS, 2019).

Baseado no princípio da promoção e prevenção de saúde, a Estratégia Saúde da Família (ESF), com o apoio dos profissionais psicólogos, alcança a assistência em saúde de forma integral e individualizada. Nesse sentido, o apoio psicológico permite o alcance eficiente dos princípios da integralidade, resolutividade e longitudinalidade, preconizados pelo SUS (SILVA G, et al., 2017).

Contudo, a atuação e agregação desses profissionais ao cuidado em saúde ainda se mostra parcial, principalmente, frente à dificuldade do trabalho multiprofissional e multissocial, entre equipe-profissionalusuário. Sendo empecilhos, a burocratização para a criação de projetos sociais, a dificuldade no envolvimento e participação social e, ainda, no compartilhamento de conhecimento entre profissionais (PERRELA AC, 2015).

\section{CONSIDERAÇÕES FINAIS}


Faz-se necessária a incorporação efetiva de psicólogos na ESF. Para isso, mostram-se indispensáveis estratégias articuladas do SUS que facilitem o trabalho desses profissionais, tornando-os consolidados na equipe de Atenção Primária. Fortalecendo, assim, a ação integral e preventiva do serviço público de saúde, a fim de ampliar qualidade de vida de seus usuários.

\section{REFERÊNCIAS}

1. OLIVEIRA IF, et al. A Atuação do Psicólogo nos NASF: desafios e perspectivas na atenção básica. Temas em Psicologia, 2017; 25(1): 291-304.

2. PERRELLA AC. A experiência da Psicologia no NASF: capturas, embates e invenções. Gerais, Rev. Interinst. Psicol. [online], 2015; 8(2): 443-52.

3. SILVA G, et al. Práticas de Cuidado Integral às Pessoas em Sofrimento Mental na Atenção Básica. Psicologia: Ciência e Profissão, 2017; 37(2): 404-17.

4. VASCONCELOS FG, ALESSIO RLS. Construções Identitárias de Psicólogos em NASF: Reflexões para a Prática Profissional. Psicol. cienc. prof. [online], 2019; 39: e174637. 
RESUMO SIMPLES: Revisão Bibliográfica

Título: A diferenciação sexual cerebral e o gênero

Autor/coautores: Gabrielle Martins Marra; Natália Aparecida Faria Viana; Patrícia Guimarães Teixeira; Ize

Amanda Pereira Marques; Evaldo Cardoso Gomes.

Instituição: Centro Universitário Atenas (UNIATENAS), Paracatu - MG.

Palavras-chave: Diferenciação sexual, Diversidade de gênero, Sexualidade.

\section{INTRODUÇÃO}

A liberação de hormônios produzidos durante o período embrionário determina o volume total cerebral e assim interferem no comportamento diferenciado entre os sexos. Com isso, a insensibilidade do cérebro do transexual está relacionada com a interação entre esses hormônios e receptores e, assim, induzir alterações em áreas cerebrais sexualmente dimórficas (ABRAMOVICH S, 2017). Porém, o fato de abordarmos este assunto sob um ponto de vista mais biológico não significa que a transexualidade deva ser considerado uma doença, ela é apenas mais uma das muitas manifestações da grande variabilidade intrínseca do ser humano (SOUSA JF, et al., 2019).

\section{OBJETIVO}

Revisar literatura científica com objetivo de abordar a diferenciação sexual cerebral em relação ao gênero, que deve ser entendido como a identificação psicossocial independente do sexo de modo a sintetizar aspectos genotípicos, fenotípicos e embriológicos relacionados.

\section{MÉTODO}

Trata-se de uma revisão integrativa, sendo realizado por meio de buscas na base de dados BVS utilizando as palavras-chaves: "Diferenciação sexual", "transexualidade" e "gênero". Os critérios de inclusão foram: artigos com disponibilidade na íntegra, em idioma português que apresentem coerência com a temática. Foram excluídos trabalhos que não atenderam os objetivos e que não foram realizados nos últimos 5 anos.

\section{REVISÃO BIBLIOGRÁFICA}

No cérebro masculino a enzima aromatase presente converte a testosterona em estrógeno, e este é essencial para induzir o comportamento sexual masculino pela síntese de prostaglandina E2 em uma proporção sete vezes maior que o normal na área pré-óptica (OLIVEIRA, et al., 2018; SOUSA JF, 2019).

$\mathrm{Na}$ ausência do gene SRY, as gônadas permanecem no estágio indiferenciado até o fim da décima semana, em que se inicia a diferenciação ovariana. Sendo assim, o que protege o cérebro da masculinização é a ausência da produção de testosterona (ABRAMOVICH S, 2017; CARVALHO MC, 2020).

A determinação do gênero do indivíduo é estabelecida pela impregnação hormonal e assim influenciar a identidade de gênero. Ocorre que nos transexuais masculinos e femininos nota-se evidências que a diferenciação sexual cerebral pode caminhar em sentido oposto a diferenciação genital (SPIZZIRRII G, 2018; OLIVEIRA TLS, et al., 2018).

\section{CONSIDERAÇÕES FINAIS}


O presente trabalho buscou fazer um recorte do tema diferenciação sexual cerebral relacionando com a identificação psicossocial de cada indivíduo. A anatomia cerebral mostra-se diferenciada com a identidade de gênero, sendo importante destacar a testosterona como um fator determinante. A percepção da sua própria masculinidade, feminilidade ou intersexualidade, portanto, se inicia antes do nascimento.

\section{REFERÊNCIAS}

1. ABRAMOVICH S. Sexo, gênero; Sintoma e sinthoma. Revista de Psicanálise Stylus, 2017; 34: 129-35.

2. CARVALHO MC. De algumas vontades de saber na neurociência: a saga dos cérebros sexuados. Teoria e Cultura, 2020; 15: 1-27.

3. OLIVEIRA TLS, et al. Abordagens da sexualidade humana em livros didáticos de Biologia publicados entre 2004 A 2011. Revista Eixo, 2018. 7(1): 36-46.

4. SOUSA JF. A Análise do Comportamento e a Intersexualidade. Psicol. cienc. prof., 2019; 5 (1): e229830.

5. SPIZZIRRII G. Diferenciação sexual cerebral por neuroimagens em indivíduos transgêneros. Diagn. tratamento, 2018; 1: 105-08. 
RESUMO SIMPLES: Revisão Bibliográfica

Título: A doença de Crohn como fator de risco para câncer colorretal

Autor/coautores: Clara Rabelo de Castro, Anna Carolina Alkmim Otoni, Daniele Barbosa de Medeiros, Milla Mariane Freitas Silva e Thiago Alvares da Costa.

Instituição: Centro Universitário Atenas (UniAtenas), Paracatu - MG.

Palavras-chave: Doença de Crohn, câncer e intestino.

\section{INTRODUÇÃO}

A doença de Crohn é um problema intestinal inflamatório crônico, que não possui causa conhecida e apresenta episódios frequentes de inflamação (DULAI PS, et al., 2016). Tal enfermidade pode afetar qualquer parte do trato digestivo, entretanto, a parte inferior do intestino delgado e o intestino grosso são comumente mais afetados. Por ser uma patologia que ainda não possui cura, o tratamento é paliativo. Devido ao processo de inflamação crônica da mucosa da parede intestinal há possibilidades de complicações, sendo, assim, uma delas o câncer colorretal (DULAI PS, et al., 2016).

\section{OBJETIVO}

Estudar por meio dessa revisão de literatura a existência da relação entre as doenças inflamatórias intestinais, especificamente a da doença de Cronh e sua fisiopatologia, ao desenvolvimento de câncer colorretal.

\section{MÉTODO}

Trata-se de uma revisão bibliográfica integrativa, com referências publicadas no período entre 2015 e 2020 na língua inglesa e portuguesa. Utilizou-se a base de dados PubMed e os descritores: "Crohn's disease and câncer and intestine". Esta pesquisa encontrou 47 artigos, no entanto, para essa revisão apenas 3 foram selecionados a partir de determinados critérios de inclusão (relação direta entre doença de Crohn e o câncer colorretal) e exclusão (ausência de dados).

\section{REVISÃO BIBLIOGRÁFICA}

Diante disso, notou-se que pacientes que apresentam a doença de Crohn (DC) têm um risco elevado de desenvolver câncer colorretal (CCR), visto que doenças inflamatórias intestinais comprometem a integridade do epitélio e o deixa mais suscetível a processos (HIRSCH D, et al., 2018). Esse mecanismo, através da indução de citocinas e quimiocinas, promove alterações funcionais das células epiteliais, o que resulta em uma mucosa associada ao câncer (DULAI PS, et al., 2016).

Um estudo baseado no Kaiser Permanente Healthcare System mostrou que a incidência de câncer colorretal entre pacientes com doenças inflamatórias intestinais, inclusive a DC, era $60 \%$ maior do que no restante da população (DULAI PS, et al. 2016). Ademais, estudos mostraram que pacientes com doenças inflamatórias que realizaram acompanhamento por meio da colonoscopia, apresentaram menor taxa de detecção de CRC (1,8\%) quando comparados àqueles que não fizeram vigilância $(3,2 \%)$ (BYE WA, et al., 2018).

\section{CONSIDERAÇÕES FINAIS}


Desse modo, fica evidente que doenças inflamatórias intestinais são processos crônicos que comprometem a integridade da barreira epitelial. Os fatores de risco para o aparecimento do câncer em DC não estão definidos, mas se aceita o desenvolvimento precoce e a evolução da doença inflamatória.

\section{REFERÊNCIAS}

1. BYE WA, et al. Strategies for Detecting Colorectal Cancer in Patients with Inflammatory Bowel Disease: A Cochrane Systematic Review and Meta-Analysis. The American Journal of Gastroenterology, 2018; 113 (12): 1801-1809.

2. DULAI PS, et al. Colorectal Cancer and Dysplasia in Inflammatory Bowel Disease: A Review of Disease Epidemiology, Pathophysiology and Management. Cancer Prevention Research, 2016; 9(12): 887-894.

3. HIRSCH D, et al. Dynamics of Genome Alterations in Crohn's Disease-Associated Colorectal Carcinogenesis. Clinical Cancer Research, 2018; 24(20): 4997-5011. 
RESUMO SIMPLES: Revisão Bibliográfica

Título: A importância da promoção em saúde para o acidente escorpiônico no Brasil

Autor/coautores: Rafaela Zacheo Zanon, Rafaela Borges Nogueira, Pedro Henrique Dias Órfão, Benedito de

Souza Gonçalves Júnior

Instituição: Centro Universitário Atenas (UniAtenas), Paracatu - MG.

Palavras-chave: Picada de Escorpião, Mortalidade, Prevenção de Doença.

\section{INTRODUÇÃO}

Os acidentes escorpiônicos ocorrem nos meses quentes e chuvosos, sendo os mais graves causados pela espécie Tityus serrulatus. São considerados um problema de saúde pública no Brasil devido à incidência e letalidade, uma vez que a subnotificação dos casos, decorrente de falhas no registro e na procura por atendimento, acarreta a menor informação e proteção da população (LISBOA NS, et al., 2020; CARMO EA, et al., 2019). Portanto, é imprescindível discutir o papel da promoção de saúde frente ao escorpionismo, visto que o objetivo primário do sistema de saúde é a prevenção de óbitos evitáveis (SOUZA CM e BOCHNER R, 2019).

\section{OBJETIVO}

Revisar a literatura científica sobre a promoção de saúde perante o escorpionismo no Brasil, discutindo o papel do Sistema Único de Saúde (SUS) e de suas estratégias na prevenção desses acidentes.

\section{MÉTODO}

Trata-se de um estudo de revisão bibliográfica integrativa, com referências inglesa e portuguesa, publicadas entre 2015 e 2020. Utilizou-se descritores padronizados pela BIREME para a pesquisa nas plataformas PubMed e Scielo. Considerou-se critérios de inclusão: publicações referentes ao Brasil no período indicado; dados e arguições coerentes com o tema. E de exclusão: dados incompletos e/ou desatualizados.

\section{REVISÃO BIBLIOGRÁFICA}

O aumento da incidência de escorpionismo está relacionado com: a urbanização, o saneamento básico desfavorável e a adaptação de espécies aos ambientes antropizados (CARMO DMC, et al., 2019). Segundo o Programa Nacional de Atenção Básica (PNAB), é papel da equipe de Estratégia Saúde da Família (ESF) a implementação de ações educativas em saúde, baseadas na necessidade da população adscrita. Com a orientação sobre hábitos, hábitat e alimentação do escorpião, a Atenção Básica intervém na realidade clínica e sanitária dos usuários, possibilitando o aprendizado sobre o animal e o empoderamento do autocuidado, tornando a população agente da promoção de sua saúde (SOUZA CM e BOCHNER R, 2019).

De acordo com o SINAN (Sistema de Informação de Agravos de Notificação), entre 2007 e 2017, houve um aumento de $47,5 \%$ no número de óbitos brasileiros por escorpionismo, passando de 61 para 90 casos anuais, revelando a imprecisão assistencial na prevenção e promoção em saúde no país (TORREZ PPQ, et al., 2019).

\section{CONSIDERAÇÕES FINAIS}


Diante do exposto, capacitar para a prevenção e procura por assistência permite a independência do usuário. Além disso, a notificação de acidentes escorpiônicos eficiente possibilita o principal papel epidemiológico: ser um panorama para a análise do desenvolvimento em saúde e para a criação de políticas públicas válidas.

\section{REFERÊNCIAS}

1. CARMO DMC, et al. Perfil epidemiológico do escorpionismo em Uberlândia, Minas Gerais. Revista de Medicina e Saúde de Brasília 2019; 8(1): 45-53.

2. CARMO EA, et al. Factors associated with the severity of scorpio poisoning. Texto \& ContextoEnfermagem. 2019; 28: e20170561.

3. LISBOA NS, et al. Escorpionismo no Extremo Sul da Bahia, 2010-2017: perfil dos casos e fatores associados à gravidade. Epidemiologia e Serviços de Saúde. 2020; 29: e2019345.

4. SOUZA CM, BOCHNER R. Escorpionismo no Rio De Janeiro: Contribuições da Ciência Cidadã para o Aprimoramento das Políticas de Atenção em Saúde. P2p E Inovação. 2019; 6(1): 33-49.

5. TORREZ PPQ, et al. Scorpionism in Brazil: exponential growth of accidents and deaths from scorpion stings. Revista da Sociedade Brasileira de Medicina Tropical, 2019; 52: e20180350. 
RESUMO SIMPLES: Revisão Bibliográfica

Título: A influência da microbiota intestinal no desenvolvimento de transtornos mentais

Autor/coautores: João Lucas Pereira Mariano', Gabriela Fonseca Marçal'1, Laynne Lorrane Santos ${ }^{1}$, Daniel Lopes Marques de Araújo', Micaella Silva Leandro².

Instituição: Centro Universitário Atenas (UniAtenas)¹, Paracatu - MG; Universidade Federal de São Paulo (UNIFESP), São Paulo - SP².

Palavras-chave: Transtornos mentais, Microbiota gastrointestinal, Sistema nervoso entérico.

\section{INTRODUÇÃO}

A comunicação bidirecional entre o intestino e cérebro, por meio do eixo intestino-cérebro, transcende a finalidade nutricional no organismo. Nesta perspectiva, estudos demonstram que alterações na intercomunicação desse eixo estão presentes em patologias mentais como, por exemplo, ansiedade, depressão, estresse e fins (TONINI IGO, et al., 2016). Ademais, há evidências de que o nervo vago, principal representante da via aferente do eixo intestino-cérebro, consegue modular efeitos não só fisiológicos, mas também comportamentais no cérebro. Portanto, é possível associar impactos mútuos entre o sistema nervoso entérico e as doenças mentais (COSTA BC, et al., 2020).

\section{OBJETIVO}

Revisar a literatura científica para elucidar a relação entre a microbiota do trato gastrointestinal e os distúrbios mentais, visando assim, um novo meio de abordagem e tratamento de tais patologias.

\section{MÉTODO}

Trata-se de uma revisão integrativa com busca na base de dados SciELO e PubMed, nas quais foram selecionados cinco em português e inglês, no período de 2016 a 2020. Os critérios de inclusão foram a partir da busca de termos como "Transtornos mentais" e "Microbiota Gastrointestinal" e os de exclusão foram publicações com mais de 5 anos.

\section{REVISÃO BIBLIOGRÁFICA}

A microbiota intestinal libera neurotransmissores como produtos de seus metabólitos, com ênfase ao ácido $\mathrm{Y}$-aminobutírico, serotonina, dopamina, epinefrina e acetilcolina (MEDEIROS CIS e COSTA TP, 2020). Tais neurotransmissores exercem efeitos sobre o humor, comportamento, cognição e emoção. Consequentemente, a desregulação deles pode ocasionar ansiedade e depressão. Devido à intercomunicação intestino-cérebro, alterações na microbiota intestinal causam hiperativação do eixo hipotálamo-hipófise-adrenal, seguida por interrupção dos circuitos neurais e dos níveis de neurotransmissores, produção excessiva de citocinas pró-inflamatórias pelo sistema imunológico e ruptura da barreira intestinal (BASTIAANSSEN TFS, et al., 2020). Assim, a microbiota atua na manutenção da homeostase do sistema nervoso central. Nesse contexto, a suplementação com probióticos e prébióticos é alvo de estudos que buscam efeitos preventivos e terapêuticos de desordens mentais. As sinapses no eixo intestino-cérebro são mantidas pelo nervo vago, o qual também é responsável por mediar os efeitos benéficos dos probióticos. (MOSS WH, et al., 2016).

\section{CONSIDERAÇÕES FINAIS}


Dessa forma, constata-se uma influência da microbiota do trato gastrointestinal na modulação do humor e na homeostase de um indivíduo, de forma que sua composição inadequada gere modificações comportamentais. Logo, uma má alimentação é um fator predisponente a doenças como depressão e ansiedade. Assim, é necessário instigar na população um estilo de vida e alimentação adequados, tanto para prevenir como para tratar desordens mentais.

\section{REFERÊNCIAS}

1. BASTIAANSSEN TFS, et al. Gutted! Unraveling the role of the microbiome in major depressive disorder. Harvard Review of Psychiatry, 2020; 19(2): 26.

2. COSTA BC, et al. Probióticos na redução de sintomas de ansiedade e depressão: uma revisão integrativa. Health Sciences Journal, 2020; 10(4): 97-108.

3. MEDEIROS CIS, COSTA TP. Repercussão da microbiota intestinal na modulação do sistema nervoso central e sua relação com doenças neurológicas. Revista de Ciências Médicas e Biológicas, 2020; 19 : 342-346.

4. MOOS WH, et al. Microbiota and Neurological Disorders: A Gut Feeling. BioResearch open access, 2016; 5(1): 137-145.

5. TONINI IGO, et al. Eixo intestino-cérebro: relação entre a microbiota intestinal e desordens mentais. Research, Society and Development, 2020; 9(7): e499974303. 
RESUMO SIMPLES: Revisão Bibliográfica

Título: A influência dos maus-tratos na infância no desenvolvimento do Transtorno de Personalidade Borderline

Autor/coautores: Mariana de Paula Ferreira, Andressa Alves Guimarães, Leticya Alves Guimarães, Pedro Eduardo Murad Mendonça Porto, Neiber Fausto de Azevedo Silva.

Instituição: Centro Universitário Atenas (Uniatenas), Paracatu - MG.

Palavras-chave: Borderline, Trauma, Infância.

\section{INTRODUÇÃO}

O Transtorno de Personalidade Borderline (TPB) é caracterizado pela reação exacerbada a qualquer situação. O posicionamento desse paciente oscila entre tudo e nada, além de apresentar instabilidade humoral, alto grau de irritabilidade, comportamento impulsivo e baixa tolerância à frustração (QUENNEVILLE $A F$, et al., 2020). Estudos recentes evidenciam que situações de maus-tratos vivenciadas durante a infância, como abuso sexual e negligência, são capazes de explicar o desenvolvimento do TPB durante a vida adulta, visto que, esse tipo de situação traumática pode acarretar desregulação emocional e alterações na personalidade (REBESCHINI C, 2017).

\section{OBJETIVO}

Revisar a literatura científica para compreender a relação existente entre o desenvolvimento do Transtorno de Personalidade Borderline e a vivência de traumas ou maus-tratos durante a infância e adolescência do paciente.

\section{MÉTODO}

Trata-se de uma revisão bibliográfica integrativa, em que foram realizadas buscas nas bases de dados PubMed e SciELO, com termos "Borderline disorder" e "Childhood", utilizando o operado booleano "AND". Selecionou-se artigos nas línguas inglesa e portuguesa, filtrou-se resultados obtidos nos últimos cinco anos, que atendem aos critérios de elegibilidade, excluindo aqueles contrários ao objetivo do trabalho e/ou desatualizados.

\section{REVISÃO BIBLIOGRÁFICA}

O surgimento do TPB depende da associação entre fatores genéticos e vulnerabilidades ambientais, em especial, relacionados às experiências traumáticas na infância (CATTANE N, et al., 2017). É nessa fase que se desenvolvem as funções emocionais e comportamentais, portanto, fatos traumáticos são capazes de afetar a maturação cerebral, influenciando no desenvolvimento da personalidade da criança. Além disso, a exposição aos maus-tratos pode provocar uma hipersensibilidade persistente à fatores estressantes, o que é um gatilho para psicopatologias (REBESCHINI C, 2017).

Pesquisas comprovam que esses pacientes possuem uma alteração estrutural e funcional do cérebro, como o volume reduzido da amígdala, o que altera o processamento de emoções negativas (LEITE LH e CAMPOS EM, 2016). Um estudo realizado com 22 indivíduos, de ambos os sexos, avaliou a presença do histórico de maus-tratos no desenvolvimento da doença. Os resultados mostraram que $81 \%$ dos entrevistados apresentaram algum tipo de abuso emocional, 66,6\% sofreram abuso físico, e 14,4\% passaram por abuso sexual (CONCEIÇÃO IK, et al., 2015). 


\section{CONSIDERAÇÕES FINAIS}

Em análise dos estudos coletados, fica evidente que a vivência de trauma emocional, físico e verbal na infância, além de menor afetividade paternal e hereditariedade genética predispõem o desenvolvimento de TPB. Portanto, a partir de uma melhor compreensão dos mecanismos afetados por traumas, seria possível identificar e minimizar o desenvolvimento da doença.

\section{REFERÊNCIAS}

1. CATTANE N, et al. Borderline personality disorder and childhood trauma: exploring the affected biological systems and mechanisms. BMC Psychiatry, 2017; 17(1): 221.

2. CONCEIÇÃO IK, et al. Sintomas de TEPT e trauma na infância em pacientes com transtorno da personalidade bordeline. Psicologia em revista, 2015; 21(1): 87-107.

3. LEITE LH, CAMPOS EM. Investigações brasileiras sobre o transtorno de personalidade borderline: uma revisão integrativa. Revista de Medicina da UFC 2016; 56(1): 29-37.

4. QUENNEVILLE AF, et al. Childhood maltreatment, anxiety disorders and outcome in borderline personality disorder. Psychiatry Research, 2020; 284:112688.

5. REBESCHINI C. Trauma na infância e transtornos da personalidade na vida adulta: relações e diagnósticos. Revista Saúde e Desenvolvimento Humano, 2017; 5(2): 67-74. 
RESUMO SIMPLES: Revisão Bibliográfica

Título: A negligência ao atendimento de dependentes químicos na Atenção Primária à Saúde e suas consequências

Autor/coautores: Gabriela Fonseca Marçal ${ }^{1}$, Laynne Lorrane Santos ${ }^{1}$, Daniel Lopes Marques de Araújo ${ }^{1}$, João Lucas Pereira Mariano ${ }^{1}$, Micaella Silva Leandro²

Instituição: ${ }^{1}$ Centro Universitário Atenas (UniAtenas), Paracatu - MG; ${ }^{2}$ Universidade Federal de São Paulo (UNIFESP), São Paulo - SP.

Palavras-chave: Abuso de Drogas, Assistência à saúde mental, Atenção Primária à Saúde.

\section{INTRODUÇÃO}

Entre os pacientes psiquiátricos atendidos pela Atenção Básica de Saúde (ABS) estão aqueles que sofrem de dependência química. Entre 2000 e 2015, as mortes causadas diretamente pelo uso de drogas aumentaram $60 \%$. Por ser considerada a porta de entrada do SUS, a ABS deve exercer função estratégica para identificar e acolher essa clientela adequadamente (PIRES LFB, et al., 2016). Entretanto, a abordagem dos dependentes pode ser considerada um tabu para muitos profissionais de saúde, de forma que o paciente seja discriminado durante o atendimento (LIMA TL e ALVES ES, 2019).

\section{OBJETIVO}

Revisar a literatura científica sobre a negligência e os entraves que permeiam o atendimento ao dependente químico na Atenção Primária à Saúde e a consequente aniquilação de políticas voltadas a esses pacientes.

\section{MÉTODO}

Trata-se de uma revisão integrativa de literatura estabelecida na base de dado SciELO, usando os descritores "abuso de drogas", "assistência à saúde mental" e "Atenção Primária à Saúde" combinados entre si. Em dezembro de 2020, foram selecionados 3 artigos científicos, usando como critério de inclusão trabalhos na língua portuguesa na íntegra. Os de exclusão foram publicações com mais de 5 anos.

\section{REVISÃO BIBLIOGRÁFICA}

A abordagem dos transtornos mentais tem sido negligenciada ao longo de séculos na história brasileira. Nesse cenário, estigmas e estereótipos são estruturais na sociedade, principalmente quando se trata de dependentes químicos. Tais encalhes do meio social permeiam o processo de saúde. Tendo em vista a ABS, muitos profissionais possuem uma visão tendenciosa e moralista sobre os usuários de drogas lícitas e ilícitas (PIRES LFB, et al., 2016). Por conseguinte, há um maior número de encaminhamentos para serviços especializados, como o Centro de Atenção Psicossocial (CAPS), e uma menor resolutividade e equidade no atendimento. Toda essa problemática é fruto de uma preconcepção social que é refletida no profissional da saúde. Ademais, o desconhecimento da Política de Saúde para a Atenção Integral a Usuários de Álcool e Outras Drogas é um grande entrave (FILHO AJT, 2016). Assim, o indivíduo é visto como necessidade menor frente às demais queixas da ABS (LIMA TL e ALVES ES, 2019).

\section{CONSIDERAÇÕES FINAIS}


Assim, o estudo retrata que dependentes químicos ainda são tratados com displicência. Devido a essa esteriotipação social, o desdenho dessa problemática tende a ser infindável. Entretanto, é possível transformar o atendimento mais resolutivo na ABS por meio de programas de educação permanente para os profissionais de saúde e consolidação de redes de apoio na atenção primária.

\section{REFERÊNCIAS}

1. FILHO AJT. Abordagem ao uso de drogas na atenção primária - uma sensibilização. Revista Med Minas Gerais, 2016; 26: S11-S14.

2. LIMA TL, ALVES ES. Reflexões sobre o cuidado com as pessoas que fazem uso abusivo de drogas na Atenção Básica. REVISTA HUM@ NAE, 2019; 13(2): 1-19.

3. PIRES LFB, et al. Estratégia saúde da família e assistência ao dependente químico: ações conjuntas ou isoladas?. Revista Eletrônica de Enfermagem, 2016; 18: 1-11. 
RESUMO SIMPLES: Revisão Bibliográfica

Título: A terapia cognitivo comportamental por intermédio do telefone como tratamento da depressão na doença de Parkinson: uma revisão bibliográfica

Autor/coautores: Wender Dhiego Soares, Anderson Eduardo Anadinho da Silva, Rafael Muniz Gama e

Thiago Alvares da Costa.

Instituição: Centro Universitário Atenas (UniAtenas), Paracatu - MG.

Palavras-chave: Doença de Parkinson, Depressão, Terapia cognitivo comportamental.

\section{INTRODUÇÃO}

A doença de Parkinson (DP), além da depleção dopaminérgica, apresenta caráter neuropsiquiátrico, visto que sintomas não motores, como a depressão, acometem quase $50 \%$ dos indivíduos. Ao debilitar, diminuir a cognição e necessitar de um cuidador, a doença reduz a autoestima, motivação e a qualidade de vida do paciente. Esse cenário complexo demanda tratamentos psiquiátricos específicos à $\mathrm{DP}$, porém, ainda são tratados pela abordagem usual e geral, pois terapias que contemplem os diversos elementos da afecção são escassas, tornando o manejo psicológico da DP pouco eficaz (PONTONE GM e MILLS KA, 2020; WEINTRAUB D e MAMIKONYAN E, 2019).

\section{OBJETIVO}

Revisar a aplicação da terapia cognitivo comportamental por intermédio do telefone (TCC-T) como alternativa de tratamento complementar ao usual na doença de Parkinson em relação aos seus sintomas psiquiátricos prevalentes.

\section{MÉTODO}

Foi realizada uma revisão integrativa nas bases de dados MEDLINE e SciElo. Foram utilizados as palavras "depressão", "terapia cognitivo comportamental", "telefone", associados com "doença de Parkinson" em português e os correspondentes em inglês. A busca dos artigos foi realizada no recorte dos últimos 5 anos. Foram excluídos os trabalhos sem os termos "telefone" e "terapia cognitivo comportamental", enquanto aqueles que os abordaram foram incluídos conforme relevância e adequação ao tema.

\section{REVISÃO BIBLIOGRÁFICA}

O tratamento típico da depressão não atende satisfatoriamente as nuances da doença de Parkinson ao não oferecer suporte quanto ao manejo em caso de resistência ao tratamento (PONTONE GM e MILLS KA, 2020). Na tentativa de suplantar essa questão, foi analisada a utilização da TCC-T, comparando sua eficácia com o tratamento usual em pacientes com depressão na DP (DOBKIN RD, et al., 2020). A abordagem testada foi feita por chamadas telefônicas, apresentando resultados significativos, pois foi moldada de acordo com as necessidades e o cotidiano do paciente, ao fornecer uma base para seu empoderamento, o que aprimorou o autocuidado, e orientações ao cuidador. Ao contrário do modelo face-a-face, nesse o paciente tende a se sentir mais confortável e colaborar mais com a consulta, reduzindo as interrupções de tratamento, além de apresentar um bom custo-benefício, possibilitando que grupos economicamente vulneráveis tenham acesso (WATZKE B, et al., 2017).

\section{CONSIDERAÇÕES FINAIS}


A TCC-T apresenta-se como uma alternativa complementar ao tratamento da depressão na DP ao se adequar ao contexto do paciente e atingir classes sociais negligenciadas. Contudo, algumas ressalvas devem ser feitas, como a necessidade de treinamento profissional para aplicação da terapia pelo telefone.

\section{REFERÊNCIAS}

1. DOBKIN RD, et al. Telephone-based cognitive behavioral therapy for depression in Parkinson disease: A randomized controlled trial. Neurology, 2020; 94(16): 1-10.

2. PONTONE GM, MILLS KA. A call for better depression treatment in people with Parkinson disease. Neurology, 2020; 94(16): 691-692.

3. WATZKE B. et al. Effectiveness and cost-effectiveness of telephone-based cognitive-behavioural therapy in primary care: Study protocol of TIDe - telephone intervention for depression. BMC Psychiatry, 2017; 17(1): 1-9.

4. WEINTRAUB D, MAMIKONYAN E. The Neuropsychiatry of Parkinson Disease: A Perfect Storm. American Journal of Geriatric Psychiatry, 2019; 27(9): 998-1018. 
RESUMO SIMPLES: Revisão Bibliográfica

Título: Aspectos nutricionais para o tratamento da doença de Crohn

Autor/coautores: Larissa Andrade Moreira, Marília Milena Andrade Rodrigues, Pedro Augusto Silva Moreira,

Túlio Ferracini Costa e lury Camargos Nery Ferreira.

Instituição: Centro Universitário Atenas (UNIATENAS), Paracatu - MG.

Palavras-chave: Dieta, Doença de Crohn, Tratamento.

\section{INTRODUÇÃO}

A doença de Crohn (DC) é uma doença inflamatória intestinal crônica que pode afetar qualquer porção do trato gastrointestinal, especialmente a região íleo terminal. A etiologia da doença ainda é desconhecida, mas ocorre com maior frequência em pacientes jovens, entre 15 a 25 anos, sendo ambos os sexos igualmente afetados. Nesta patologia, o sistema digestório não consegue realizar o metabolismo e absorção adequada dos alimentos, o que promove uma insuficiência nutricional associada a diarreias, cólicas abdominais e inapetência. Assim, é necessária uma intervenção alimentar individual para amenizar as sintomatologias da doença e garantir um suporte nutricional (SANTOS GMD, et al., 2018).

\section{OBJETIVO}

Revisar a literatura científica sobre a influência dos aspectos nutricionais para o tratamento da doença de Crohn e os impactos na redução das sintomatologias para melhoria da qualidade vida do paciente.

\section{MÉTODO}

Trata-se de uma revisão integrativa que buscou nas bases de dados da PubMed, Scielo e Bireme os descritores "doença de Crohn", "alimentos" e "tratamento". Foram selecionados artigos dos últimos 5 anos em inglês e português. Excluiu-se estudos de casos e revisões de literatura.

\section{REVISÃO BIBLIOGRÁFICA}

Sabe-se que a DC propicia a deficiência na absorção de nutrientes, acarretando certos desequilíbrios, como déficit de vitaminas e minerais, anemia e desnutrição proteico-calórica. A maior parte dos estudos demonstrou que, para amenizar os efeitos da doença, a terapia nutricional é imprescindível, na qual utiliza-se suplementação de ferro e vitamina B12, associada ao uso farmacológico de anti-inflamatórios e antibióticos a fim de minimizar a sintomatologia. Ademais, destacou-se também nutrientes que aumentam a morbidade, sendo eles o colesterol, as gorduras animais e os monossacarídeos, os quais devem ser evitados para otimizar o tratamento (HIRAI F, et al., 2019).

Destarte, a dieta, de acordo com individualidade do paciente, é eficaz na suplementação de vitaminas e minerais, sendo tolerado refeições fracionadas, em pequenas quantidades, com dietas de resíduos mínimos, na tentativa de reduzir a diarreia e limitação dos alimentos fibrosos na prevenção de sintomas obstrutivos. Estudos de meta-análises também demonstraram resultados positivos na manutenção da flora intestinal com o uso de probióticos associados a terapia nutricional para indução da remissão e controle da DC (LOGAN M, et al., 2020).

\section{CONSIDERAÇÕES FINAIS}


Em análise dos estudos apresentados, fica evidente ressaltar que a terapia nutricional individual, associada a suplementação de vitaminas, é uma medida terapêutica para amenizar as sintomatologias, bem como o déficit nutricional em decorrência da má absorção intestinal acarretado pela doença de Crohn.

\section{REFERÊNCIAS}

1. HIRAI $F$, et al. Effect of a concomitant elemental diet with maintenance antitumor necrosis factor- $\alpha$ antibody therapy in patients with Crohn's disease: A multicenter, prospective cohort study. Journal of Gastroenterology and Hepatology, 2019; 34: 132-39.

2. LOGAN M, et al. Analysis of 61 exclusive enteral nutrition formulas used in the management of active Crohn's disease-new insights into dietary disease triggers. Alimentary Pharmacology \& Therapeutics, 2020; 51(10): 935-47.

3. SANTOS GMD, et al. Probióticos na terapia nutricional da doença de de Crohn. Revista Uningá, 2018; 33 : 111-20. 
RESUMO SIMPLES: Revisão Bibliográfica

Título: Ictiose Lamelar Congênita: uma revisão do impacto psicossocial na vida dos pacientes

Autor/coautores: Pedro Eduardo Murad Mendonça Porto, Leticya Alves Guimarães, Andressa Alves Guimarães, Mariana de Paula Ferreira, Raíssa Mendonça Porto Franco.

Instituição: Centro Universitário Atenas (Uniatenas), Paracatu - MG.

Palavras-chave: Ictiose Lamelar, Dermatopatia, Tratamento.

\section{INTRODUÇÃO}

A Ictiose Lamelar Congênita (ILC) é uma doença rara, hereditária, que compromete a pele devido uma disfunção no processo de maturação celular. Isso leva a um aumento na produção de queratina e diminuição da velocidade de descamação, gerando uma pele seca e áspera, com aspecto descamativo peculiar, como escamas (PRADO AS, et al., 2020). As manifestações clínicas incluem alterações físicas e estéticas que, por vezes, podem ocasionar distúrbios psíquicos e sociais ao paciente, devido a ele se sentir desconfortável quanto a sua aparência perante o restante da sociedade (SOUSA APR, et al., 2017).

\section{OBJETIVO}

Revisar a literatura científica com a finalidade de analisar as características clinicopatológica do paciente portador de Ictiose Lamelar Congênita e o impacto causado por essa doença em seu desenvolvimento pessoal e social.

\section{MÉTODO}

Trata-se de um estudo de revisão bibliográfica integrativa, com referências inglesa e portuguesa publicadas entre 2017 e 2020. Utilizou-se os descritores "ictiose", "genodermatose" e "tratamento" para a pesquisa nas plataformas SciELO e PubMed. Considerou-se critérios de inclusão: publicações coerentes com o objetivo do estudo no período indicado. E de exclusão: dados incompletos e/ou desatualizados.

\section{REVISÃO BIBLIOGRÁFICA}

A ILC é uma doença de herança autossômica recessiva que envolve uma mutação no gene que codifica a enzima TGM1, responsável pela diferenciação da epiderme (PRADO AS, et al., 2020). Quando ocorre alguma alteração genética, ocorre uma cornificação da pele, e o neonato nasce envolto por uma membrana que descama no decorrer das próximas semanas, evoluindo com escamas grandes, escuras e grossas, além de um eritrodermia característica (MORAES ELL, et al., 2019).

Nesse sentido, portadores de Ictiose Lamelar têm sua qualidade de vida afetada, uma vez que a imagem corporal é extremamente importante e tê-la de modo insatisfatório pode causar sentimentos de desvalorização, inferioridade e baixa autoestima (COSTA CS, 2020). Diante disso, o acompanhamento psicológico é parte fundamental do tratamento, incentivando a autonomia e a confiança destas pessoas, no desenvolvimento de competências pessoais e sociais que lhe faça sentir melhor (COSTA CS, et al., 2020).

\section{CONSIDERAÇÕES FINAIS}

Conclui-se que a ILC é uma patologia rara, pouco conhecida e traz danos físicos e psicológicos aos pacientes. Estes podem ser minimizados a partir do momento que a doença é mais pesquisada, estudada e divulgada. Maior conhecimento gerado sobre a doença, poderá levar a menor causa de afastamento social e 
ao desenvolvimento de novos tratamentos, que ao melhorar sintomas e estética, melhore a qualidade de vida dos pacientes.

\section{REFERÊNCIAS}

1. COSTA CS, et al. Podendo ser si-mesmo: experiências de adolescentes com doenças crônicas de pele em acampamento. Esc. Anna Nery, 2020;24(3): e20190333.

2. MORAES ELL, et al. Assistência de enfermagem ao recém-nascido com Ictiose Lamelar: um estudo de caso em unidade neonatal. Revista da Escola de Enfermagem da USP, 2019; 53: 1-7.

3. PRADO AS, et al. Ictiose Lamelar Congênita e o Papel da Estética para Controle Clínico / Congenital Lamellarylcthiosisandthe Role ofAesthetics for ClinicalControl. Revista de Psicologia, 2020;14: 1008-17.

4. SOUSA APR, et al. Ictiose Lamelar Congênita: uma abordagem literária. Mostra Científica da Farmácia, $2017 ; 3(1)$. 
RESUMO SIMPLES: Revisão Bibliográfica

Título: Infecção pelo HPV masculino relacionado ao câncer de pênis

Autor/coautores: Jean Carlos Martins da Silva, Ana Karoline Mendes Lima, Claudia Balestra de Oliveira, Denise Abud de Castro, Ana Carolina Albernaz Barbosa.

Instituição: Centro Universitário Atenas (UniAtenas), Paracatu - MG.

Palavras-chave: Infecções por Papillomavirus, Neoplasias penianas, Vacinas contra Papillomavirus.

\section{INTRODUÇÃO}

O Papiloma Vírus Humano (HPV) é um vírus de DNA responsável por infecções da pele e mucosa genital, sendo uma das infeções sexualmente transmissíveis mais comuns. Com mais de 100 genótipos conhecidos, 13 são oncogênicos de alto risco, sendo o 16 e 18 mais frequentes. Apesar de quase onipresente nos casos de câncer de colo de útero, ele está relacionado a $40 \%$ dos casos de câncer de pênis no mundo (STRATTON KL e CULKIN DJ, 2016). Por ser um considerável fator de risco também entre os homens, o incentivo à vacinação se constitui um importante meio de prevenção e promoção de saúde (SCHNEEDE P e SCHLENKER B, 2018).

\section{OBJETIVO}

Analisar a partir de uma revisão de literatura os mecanismos oncogênicos do HPV para o câncer de pênis, bem como a vacinação entre os meninos como mecanismo para redução da incidência dos casos.

\section{MÉTODO}

Para realização dessa revisão integrativa foram realizadas buscas na base de dados PubMed utilizando os descritores: "Papilomavírus humano", "câncer de pênis" e "vacinação" usando os operadores booleanos "AND" e "OR". Foram selecionados 3 artigos publicados nos últimos 5 anos (2015-2020) na língua portuguesa e inglesa que atendam aos critérios de elegibilidade. Foram excluídos trabalhos incompletos e que não atenderam aos objetivos dos estudos.

\section{REVISÃO BIBLIOGRÁFICA}

Com prevalência de $20 \%$ nos homens e relacionado a uma variedade de patologias geniturinárias, o vírus é comumente relacionado a carcinomas basalóides e condilomatosos. Apesar de majoritariamente serem benignos, podem gerar prurido, dor e sangramento, potencialmente evoluindo para formas mais graves quando não tratados (STRATTON KL e CULKIN DJ, 2016).

A oncogenicidade do HPV deve-se à interferência nas proteínas supressoras de tumor E6, que atua na via da P53, e a E7, supressor de retinoblastoma. Evidencia-se redução da expressão de micro RNA (miR-218), impactando genes regulatórios de carcinomas espinocelulares (OLESEN TB, et al., 2019). Por não haver tratamento, a prevenção é o melhor meio para redução da incidência. Assim, a comprovada vacina quadrivalente, indicada na faixa etária de 11 a 14 anos entre os meninos, protege tantos os homens contra o HPV, como as mulheres através da imunização de rebanho (SCHNEEDE P e SCHLENKER B, 2018).

\section{CONSIDERAÇÕES FINAIS}


Não restrito apenas à população feminina, o HPV também se mostrou um importante fator de risco para o câncer peniano. Dessa forma, é importante o incentivo a vacinação nessa população, de maneira a proteger homens e mulheres de modo equivalente.

\section{REFERÊNCIAS}

1. OLESEN TB, et al. Prevalence of human papillomavirus DNA and p16 (INK4a) in penile cancer and penile intraepithelial neoplasia: a systematic review and meta-analysis. The lancet oncology, 2019; 20(1): 14558.

2. SCHNEEDE P, SCHLENKER B. Human papillomavirus and penile cancer: Thinking about measures for prevention. Der urologe, 2018; 57(4): 413-17.

3. STRATTON KL, CULKIN DJ. A Contemporary Review of HPV and Penile Cancer. Oncology (Williston Park), 2016; 30(3): 245-49. 
RESUMO SIMPLES: Revisão Bibliográfica

Título: Mecanismo Neuroprotetor da Irisina aplicado a Doença de Alzheimer

Autor/coautores: Ana Karoline Mendes Lima; Claudia Balestra de Oliveira; Gabrielle Martins Marra; Jean

Carlos Martins da Silva; Ana Carolina Albernaz Barbosa.

Instituição: Centro Universitário Atenas (UniAtenas), Paracatu - MG.

Palavras-chave: Doença de Alzheimer, Exercício, Proteína de desacoplamento mitocondrial.

\section{INTRODUÇÃO}

Apesar de indicada a muito tempo como prevenção e terapêutica, pouco ainda se sabia a respeito da real contribuição da atividade física regular na história natural da Doença de Alzheimer (DA). Recentemente, a partir da descoberta da Irisina, intensificaram-se os estudos voltados para essa área (FREITAS GB, et al., 2020). Trata-se de um hormônio produzido pelo tecido muscular durante a atividade física, o qual protege e restaura a memória afetada pela doença. Atua impedindo o acúmulo de placas $\beta$-amiloides, que em excesso caracterizam a doença (KIM OY, et al., 2018).

\section{OBJETIVO}

Compreender, a partir da revisão de recentes estudos publicados, os mecanismos neuroprotetores da Irisina que incidem sobre o início e progressão de doenças neurodegenerativas, em especial a Doença de Alzheimer.

\section{MÉTODO}

Para realização desta revisão sistemática foram realizadas buscas na base de dados PubMed utilizando os seguintes descritores: "Alzheimer" e "Irisin", usando os operadores booleanos "AND" e "OR". Foram selecionados 3 artigos publicados nos últimos 5 anos (2015-2020) na língua portuguesa e inglesa que atendam aos critérios de elegibilidade. Foram excluídos trabalhos incompletos e que não atendiam aos objetivos do estudo.

\section{REVISÃO BIBLIOGRÁFICA}

A Irisina é uma enzima produzida sobretudo nos miócitos, oriunda da quebra da FNDC-5, uma fibronectina tipo III, durante atividades físicas (FREITAS GB, et al., 2020). Atua na regulação do tecido adiposo e ósseo, além de aumentar consumo energético e termogênese (KIM OY, et al., 2018). A partir de estudos imunológicos constatou-se quantidades consideravelmente baixas desse hormônio em pacientes com a DA em fases avançadas, levantando-se às hipóteses a respeito de seu papel na doença (LOURENCO MV, et al., 2019). Teoricamente seu efeito no cérebro se deve a dois mecanismos básicos: tornar os neurônios pouco imunorreativos à presença das placas beta-amiloides e estimular à produção de compostos como o Fator Neurotrófico Derivado do Cérebro (FNDC), que auxilia na formação da memória (KIM OY, et al., 2018). Em testes com camundongos com elevado nível de Irisina no hipocampo, observa-se uma melhora da neuroplasticidade e da memória dos ratos usados como modelo, demonstrando ser um promissor campo de estudos terapêuticos voltados para a doença (LOURENCO MV, et al., 2019).

\section{CONSIDERAÇÕES FINAIS}


A prática de atividades físicas regulares tem demonstrado ser um importante modo de prevenção não apenas em doenças de base, mas também da DA. Mais estudos na área são necessários, visto o potencial terapêutico deste hormônio e a alta prevalência da doença no Brasil.

\section{REFERÊNCIAS}

1. FREITAS GB, et al. Protective actions of exercise-related FNDC5/Irisin in memory and Alzheimer's disease. Journal of Neurochemistry, 2020; 155(6): 602-11

2. KIM OY, et al. The Role of Irisin in Alzheimer's Disease. Journal of Clinical Medicine, 2018; 7(11): 407-08

3. LOURENCO MV, et al. Exercise-linked FNDC5/irisin rescues synaptic plasticity and memory defects in Alzheimer's models. Nature Medicine, 2019; 25(1): 165-75. 
RESUMO SIMPLES: Revisão Bibliográfica

Título: Os componentes psicopatológicos que envolvem a doença do refluxo gastroesofágico

Autor/coautores: Gabriel Meira Cardoso Pereira, Nicole Assis Valadares Tavares e Thiago Álvares da Costa.

Instituição: Centro Universitário Atenas (UniAtenas), Paracatu - MG.

Palavras-chave: Doença do Refluxo Gastroesofágico, Esofagite, Sintomas Psíquicos.

\section{INTRODUÇÃO}

A doença do refluxo gastroesofágico (DRGE) é caracterizada por uma disfunção da junção gastroesofágica que resulta em um fluxo retrógrado do conteúdo gástrico para o esôfago e/ou órgãos adjacentes. Esse tipo de doença é uma das mais comuns nos países ocidentais, e leva a sintomas como regurgitamento e pirose (SAVARINO E, et al., 2017). Essas manifestações clínicas quando chegam a uma forma crônica levam à mudanças no estilo de vida do paciente, o que pode gerar um efeito negativo em sua qualidade de vida, afetando-o psicologicamente e predispondo-o à doenças mentais (LI P, et al., 2018).

\section{OBJETIVO}

Revisar estudos que associam a Doença do Refluxo Gastroesofágico com sintomas psíquicos, com o intuito de fazer uma varredura bibliográfica que demonstre as diversas manifestações clínicas mentais relacionadas à essa doença.

\section{MÉTODO}

Trata-se de uma revisão bibliográfica sistemática, baseada na análise de dados encontrados nas plataformas Scielo, PubMed e UpToDate. Foram encontrados cerca de 4 pesquisados entre os anos 2016 e 2019. Utilizou-se os descritores "Doença do Refluxo Gastroesofágico", "Esofagite" e "Sintomas Psíquicos", incluindo-se os estudos que correlacionassem DRGE e saúde mental e excluiu-se estudos que se limitassem à DRGE ou sintomas psíquicos.

\section{REVISÃO BIBLIOGRÁFICA}

A DRGE se configura como um quadro crônico e doloroso, com alto potencial de desenvolver comorbidades psíquicas. O tratamento da DRGE envolve, além de medicamentos, mudanças do hábito e estilo de vida que muitos pacientes não se adaptam, como restrições da ingesta de bebidas gaseificadas, cafeinadas e alcoólicas, posição para dormir e horários alimentares restritivos, que podem desestimular o paciente e servirem como estressor psicológico, prolongando o período de tratamento e reduzindo a eficácia (NESS-JENSEN E, et al., 2016). Além disso, os pacientes com DRGE têm menores índices de qualidade de vida que a população geral devido a pirose e regurgitação frequentes que causam desconforto durante o dia e geram quadros ansioso-depressivos por medo e sentimento de culpa, desmotivação, desregulação no ciclo circadiano e outros sintomas. Ratificando a importância do estado mental para o manejo da doença (ODARUSHCHENKO OI, 2019).

\section{CONSIDERAÇÕES FINAIS}

Desse modo, nota-se que DRGE e sua cronicidade causam sofrimento físico e psíquico à rotina, afetando a vida dos pacientes. Os redutores da qualidade de vida são, primordialmente, os sintomas repetitivos e incômodos da doença, bem como o tratamento restritivo e os desconfortos psicossociais. Portanto, DRGE 
mostra-se uma patologia altamente influenciada por fatores psicossociais que têm potencial de gerar evolução com piora em pacientes.

\section{REFERÊNCIAS}

1. LI P, et al. The psychological results of 438 patients with persisting GERD symptoms by Symptom Checklist 90-Revised (SCL-90-R) questionnaire. Medicine (Baltimore). 2018; 97(22): e10768.

2. NESS-JENSEN E, et al. Lifestyle Intervention in Gastroesophageal Reflux Disease. Clin Gastroenterol Hepatol., 2016; 14(2): 175-82.

3. ODARUSHCHENKO OI. Émotsional'no-lichnostnaia sfera patsientov s gastroézofageal'noĭ refliuksnoI bolezn'iu [The emotional-personal sphere of patients with gastroesophageal reflux disease]. Vopr Kurortol Fizioter Lech Fiz Kult. 2019; 96(3): 25-30.

4. SAVARINO E, et al. Advances in the physiological assessment and diagnosis of GERD. Nat Rev Gastroenterol Hepatol, 2017; 14: 665-76. 
RESUMO SIMPLES: Revisão Bibliográfica

Título: Uso do extrato de cannabis para tratamento de náuseas e vômitos induzidos por quimioterapia

Autor/coautores: Larissa Andrade Moreira, Marília Milena Andrade Rodrigues, Túlio Ferracini Costa, Nathália Marra Aguiar e lury Camargos Nery Ferreira.

Instituição: Centro Universitário Atenas (UNIATENAS), Paracatu - Minas Gerais.

Palavras-chave: Cannabis, Quimioterapia, Vômitos.

\section{INTRODUÇÃO}

Alguns dos efeitos colaterais ocasionados pela quimioterapia, como náuseas e vômitos, são um desafio para a área médica, tendo em vista que os medicamentos antieméticos, muitas vezes, não conseguem sanar essa sintomatologia e, assim, podem dificultar 0 andamento do tratamento. Diante disso, 0 uso de medicamentos à base de cannabis tornaram-se um potencial fármaco na terapêutica de pacientes quimioterápicos, pois os agentes ativos presentes podem auxiliar no controle de náuseas e vômitos, portanto, é considerada uma terapia adicional a ser estudada para melhorar a qualidade de vida e o bem-estar do paciente (GRIMISON P, et al., 2020).

\section{OBJETIVO}

Revisar a literatura científica para compreender o uso do extrato de cannabis no tratamento de náuseas e vômitos induzidos por quimioterapia, além dos impactos na qualidade de vida dos pacientes.

\section{MÉTODO}

Trata-se de uma revisão bibliográfica integrativa que buscou nas bases de dados PubMed, SciELO e MedLine os descritores em saúde: "cannabis", "quimioterapia combinada", "vômito" e "tratamento". Como critério de inclusão, foram selecionados artigos publicados apenas nos últimos 5 anos e na língua inglesa. Excluiu-se estudos de casos e revisões de literatura.

\section{REVISÃO BIBLIOGRÁFICA}

A utilização do medicamento à base de cannabis é relevante em virtude da presença do elemento ativo delta-9-tetrahidrocanabinol (THC). Estudos demonstram que os canabinóides afetam o usuário pelo fato de se ligarem aos receptores CB1 e CB2 presentes em diferentes áreas do cérebro. Porém, duas substâncias presentes no cérebro, anandamida e 2-araquidonoilglicerol, são capazes de se ligarem e bloquearem tais receptores, o que induz as náuseas e vômitos. Entretanto, na presença do elemento ativo THC, tem-se uma atividade antiemética decorrente da estimulação dos receptores CB1 e CB2 (TAFELSKY S, et al., 2016).

Ademais, estudos randomizados concluíram que os canabinóides podem ser úteis para controlar êmeses induzidas pela quimioterapia. Assim, três ensaios envolvendo 288 participantes mostraram que indivíduos submetidos ao uso de THC foram cinco vezes mais propensos a relatarem uma ausência completa de náuseas e vômitos quando comparado ao grupo que utilizou o placebo (MAKARY P, et al., 2019). 


\section{CONSIDERAÇÕES FINAIS}

Portanto, observa-se a importância da utilização de métodos alternativos como a manipulação de canabinóides na redução dos quadros de náuseas e êmeses desencadeados pelo tratamento quimioterápico. Essa alternativa se torna viável, ao ser expressamente comprovada como ferramenta semelhante a terapia convencional com antieméticos contra os efeitos da quimioterapia, se mostrando assim, como uma realidade promissora.

\section{REFERÊNCIAS}

1. GRIMISON P, et al. Oral THC: CBD cannabis extract for refractory chemotherapy-induced nausea and vomiting: a randomised, placebo-controlled, phase II crossover trial. Annals of Oncology driving innovation in oncology, 2020; 31(11): 1553-1560.

2. MAKARY $P$, et al. Patient Counseling Guidelines for the Use of Cannabis for the Treatment of Chemotherapy-Induced Nausea/Vomiting and Chronic Pain. Journal of Pain \& Palliative Care Pharmacotherapy, 2019; 32(4): 216-225.

3. TAFELSKY S, et al. Efficacy, tolerability, and safety of cannabinoids for chemotherapy-induced nause and vomiting-a systematic review of systematic reviews. Springer, 2016; 30(1): 14-24. 
RESUMO SIMPLES: Revisão Bibliográfica

Título: Covid 19: dinâmica de transmissão e controle associado à vulnerabilidade

Autor/coautores: Larissa Ferreira Sá, Beatriz de Oliveira, Pâmella Francyelle Dias Silva, Pedro Barbosa

Gomes, Flávia Tolentino Marra.

Instituição: Centro Universitário Atenas (UniAtenas), Paracatu - MG.

Palavras-chave: Covid-19, Transmissão,Vulnerabilidade.

\section{INTRODUÇÃO}

Existem atualmente seis coronavírus humanos descritos. Os bem conhecidos coronavírus humanos (HCoV) 229E e OC43 foram descritos na década de 1960 e por quase 40 anos foram considerados os únicos representantes de Coronaviridae infectando humanos. O surgimento de coronavírus associado à Síndrome Respiratória Aguda Grave (SARS-CoV) em 2002, seguido pela identificação de HCoV-NL63 e HCoV-HKU1, revelou que esses vírus são muito mais comuns e clinicamente relevantes do que o esperado anteriormente (OWCZAREK KA, et al., 2018).

O quadro clínico da doença varia de forma assintomática até quadros graves, o que torna necessário um quadro de isolamento social para controle, principalmente para indivíduos que se encontram no grupo de risco (THE LANCET, 2020).

\section{OBJETIVO}

Correlacionar a dinâmica de transmissão e controle do Covid-19 em uma realidade de vulnerabilidade social, mostrando que o cenário de calamidade não é exclusivo apenas da saúde pública, abrangendo também a esfera socioeconômica e as relações interpessoais.

\section{REVISÃO BIBLIOGRÁFICA}

O vírus recém-descoberto tem sua transmissão gerada de pessoa a pessoa principalmente por gotículas de saliva, tosse, espirro e secreções geradas pela doença, além de poder causar episódios de febre, desconforto respiratório e outros sintomas; características que contribuíram para o cenário da presente pandemia (PETROPOULOS, et al., 2020). Dados mostram que a população idosa e pessoas com comorbidades, como exemplo as doenças cardiovasculares e a diabetes mellitus, podem ter um maior risco de apresentarem um quadro grave da Covid-19 e, como consequência, a morte. Dessa forma e com a dinâmica de transmissão, foi implantado o isolamento físico como meio eficaz de prevenção, sendo a China o primeiro país a mostrar resultados positivos (ANASTASSOPOULOU C, et al., 2020). Em contrapartida, o setor econômico compôs o desdobramento secundário de uma crise inicialmente sanitária. Assim, tem sido importante objeto de análise dentro dos grupos de vulnerabilidade social, dado o efeito cascata sobre a vida financeira familiar, saúde física e especialmente a saúde mental de toda a população. Em países subdesenvolvidos como o Brasil, além da exposição à nova doença, a sociedade lida com desigualdade $\mathrm{e}$ miséria já instaladas (AHMAD A, et al., 2020).

\section{CONSIDERAÇÕES FINAIS}

O avanço da Covid-19 traz consigo o caos. Sendo assim, são necessárias estratégias efetivas em torno do controle de transmissão do novo coronavírus, bem como atendimento direcionado aos principais grupos vulneráveis de cada país. Sob tal perspectiva, torna-se imprescindível um alinhamento entre dois importantes setores: comunidade científica e o Estado na redução dos danos à saúde e à sociedade. 


\section{REFERÊNCIAS}

1. AHMAD A, et al. What does it mean to be made vulnerable in the era of COVID-19? The Lancet, 2020; 395(10235): 1481-1482.

2. ANASTASSOPOULOU $\mathrm{C}$, et al. Data-based analysis, modelling and forecasting of the COVID-19 outbreak. PLoS One, 2020; 15(3): e0230405.

3. OWCZAREK, K., A. et al. Early events during human coronavirus OC43 entry to the cell. Sci Rep, 2018; 8: 7124-7125.

4. PETROPOULOS, et al. Forecasting the novel coronavirus COVID-19. PloS one vol, 2020; 15(3): e0231236.

5. THE LANCET. Redefining vulnerability in the era of COVID-19. Lancet, 2020; 395(10230): 1089. 
RESUMO SIMPLES: Revisão Bibliográfica

Título: Contribuições otorrinolaringológicas para a COVID-19 no Brasil

Autor/coautores: Laura Couto Cunha; André Luiz Botelho Teixeira; Bernardo Campos Faria.

Instituição: Centro Universitário Atenas (UniAtenas), Paracatu - MG.

Palavras-chave: Covid-19; Anosmia; Otorrinolaringologia.

\section{INTRODUÇÃO}

Devido às múltiplas apresentações clínicas desencadeadas pelo Coronavírus (SARSCoV-2) o conceito diagnóstico para essa infecção doença permanece muito amplo e sensível, dessa forma não é possível definir um sinal e sintoma obrigatório para determinar a presença da infecção (KOSUGI EM, et al., 2020). Portanto, é essencial que a prática médica seja baseada na clínica do paciente. Assim, torna-se imprescindível propor critérios que efetivem as condutas do profissional de saúde presentes na linha de frente do combate, embasadas principalmente nos dados estatísticos que comprovem a sintomatologia e a evolução mais comumente observada.

\section{OBJETIVO}

Descrever o envolvimento da otorrinolaringologia no que diz respeito a suas principais contribuições no entendimento da fisiopatologia do SARSCoV-2 e na elaboração de diretivas das quais favoreçam o diagnóstico e o tratamento precoce.

\section{MÉTODO}

Realizou-se uma revisão integrativa a partir de dados científicos do Jornal Brasileiro de Otorrinolaringologia. Foi utilizado como critério de inclusão os seguintes itens: artigos que tivessem os descritores "Covid-19", anosmia" e "otorrinolaringologia" e que fossem datados de 2020. Excluiu-se todos os materiais científicos que não constavam na bibliografia desejada. Encontrou-se 22 referências, das quais utilizou-se apenas 3 para constituição do trabalho em questão.

\section{REVISÃO BIBLIOGRÁFICA}

Conforme a Organização Mundial da Saúde (OMS,2020), os primeiros os sintomas do Coronavírus são conhecidos como quadro gripal comum, variando de manifestação branda e até a formas mais severas (LIMA CMAO, 2020).

Uma pesquisa realizada pela Associação Brasileira de Otorrinolaringologia mostrou que a maior parte dos pacientes apresentaram anosmia súbita em vez de hiposmia súbita. A anosmia foi acompanhada de sintomas inflamatórios inespecíficos: anorexia, febre, mialgia. Foram relatados também sintomas nasais como prurido, obstrução, espirros. A recuperação da anosmia súbita foi alta, com pacientes que apresentaram recuperação total ou parcial, existindo ainda, uma minoria de pacientes que não recuperaram de forma alguma (MACHADO AJJ e PAUNA HF, 2020).

Essas constatações demonstram a atuação da otorrinolaringologia como um fator adjuvante no diagnóstico precoce da COVID-19. Visto que ainda não há abrangência dos métodos diagnósticos em todo o Brasil, fazendo com que o curso clínico, prognóstico e a recuperação do paciente sejam deficitários.

\section{CONSIDERAÇÕES FINAIS}


Diante da heterogeneidade e da inespecificidade da conformação clínica, considera caso confirmado quando há afirmação laboratorial conclusiva para SARSCoV-2, extinguindo a necessidade de haver sinais e sintomas, uma vez que existem pessoas assintomáticas.

Dessa forma, deve-se correlacionar aspectos clínicos embasados nos principais achados otorrinolaringológicos proporcionando uma evolução mais estável ao acometido, destituída de sequelas graves.

\section{REFERÊNCIAS}

1. KOSUGI E, et al. Recuperação incompleta e tardia da perda súbita do olfato na COVID-19. Jornal Brasileiro de Otorrinolaringologia, 2020; 86: 490-496.

2. LIMA CMAO. Informações sobre o novo coronavírus (COVID-19). Radiologia Brasileira, 2020; 53: 5-6.

3. MACHADO AJJ, PAUNA HF. Ensino à distância e telemedicina na área da Otorrinolaringologia: lições em tempos de pandemia. Jornal Brasileiro de Otorrinolaringologia, 2020; 86: 271-272. 
RESUMO SIMPLES: Revisão Bibliográfica

Título: Disfonia pós intubação orotraqueal

Autor/coautores: Guilherme Mendes Galvão; Melissa Soares Ferreira²; Raquel de Oliveira Brito3; Gustavo

Cunha Lima*; Bernardo Campos Faria ${ }^{5}$.

Instituição: Centro Universitário Atenas (UniAtenas) ${ }^{1,2,3,5}$, Paracatu - MG; Universidade Federal de

Uberlândia (UFU) ${ }^{4}$, Uberlândia - MG.

Palavras-chave: Disfonia, Intubação, Complicação.

\section{INTRODUÇÃO}

A intubação orotraqueal (IOT) permite assistência ventilatória em pacientes anestesiados ou sob ventilação mecânica, podendo ser de curta ou longa duração. A presença de tubos orotraqueais em contato direto com as vias aéreas podem provocar lesões. Um dos sintomas mais frequentes apresentados pelos pacientes é a disfonia, que acomete de 14,4 a $50 \%$ dos indivíduos submetidos à IOT. A rouquidão, rotineiramente é temporária, desaparecendo entre dois a três dias, entretanto, cerca de $10 \%$ dos casos pode ser permanente, alterando a qualidade de vida destes pacientes (CAMPOS NF, et al., 2016).

\section{OBJETIVO}

Elucidar os achados da literatura a respeito da disfonia pós intubação orotraqueal e seus mecanismos de lesão, além de esclarecer as medidas que possam reduzir a incidência e gravidade dessa patologia.

\section{MÉTODO}

Trata-se de um estudo de revisão bibliográfica integrativa, com referências portuguesa, publicadas entre 2016 e 2021. Utilizou-se os descritores "Disfonia" "Intubação" e "Complicação" para a pesquisa nas plataformas PubMed, Scielo e UpToDate. Considerou-se critérios de inclusão: publicações coerentes ao período indicado, dados e arguições. E de exclusão: dados incompletos e/ou desatualizados.

\section{REVISÃO BIBLIOGRÁFICA}

A partir da introdução da cânula, mediante tentativas de exposição da glote com o laringoscópio, são descritas lacerações em lábios, gengivas, faringe e traquéia. Também se observam hematomas e avulsão de pregas vocais, além de luxação das cartilagens aritenóideas, ocasionando uma disfonia (OLIVEIRA, et al., 2018).

O diâmetro inadequado das cânulas, o tempo prolongado acima de 48 horas e a dificuldade em manter o paciente imóvel são fatores predisponentes ao desenvolvimento de lesões de vias aéreas. Em pacientes não sedados, estão presentes movimentos reflexos de deglutição e adução das pregas vocais sobre a traqueia, portanto, o uso de bloqueadores neuromusculares é indicado (UNSAL, 2018).

Grande parte das lesões ocorrem na porção posterior da laringe, onde a sonda encontra-se em íntimo contato com a mucosa dos processos vocais. Devido a capacidade de regeneração do epitélio, a maioria das lesões resolvem-se espontaneamente, contudo, em pacientes debilitados, pode haver alteração da perfusão tecidual e uma cicatrização deficiente, acarretando danos permanentes (OLIVEIRA A, et al., 2018). 


\section{CONSIDERAÇÕES FINAIS}

As desordens das vias aéreas associadas à IOT são frequentes, podendo tal incidência ser reduzida mediante o conhecimento de sua fisiopatologia, do tempo de permanência do tubo e experiência profissional para sua inserção, além do uso do bloqueador neuromuscular precedido da intubação. A avaliação endoscópica precoce rotineira nos pacientes submetidos à IOT que apresentem sintomas vocais se faz necessária.

\section{REFERÊNCIAS}

1. CAMPOS NF, et al. Efeitos da intubação orotraqueal na voz e deglutição de adultos e idosos. Distúrb Comun, 2016; 28(4): 597-608.

2. OLIVEIRA A, et al. Fatores preditivos para disfagia orofaríngea após intubação orotraqueal prolongada. Revista Brasileira de Otorrinolaringologia, 2018; 84(6): 722-728.

3. UNSAL. The Evaluation of Upper Airway Complications Secondary to Intubation: Cuff Pressure Manometer Versus Conventional Palpation Method. Sisli Etfal Hastan Tip Bul, 2018; 52(4): 289-295. 
RESUMO SIMPLES: Revisão Bibliográfica

Título: Perspectiva otorrinolaringológica da doença do refluxo laringofaríngeo pediátrico

Autor/coautores: Ana Luisa Ferreira Vilela Marques, Gabriel Araújo Nascimento, Rafaela Amaral Silva,

Stheffany Oliveira Guimarães Maciel, Bernardo Campos Faria

Instituição: Centro Universitário Atenas (UNIATENAS) - Paracatu - MG.

Palavras-chave: Refluxo Laringofaríngeo, Pediatria, Otorrinolaringologia.

\section{INTRODUÇÃO}

A doença do refluxo laringofaríngeo (DRLF) é decorrente da doença do refluxo gastroesofágico (DRGE) e é caracterizada pelo fluxo retrógrado do suco gastrointestinal pelo esôfago que atinge laringe, orofaringe e nasofaringe. Por afetar diferentes estruturas na cabeça e no pescoço, exige tratamento médico diferenciado com um otorrinolaringologista (GALLUZZI F, et al., 2015). A afecção crônica do RLF é evidenciada recorrentemente na pediatria apresentando sinusite, otites, estertor, apneia, tosse crônica, faringite, laringite e disfonia como sintomas (WERTZ A, et al., 2020). A prevalência dessa doença em crianças ainda é desconhecida, mas sabe-se que $1,8 \%$ a $22 \%$ delas apresentam casos de RGE (GALLUZZI F, et al., 2015).

\section{OBJETIVO}

Analisar e diferenciar os sintomas e achados diagnósticos da DRLF a partir de uma visão otorrinolaringológica pediátrica, bem como abordar a perspectiva a respeito de um diagnóstico padrão ouro para essa patologia.

\section{MÉTODO}

Trata-se de uma revisão integrativa com busca na base de dados Scielo e Pubmed, usando os descritores "Refluxo laringofaríngeo pediátrico" e "evolução do refluxo laringofaríngeo" como critérios de inclusão em dezembro de 2020. Encontrou-se uma média de 23 estudos e selecionou-se 4. Os critérios de exclusão foram publicações com mais de 5 anos.

\section{REVISÃO BIBLIOGRÁFICA}

A DRLF tem-se como base na inflamação dos tecidos do trato aerodigestivo superior que se desenvolve pelos efeitos do refluxo gastroduodenal e podem induzir a alterações morfológicas nas crianças (LECHIEN J, et al., 2019). As manifestações clínicas do RLF são diversas na pediatria. Além disso, pelos pequenos não possuírem uma completa capacidade de comunicação e as expressões sintomáticas serem extremamente diversificadas, o refluxo e a regurgitação são difíceis de serem diferenciados entre patológicos ou fisiológicos.

Dessa forma, o diagnóstico requer uma avaliação mais criteriosa. Não há nenhum teste diagnóstico padrão ouro para a detecção de RLF em crianças no momento. Contudo, há alguns instrumentos diagnósticos que visam facilitar o resultado como a esofagogastroduodenoscopia (EGD) e a impedância multicanal com pH monitoramento (MII-pH) que objetiva medir os níveis de pepsina do fluido bucal e analisar se há RLF e sua gravidade (ECKLEY CA e TANGERINA R, 2019).

\section{CONSIDERAÇÕES FINAIS}

Evidencia-se, portanto, a DRLF pediátrico ressaltando a incapacidade em identificar sintomas típicos capazes de comprovar o diagnóstico clínico da moléstia. Sendo assim, por mais que a EGD e a MII-pH sejam importantes ferramentas diagnósticas, maiores estudos e análises devem ser feitas para que haja validação de um método padrão ouro para diagnosticar RLF em crianças. 


\section{REFERÊNCIAS}

1. ECKLEY CA, TANGERINA R. Sensitivity, Specificity, and Reproducibility of the Brazilian Portuguese Version of the Reflux Symptom Index. Journal of Voice, 2019; 35(1): 15-19.

2. GALLUZZI $F$, et al. The assessment of children with suspected laryngopharyngeal reflux: An Otorhinolaringological persepective. International Journal of Pediatric Otorhinolaryngology, 2015; 79(10): 1613-1619.

3. LECHIEN J, et al. Evaluation and Management of Laryngopharyngeal Reflux Disease: State of the Art Review. Otolaryngology-Head and Neck Surgery, 2019; 160(5): 762-782.

4. WERTZ A, et al. Pediatric laryngopharyngeal reflux: Perceptual, acoustic, and laryngeal findings. International Journal of Pediatric Otorhinolaryngology, 2020; 133(1): 1-5. 
RESUMO SIMPLES: Revisão Bibliográfica

Título: Hipertensão arterial e perda auditiva: uma revisão bibliográfica

Autor/coautores: André Pereira Lopes, Bruna Santiago Teixeira, Lucas Aragão Martins; Bernardo Campos

Faria.

Instituição: Centro Universitário Atenas - UNIATENAS, Paracatu - MG.

Palavras-chave: Hipertensão Arterial Sistêmica, Zumbido, Perda auditiva.

\section{INTRODUÇÃO}

A pressão arterial é conceituada como a pressão que o sangue exerce sobre os vasos sanguíneos, podendo acarretar danos e complicações em órgãos-alvo. Nesse sentido, alterações que acarretam comprometimento do aparelho circulatório, podem afetar diretamente o ouvido interno e seu funcionamento de diversas maneiras. Umas das maneiras descritas é o aumento da viscosidade sanguínea, ocasionando redução do fluxo sanguíneo capilar, que leva a uma diminuição do transporte de oxigênio, gerando hipóxia tecidual, trazendo tanto queixas quanto perdas auditivas aos seus portadores e justifica a relação entre HAS, zumbido e perda auditiva. (PRZEWOŹNY T, et al., 2018; FIGUEIREDO RR, et al., 2015)

\section{OBJETIVO}

Revisar a literatura científica, a fim de elucidar a existência ou não de uma relação entre Hipertensão Arterial Sistêmica (HAS), zumbido e perda auditiva, como também os seus mecanismos fisiopatológicos.

\section{MÉTODO}

Trata-se de uma revisão integrativa da literatura; executada através de pesquisa nas bases SCIELO, PUBMED e INTERNATIONAL ARCHIEVES OF OTORHINOLARYNGOLOGY, utilizando os termos: "Hipertensão Arterial Sistêmica", "zumbido", "perda auditiva". Critérios de inclusão: artigos com disponibilidade na íntegra, em português ou inglês, que apresentem coerência com o tema, data de publicação entre 2015 e 2019. Foram excluídas publicações indisponíveis e cujos títulos ou objetivos não possuíam ligação direta com a temática.

\section{REVISÃO BIBLIOGRAFICA}

A HAS nos últimos anos encontra-se como um dos máximos combates da saúde pública, possuindo enorme prevalecimento, principalmente entre adultos jovens. Alterações ocorridas na orelha interna que ocasionam zumbido, vertigem e perda auditiva, podem ser relacionados com uma insuficiência microcirculatória proveniente de uma oclusão vascular por embolia, hemorragia ou vasoespasmo e que estes, por sua vez, decorrem de uma síndrome de hiperviscosidade ou microangiopatia. (MENESES-BARRIVIERA C, et al., 2018; FIGUEIREDO RR, et al., 2015; REED NS, et al., 2019)

O aumento da pressão no sistema vascular pode resultar em hemorragias na orelha interna, que é vascularizada pela artéria cerebelar inferior anterior, que fornece suprimento sanguíneo e se ramifica em artéria coclear e artéria vestibular anterior, que pode favorecer e ocasionar perdas auditivas súbitas ou progressivas, sendo a sensorioneural, o modelo que ocorre em pacientes como consequência da HAS. (FIGUEIREDO RR, et al., 2015; FIGUEIREDO RR, et al., 2016).

\section{CONSIDERAÇÕES FINAIS}


Foi constatada a relação de HAS com zumbido e perda auditiva. Todavia, é necessário realizar mais pesquisas com população jovem, para dissociar o que é causado pela HAS, dos efeitos senis no organismo, estreitando ou alargando, assim, a relação de hipertensão e perda auditiva.

\section{REFERÊNCIAS}

1. FIGUEIREDO RR, et al. Zumbido e hipertensão arterial: uma revisão sistemática. Eur Arch Otorhinolaryngol. 2015; 272: 3089-3094.

2. FIGUEIREDO RR, et al. Positive Association between Tinnitus and Arterial Hypertension. Frontiers in Neurology. 2016; 7:171.

3. MENESES-BARRIVIERA C, et al. Probable Association of Hearing Loss, Hypertension and Diabetes Mellitus in the Elderly. Int. Arch. Otorhinolaryngol. 2018; 22(4): 337-341.

4. PRZEWOŹNY T, et.al.Hipertensão e perda auditiva coclear. Pressão Arterial, 2015; 24: 4, 199-205

5. REED NS, et al. Associação de hipertensão na meia-idade com perda auditiva na terceira idade. Otorrinolaringologia - Cirurgia de Cabeça e Pescoço. 2019; 161(6): 996-1003. 
RESUMO SIMPLES: Revisão Bibliográfica

Título: Otorreia de tubo de timpanostomia: precauções com a água influenciam no tratamento?

Autor/coautores: André Pereira Lopes, Bruna Santiago Teixeira, Lucas Aragão Martins; Bernardo Campos Faria.

Instituição: Centro Universitário Atenas - UNIATENAS, Paracatu - MG.

Palavras-chave: Timpanostomia, Miringotomia, Otorreia de tubo.

\section{INTRODUÇÃO}

Otorreia é a complicação mais frequente na miringotomia para inserção de tubo de ventilação, tratamento de Otite Média Secretora (OMS). Embora seja uma técnica simples da inserção de tubos de timpanostomia, não isenta riscos. Assim, a passagem de água através do tímpano para a orelha média pode causar inflamação aguda da mucosa, o que leva cirurgiões aconselharem a não exposição à água após a inserção de tubos de ventilação. Porém, como tal recomendação afeta diretamente a qualidade e hábitos de vida do paciente, deve-se avaliar seu real benefício. (MACHADO A, et al., 2018; VAN DONGEN T, et al., 2018)

\section{OBJETIVO}

Revisar a literatura científica para elucidar se as precauções com a água influenciam de forma protetora e benéfica no tratamento Otorreia de Tubo de Timpanostomia (OTT) ou se acarreta malefícios.

\section{MÉTODO}

Trata-se de uma revisão integrativa da literatura; executada através de pesquisa nas bases SCIELO, PUBMED e REVISTA PORTUGUESA DE OTORRINOLARINGOLOGIA E CIRURGIA CÉRVICO-FACIAL utilizando os termos: "Timpanostomia", "Miringotomia", "Otorreia de tubo". Critérios de inclusão: artigos disponíveis na íntegra, no idioma português ou inglês, que apresentem coerência com tema, data de publicação entre 2015 e 2020. Foram excluídas publicações indisponíveis, cujos títulos ou objetivos não possuíam ligação direta com a temática.

\section{REVISÃO BIBLIOGRÁFICA}

A miringotomia para inserção de tubo de ventilação é a cirurgia otológica mais comum e otorreia é sua complicação comum e, para evitá-la, a maioria dos cirurgiões recomenda evitar contato com água, pois acredita-se que isso possa afetar negativamente a qualidade de vida pós-operatória. Todavia, ao limitar crianças a banhos, natação, pequenos mergulhos e atividades de lazer, necessitou-se avaliar os reais benefícios dessas precauções. (SUBTIL J, et al., 2018; VAN DONGEN T, et al., 2018).

Assim, estudos revelaram que a própria constituição do tubo diminui o risco de OTT e um ensaio clínico randomizado em crianças designadas para usar tampões de ouvido versus nenhuma precaução relatou um odds ratio (OR) de 0,68 (intervalo de confiança de 95\%, 0,37-1,25) para> 1 episódio de otorreia. Ademais, a Academia Americana de Otorrinolaringologia - Cirurgia de Cabeça e Pescoço não recomenda tais precauções pela falta de evidências relevantes. (SUBTIL J, et al., 2018; STEELE D, et al., 2017).

\section{CONSIDERAÇÕES FINAIS}


A miringotomia se constitui o método mais eficaz para tratamento de OMS e as precauções com água em pacientes com tubo de timpanostomia é ineficaz na prevenção de Otite de Tubo de Timpanostomia, não apresentando benefícios nem malefícios ao tratamento.

\section{REFERÊNCIAS}

1. MACHADO A, et al. Complicações de miringotomias com colocação de tubos de ventilação transtimpânicos em crianças. Revista Portuguesa de Otorrinolaringologia e Cirurgia de Cabeça e Pescoço, 2018; 56(1): 27-30.

2. STEELE D, et al. Prevention and Treatment of Tympanostomy Tube Otorrhea: A Meta-analysis. Pediatrics, 2017; 139(6): e20170667.

3. SUBTIL J, et al. Proteção contra a água após colocação de tubos de ventilação (Shepard) não diminui a incidência de otorreia - estudo retrospectivo de coorte. Braz. j. otorhinolaryngol, 2018; 84(4): 500-505.

4. VAN DONGEN T, et al. Tympanostomy tube otorrhea in children: prevention and treatment. Curr Opin Otolaryngol Head Neck Surg, 2018; 26(6): 437-440. 
RESUMO SIMPLES: Revisão Bibliográfica

Título: Vestibulopatias e suas interferências na qualidade de vida dos idosos

Autor/coautores: Rafaela Amaral Silva, Ana Luisa Ferreira Vilela Marques, Gabriel Araújo Nascimento, Stheffany Oliveira Guimarães Maciel, Bernardo Campos Faria.

Instituição: Centro Universitário Atenas (UNIATENAS) - Paracatu - MG.

Palavras-chave: Vestibulopatias. Idosos. Interferência.

\section{INTRODUÇÃO}

O sistema vestibular é responsável em suprir o sentido do equilíbrio e da posição corporal, enviando informações sobre os movimentos e a posição aos centros integrativos (BARRACHI AC, et al., 2018). Patologias que acometem esse sistema geralmente afetam o labirinto e o nervo vestibular, contribuindo para o desequilíbrio corporal (LIMA BA, et al., 2018). As vestibulopatias são mais comuns em idosos e associamse frequentemente a quadros de tontura e desequilíbrio corporal, sendo essa faixa etária mais propensa a sofrer com o inadequado funcionamento das estruturas sensoriais vestibulares, visuais e somatossensoriais devido ao próprio envelhecimento (GANANÇA MM, 2015).

\section{OBJETIVO}

Analisar as vestibulopatias, levando-se em consideração principalmente a perda de equilíbrio e as consequências disso sobre a qualidade de vida dos idosos, além de abranger sobre sintomas e sobre diferentes formas de tratamentos.

\section{MÉTODO}

Realizou-se uma revisão integrativa da literatura nas bases de dados SciELO e PubMed, considerando os descritores: "sistema vestibular", "patologias do sistema vestibular", "acometimento em idosos" e "principais sintomas e tratamento". Considerou-se critérios de inclusão: publicações em língua portuguesa; dados e questionamentos relacionados ao tema. Já os critérios de exclusão foram: dados incompletos e publicações com mais de cinco anos.

\section{REVISÃO BIBLIOGRÁFICA}

Analisando a literatura, classifica-se as vestibulopatias de duas formas: periféricas, aquelas que acometem os canais semicirculares, utrículo e parte do nervo vestibular, e centrais, aquelas advindas de lesões em estruturas vestibulares presentes no sistema nervoso central (PINTO FM, 2019). Esta é a mais comum em idosos. Acerca das causas frequentes encontram-se: vertigem posicional paroxística benigna, síndrome de Ménière, labirintite, neurite vestibular, nistagmo e alterações cerebrais (BARRACHI AC, et al., 2018). O diagnóstico provém da história clínica, sendo comumente apresentado queixas de tonturas, desequilíbrio e insegurança quanto a postura; dos antecedentes patológicos; do questionamento sobre 0 uso de medicamentos e de um exame físico detalhado (FERREIRA LMBM, et al., 2015). O tratamento engloba a busca pela causa, uso de antivertiginosos, orientação alimentar, mudança de hábitos, auxílio psicológico, procedimentos cirúrgicos e reabilitação vestibular, esta que é muito defendida por reduzir os sintomas do desequilíbrio (MARTINS TF, 2016).

\section{CONSIDERAÇÕES FINAIS}


As vestibulopatias são determinadas como disfunções no equilíbrio corporal, comumente presente nos idosos, interferindo na sociabilidade e na qualidade de vida desses indivíduos. Visando esclarecer aos portadores e afins sobre a questão, seria necessário promover atitudes periódicas com o intuito de orientar sobre os distúrbios do equilíbrio corpóreo, a busca pela segurança, diagnósticos e tratamentos adequados a cada situação.

\section{REFERÊNCIAS}

1. BARRACHI AC, et al. Fisioterapia aquática na reabilitação vestibular: estudo de caso. Revista Brasileira de Otorrinolaringologia. 2018; 01(1): 01-112.

2. FERREIRA LM de BM, et al. Prevalência de vestibulopatia em idosos institucionalizados de Natal - RN Brasil. Revista CEFAC - Saúde e Educação, 2015; 17(5): 1563-1572.

3. GANANÇA MM. Vestibulopatias em idosos. Revista Brasileira de Otorrinolaringologia. 2015; 81(1): 4-5.

4. MARTINS TF. Prevalência e tratamento da tontura: investigação do impacto de condições de saúde e hábitos de vida na redução dos sintomas em pacientes submetidos a um programa reabilitação vestibular na Atenção Primária à Saúde. Repositório Institucional da Universidade Federal de Minas Gerais - UFMG. 2016; 01(1): 01-114.

5. PINTO FM. Tontura, Vertigem, Labirintite e os efeitos na postura. Revista Escola de Postura, 2019; 01(01): 01-05. 
RESUMO SIMPLES: Revisão Bibliográfica

Título: A moderna combinação analgésica para diminuir efeitos perioperatórios

Autor/coautores: Diogo Borges Ferreira, Gabriel Meira Cardoso Pereira, Millena Nogueira Oliveira, Leticia Rodrigues Rezende, Thiago Álvares da Costa.

Instituição: Centro Universitário Atenas (UniAtenas), Paracatu - MG.

Financiamento: Sem financiamentos.

Palavras-chave: Efeitos Perioperatórios, Analgesia Multimodal, Analgesia Preventiva.

\section{INTRODUÇÃO}

Analgesia preventiva objetiva evitar desconfortos álgicos nos períodos pré, pós e intraoperatório, mediante efeito anti-nociceptivo no sistema nervoso periférico. Manejos inadequados da dor perioperatória podem produzir efeitos adversos e desfechos ruins (ANGULO RG, et al., 2019) em pacientes submetidos a diversos tipos de procedimentos cirúrgicos, a exemplo das que envolvem incisão abdominal que podem acarretar prognóstico ruim, inclusive psicológico, se a dor aguda for inadequadamente manejada (MARTíNEZ DAM, 2017). O binômio preventivo e multimodal é promissor para bons prognósticos em pacientes submetidos a cirurgias diversas.

\section{OBJETIVO}

Revisar a importância da analgesia preventiva associada à analgesia multimodal; a favor de uma abordagem antinoceptiva que ameniza a dor de forte intensidade no pós-operatório e até mesmo durante o ato cirúrgico.

\section{MÉTODO}

Trata-se de uma revisão sistemática baseada no método PRISMA. Encontrou-se cerca de 22 pesquisados procurados por descritores: "Analgesia Multimodal" e "Analgesia Preventiva" e operador booleano AND e OR na Medline e Scielo. Os critérios de inclusão foram estudos originais que informassem os benefícios desse binômio e que amenizassem a dor, e excluiu-se estudos imparciais de benefícios isolados de um único método analgésico.

\section{REVISÃO BIBLIOGRÁFICA}

O uso da analgesia multimodal é extremamente vantajosa. Já que oferece uma analgesia eficaz, auxiliando o tratamento pré e pós-operatório. Um exemplo de sucesso é analgesia pré-incisional multimodal com ibuprofeno intravenoso $(800 \mathrm{mg})$, paracetamol $(1 \mathrm{~g})$ e dexametasona $(0,1 \mathrm{mg} / \mathrm{kg})$ e infiltração de portais de inserção com trocarte bupivacaína 0,5\%; medicação analgésica de resgate com metamizol $(2 \mathrm{~g})$ e cloreto mórfico (bolus de $1 \mathrm{mg}$ ). A baixa de complicações perioperatórias oferecidas por esse tipo de manejo proporciona a possibilidade de realizar, inclusive, cirurgias ambulatoriais (HERRERO P, et al., 2020) . E, completando o binômio analgésico, tem-se a analgesia preventiva, que trata de um sistema complementar que agrega positivamente. Essa abordagem antinociceptiva atenua dores antes, durante e depois do ato cirúrgico fornecendo um maior conforto ao paciente e sucesso no tratamento. A taxa de êxito dessa técnica é de 93,5\%, reduzindo a morbidade e o tempo desse paciente internado (CORTÉS JLC e FLORES ECP, 2017).

\section{CONSIDERAÇÕES FINAIS}


Compreende-se, portanto, que a analgesia preventiva associada à multimodal apresentam-se como uma nova alternativa no manuseio da dor pós-operatória, pois consiste em suprimir a condução do impulso doloroso até o encéfalo. Todavia, apesar dessa relevância pós-cirúrgica, há controvérsias sobre sua eficácia. Assim, faz-se necessário novos estudos que alcancem resultados mais satisfatórios para as evidências científicas.

\section{REFERÊNCIAS}

1. ANGULO RG, et al. Implementacion de una estrategia de analgesia multimodal que incluye el bloqueo continuo del nervio femoral en pacientes llevados a remplazo primario total de rodilla. Revista Universitas Medica, 2019; 60(3): 1-7

2. CORTÉS JLC, FLORES ECP. Analgesia preventiva como garante en pacientes sometidos a amigdalectomía: Reporte de 62 casos. Anestesia en México, 2017; 29(1)

3. HERRERO $P$, et al. Eficacia de una estrategia analgésica preincisional con ibuprofeno, paracetamol y dexametasona en colecistectomía laparoscópica. Estudio observacional prospectivo. Revista de la Sociedad Española del Dolor, 2020; 27(2): 104-112.

4. MARTÍNEZ DAM. Bloqueo de fascia de rectos abdominales guiado por ultrasonido. Revisión narrativa.Revista Universitas Medica, 2017; 58(2) 
RESUMO SIMPLES: Revisão Bibliográfica

Título: A eficiente troca de um anestésico de via inalatória para uso tópico no manejo da dor perioperatória

Autor/coautores: Gabriel Meira Cardoso Pereira, Diogo Borges Ferreira, Luisa Canedo Lima, Sabrina Nayara da Silva Nunes e Thiago Álvares da Costa.

Instituição: Centro Universitário Atenas (UniAtenas), Paracatu - MG.

Palavras-chave: Sevoflurano, Anestesia tópica, Úlceras.

\section{INTRODUÇÃO}

A dor na úlcera venosa crônica é intensificada no manejo do desbridamento e seu tratamento era comumente à base de anti-inflamatórios não esteroides e paracetamol, entretanto não há efeito satisfatório. Com isso, uma alternativa utilizada é o sevoflurano, um analgésico tipicamente inalatório que se mostrou promissor na diminuição das escalas de dor de pacientes em desbridamento (MARTíNEZ-MONSALVE A, et al., 2019). Quando administrado no local, sevoflurano revela cicatrização satisfatória e melhora no controle da dor perante a evolução da ferida (IMBERNÓN-MOYA A, et al., 2018).

\section{OBJETIVO}

Revisar os estudos de uma nova forma de administração do Sevoflurano, que ora era usado de maneira inalatória; porém, em casos de feridas cutâneas abertas revelam bom prognóstico como um anestésico tópico para bloqueio da dor.

\section{MÉTODO}

Trata-se de revisão sistemática baseada no método PRISMA. Encontrou-se cerca de 21 pesquisados oriundos da busca dos descritores "Sevoflurane", "Ulcers" e "Topical", pesquisados por operador booleano AND e OR na base de dados Medline. Os critérios de inclusão foram estudos originais que sistematizassem benefícios do Sevoflurano como anestésico tópico para aliviando dores em feridas ulcerantes nos últimos 6 anos. A partir disso, selecionou-se 3 estudos originais e randomizados. Excluiu-se estudos obsoletos e imparcialmente randomizações do Sevoflurano quanto à anestesia local.

\section{REVISÃO BIBLIOGRÁFICA}

Grandes feridas cutâneas comumente desencadeiam intenso sofrimento físico-psíquico, podendo levar o paciente a uma redução drástica na qualidade de vida e desencadear outras doenças se não adequadamente tratada (JOAQUIM FL, et al., 2018). Sevoflurano, anestésico inalatório halogenado, tem uso consolidado em anestesiologia para indução e manutenção de anestesia geral, porém o uso tópico para o tratamento da dor em ulcerações mostra-se seguro, rápido e eficiente. Limpeza e desbridamento de feridas de membros inferiores são extremamente dolorosos mesmo sob efeito de analgésicos como Tramadol ou Morfina, mas é aliviada com o uso de $1 \mathrm{~mL} / \mathrm{cm}^{2}$ de Sevoflurano tópico (IMBERNON-MOYA A, et al. 2017), com efeito analgésico iniciado em cerca de 30 minutos e duração de 9 horas em estudos (MARTíNEZ-MONSALVE A, et al., 2019). Apesar de comprovada, eficácia de Sevoflurano tópico carece de estudos randomizados mais abrangentes para assegurar seus benefícios e possíveis riscos em grandes números de pacientes.

\section{CONSIDERAÇÕES FINAIS}


Este estudo comprova, então, a eficácia do uso analgésico de Sevoflurano tópico. Apesar de ser tipicamente utilizado para induções anestésicas gerais via inalatória, o Sevoflurano minimiza as dores locais das feridas cutâneas abertas. Tais efeitos são incomuns em outros fármacos.

\section{REFERÊNCIAS}

1. IMBERNON-MOYA A, et al. Pain and analgesic drugs in chronic venous ulcers with topical sevoflurane use. Clinical research study leg ulcers, 2018; 68(3): 830-835.

2. IMBERNON-MOYA A, et al. Treatment of chronic venous ulcers with topical sevoflurane: a retrospective clinical study. Correspondence, 2017; 119(4): 846-847.

3. JOAQUIM FL, et al. Impact of venous ulcers on patients' quality of life: an integrative review. Revista brasileira de enfermagem, 2018; 71(4): 2021-2029

4. MARTÍNEZ-MONSALVE A, et al. Analgesic effectiveness of topical sevoflurane to perform sharp debridement of painful wounds. Clinical research study wound care, 2019; 69(5): 1532-1537. 
RESUMO SIMPLES: Revisão Bibliográfica

Título: Violência obstétrica e o plano de parto como prevenção: revisão bibliográfica

Autor/coautores: Thayssa Assis Menezes ${ }^{1}$; Eduardo Henrique Antunes Mann²; Sabrina Alves Maia²; Sarah de Oliveira Rosado3; Anne Gabrielle O Melo4.

Instituição: Instituto Tocantinense Presidente Antônio Carlos (ITPAC) ${ }^{1}$, Palmas - Tocantins; Centro Universitário Atenas (UniAtenas)², Paracatu - Minas Gerais; Universidade Federal do Oeste da Bahia $(\text { UFOB })^{3}$, Barreiras - Bahia; Hospital Municipal Campo Limpo4, São Paulo - São Paulo.

Palavras-chave: Violência obstétrica; Direitos humanos; Maternidade.

\section{INTRODUÇÃO}

Diariamente gestantes são vítimas de violência obstétrica (VO) por profissionais da saúde, sejam ela agressões físicas, psicológicas, verbais, abuso de autoridade e negligência (QUEIROZ F, et al., 2016). Esse número é maior em países em desenvolvimento, onde as maternidades públicas possuem estruturas precárias, superlotação, e falta de profissionais. Aproximadamente $90 \%$ das mortes no parto poderiam ser evitados se o parto vaginal não fosse negligenciado. A VO seja ela na gestação, parto, ou puerpério, ainda é um tema pouco conhecido que tem sido denunciado com frequência nos últimos anos (MACHADO KS, et al., 2020).

\section{OBJETIVO}

Revisar as literaturas que envolvem a VO que diversas gestantes são vítimas e as repercussões causadas por essa modalidade de agressão que envolve as mulheres inseridas no contexto nacional brasileiro.

\section{MÉTODO}

Trata-se de uma revisão integrativa de literatura com busca na base de dados Pubmed, SciELO e ScienceDirect, utilizando os descritores "Violência obstétrica", "Direitos humanos" e "Maternidade". Em dezembro de 2020, foram selecionados 4 artigos científicos. Os critérios de inclusão foram trabalhos publicados em língua portuguesa e os critérios de exclusão foram publicações com mais de 5 anos.

\section{REVISÃO BIBLIOGRÁFICA}

Há várias formas de violência obstétrica que começa desde o abuso da autonomia médica, onde há uma imposição de intervenções sem o consentimento da paciente (PALHARINI LA, 2017). A imposição de cirurgias cesárias sem o esclarecimento para a gestante dos benefícios para ela e para o bebe do parto vaginal, de forma a causar a perda da autonomia e a capacidade de livre decisão também é uma forma comum de violência obstétrica (MACHADO KS, et al., 2020). A cesária deveria ser usada como uma medida de suporte quando colocado em risco a vida da mãe e do bebê, entretanto as mulheres são diariamente impostas a esse procedimento que não traz benefícios, mas uma maior facilidade e rentabilidade para os médicos, sendo recorrente atuações agressivas e desnecessárias durante o parto a fim de acelerar o processo natural do parto por impaciência e intolerância dos profissionais, favorecendo danos para mãe e para o recém-nascido (TESSER CD, et al., 2015).

\section{CONSIDERAÇÕES FINAIS}


A VO é um problema que precisa de maior importância, sendo necessário a criação de políticas que protejam essas mulheres e as conscientizem para que conheçam seus direitos, denunciando quando forem desrespeitadas. Portanto, a prática médica deve ser pautada por princípios éticos que resguardem a autonomia para reduzir o risco de morbimortalidade materna e neonatal.

\section{REFERÊNCIAS}

1. MACHADO KS, et al. Plano de parto: uma estratégia para reduzir atos de violência obstétrica? IJHEInterdisciplinary Journal of Health Education, 2020; 5(2): 1-9.

2. PALHARINI LA. Autonomia para quem? O discurso médico hegemônico sobre a violência obstétrica no Brasil. Cadernos Pagu, 2017; 49(2): 1-32.

3. QUEIROZ F, et al. Violência obstétrica: um problema de saúde pública e uma violação dos direitos humanos. Brazilian Journal of Health Review, 2016; 3(5): 14435-14445.

4. TESSER CD, et al. Violência obstétrica e prevenção quaternária: o que é e o que fazer. Revista Brasileira de Medicina de Família e Comunidade, 2015; 10(35): 1-12. 
RESUMO SIMPLES: Revisão Bibliográfica

Título: Transtornos mentais comuns em estudantes de medicina

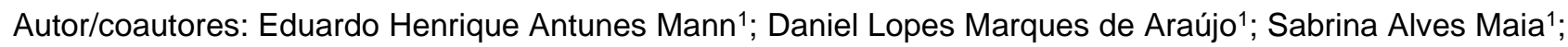
Thayssa Assis Menezes²; Anne Gabrielle O Melo³.

Instituição: Centro Universitário Atenas (UniAtenas) ${ }^{1}$, Paracatu - Minas Gerais; Instituto Tocantinense Presidente Antônio Carlos (ITPAC)로 Palmas - Tocantins; Hospital Municipal Campo Limpo ${ }^{3}$, São Paulo - São Paulo.

Palavras-chave: Ansiedade, Depressão, Estudantes de Medicina.

\section{INTRODUÇÃO}

Desde o início do curso de Medicina, os acadêmicos estão propensos a alterações de diversos fatores psicológicos que podem ser potenciais desencadeadores de transtornos mentais, entre eles os transtornos mentais comuns (TMC). O estresse é evidenciado com muita frequência por parte dos estudantes durante a faculdade, o qual pode levar a manifestações clínicas como insônia e perda de apetite. Além disso, pode gerar alterações comportamentais devido a diminuição da qualidade de vida, como retraimento social, irritação, depressão, ansiedade, impaciência e infelicidade no âmbito pessoal (DOS SANTOS LS, et al., 2017).

\section{OBJETIVO}

Revisar a literatura científica com a finalidade de elucidar os aspectos que configuram os transtornos mentais comuns entre os estudantes de medicina e analisar as suas implicações na saúde dos acadêmicos.

\section{MÉTODO}

Trata-se de uma revisão integrativa de literatura com busca na base de dados SciELO, usando os descritores "Ansiedade", "Depressão" e "Estudantes de Medicina". Em dezembro de 2020, foram selecionados 3 artigos científicos. Os critérios de inclusão foram trabalhos publicados em língua portuguesa e os critérios de exclusão foram publicações com mais de 5 anos.

\section{REVISÂO BIBLIOGRÁFICA}

O curso de Medicina é descrito como fonte de estresse para os estudantes, que relatam perda da liberdade pessoal, excesso de pressões por parte da sociedade e falta de tempo para lazer e exercícios físicos. Esses fatores são potenciais desencadeadores de TMC, como depressão e ansiedade. Ademais, tal problemática pode levar a deterioração da qualidade de vida dos estudantes, resultando em sentimento de desvalia, ideias de abandono do curso e suicídio (DA COSTA DS, et al., 2020). Estudos evidenciaram maior prevalência de TMC no sexo feminino. Entre as possíveis causas são as interações entre influências hormonais, diferenças sexuais ligadas a aspectos neuronais, papéis de gênero prescritos e a importância do apoio social para as mulheres. $O$ fato dos problemas de ansiedade e depressão não serem levados a sério pelas instituições de ensino, assim como a falta de alocação de recursos financeiros para a prevenção e promoção da saúde, contribuem para o alto índice de TMC nos acadêmicos (MAIA HAAS, et al., 2020).

\section{CONSIDERAÇÕES FINAIS}


A deterioração da qualidade de vida dos estudantes de medicina pode levar ao desenvolvimento de TMC. Faz-se necessária adoção de medidas que incrementem tais fatores, como prevenção e promoção da saúde, assim como acompanhamento do desempenho do estudante, fornecimento de psicólogos, criação de grupos de apoio e incentivo a prática de lazer e exercícios físicos.

\section{REFERÊNCIAS}

1. DOS SANTOS LS, et al. Qualidade de vida e transtornos mentais comuns em estudantes de medicina. Cogitare Enfermagem, 2017; 22(4): 2176-9133.

2. MAIA HAAS, et al. Prevalência de Sintomas Depressivos em Estudantes de Medicina com Currículo de Aprendizagem Baseada em Problemas. Rev. bras. educ. med., Brasília, 2020; 44(3): 1-6.

3. DA COSTA DS, et al. Sintomas de Depressão, Ansiedade e Estresse em Estudantes de Medicina e Estratégias Institucionais de Enfrentamento. Revista Brasileira de Educação Médica, 2020; 44(1): 1-8. 
RESUMO SIMPLES: Revisão Bibliográfica

Título: Implicações psiquiátricas no profissional da saúde durante a pandemia da COVID-19

Autor/coautores: Eduardo Henrique Antunes Mann; Francisco Vianna de Freitas Paiva2; Lucas Cassiano Buzetti3; Lucas Nascimento de Morais 4 ; Anne Gabrielle O Melo 5 .

Instituição: Centro Universitário Atenas (UniAtenas)1, Paracatu - MG; Universidade Nove de Julho (UNINOVE)2, São Paulo - São Paulo; Universidade José do Rosário Vellano (UNIFENAS)3 ${ }^{3}$, Alfenas - Minas

Gerais; Universidade Federal de Alfenas (UNIFAL)4, Alfenas - Minas Gerais; Hospital Municipal Campo Limpo5, São Paulo - São Paulo.

Palavras-chave: Pandemia, SARS-CoV-2, Comorbidades.

\section{INTRODUÇÃO}

Diversos países vêm sofrendo com a pandemia provocada pelo SARS-CoV-2 e, nesse contexto, é importante ressaltar o estado de latência a respeito da preocupação com a saúde mental dos profissionais da saúde, uma vez que estes estão mais vulneráveis ao enfrentamento da própria pandemia. Logo, torna-se relevante a categorização das principais manifestações psiquiátricas desencadeadas nos profissionais de saúde que enfrentam o novo coronavírus, visto que é importância de avaliar a saúde mental dos trabalhadores da área da saúde, possibilitando o oferecimento de melhores cuidados de saúde aos seus funcionários (TEMSAH MH, et al., 2020).

\section{OBJETIVO}

Identificar as implicações psiquiátricas causadas durante a pandemia da COVID-19 sobre os profissionais da saúde, comparando aqueles que estão na linha de frente combate com aqueles que trabalham em unidades especializadas, bem como profissionais do sexo masculino e feminino.

\section{MÉTODO}

Trata-se de uma revisão integrativa de literatura com busca na base de dados Pubmed, SciELO, ScienceDirect, usando os descritores "Pandemic", "COVID-19" e "Health workers". Em dezembro de 2020, foram selecionados 3 artigos científicos. Os critérios de inclusão foram trabalhos publicados em língua portuguesa e inglesa e os critérios de exclusão foram publicações com mais de 5 anos.

\section{REVISÃO BIBLIOGRÁFICA}

A maior tendência de profissionais da saúde desenvolverem transtornos psíquicos decorre das maiores jornadas de trabalho, risco de transmissão a amigos e familiares, aumento da mortalidade, possível colapso do sistema de saúde e condições precárias de trabalho (FIORILLO A, et al., 2020). Estudos mostraram que os profissionais da saúde apresentam manifestações em níveis leves, moderados e graves de depressão e ansiedade e síndrome de Burnout (SB); outros apontaram que mulheres sofrem mais do que homens, profissionais de saúde não médicos sofrem mais do que médicos (YUAN WU, et al., 2020). Paralelamente, demonstraram que profissionais da linha de frente apresentam menos SB entre outros traumas psíquicos do que os profissionais em áreas especializadas, revelando a capacidade da atual situação pandêmica em agir 
como um agente indireto no desenvolvimento de desordens na saúde mental de profissionais da saúde envolvidos de alguma forma no combate ao Covid-19 (TEMSAH MH, et al., 2020).

\section{CONSIDERAÇÕES FINAIS}

O contexto pandêmico agravou a propensão dos profissionais de saúde a desenvolverem agravos mentais, como estresse, ansiedade, depressão e SB. Observou-se uma maior incidência de acometimentos nas mulheres, além de averiguou que profissionais da linha de frente são mais resistentes a algumas manifestações psíquicas em relação aos profissionais de áreas especializadas.

\section{REFERÊNCIAS}

1. FIORILLO A, et al. The consequences of the COVID-19 pandemic on mental health and implications for clinical practice. European Psychiatry, 2020; 63(1): 1-2.

2. TEMSAH MH, et al. The psychological impact of COVID-19 pandemic on health care workers in a MERSCoV endemic country. J Infect Public Health, 2020; 13(6): 877-882.

3. YUAN WU, et al. The consequences of the COVID-19 pandemic on mental health and implications for clinical practice. J Pain Symptom Manage, 2020; 60(1): 1-2. 
RESUMO SIMPLES: Revisão Bibliográfica

Título: Dermatite atópica no cenário adolescente: O aspecto biopsicossocial no contexto pandêmico

Autor/coautores: Sabrina Alves Maia'; Eduardo Henrique Antunes Mann"1; Laís Maria Borges Marins²; Thayssa Assis Menezes3; Anne Gabrielle O Melo4.

Instituição: Centro Universitário Atenas (UniAtenas) ${ }^{1}$, Paracatu - Minas Gerais; Centro Universitário do Planalto Central Apparecido dos Santos (Uniceplac)2 , Gama - Distrito Federal; Instituto Tocantinense Presidente Antônio Carlos (ITPAC) ${ }^{3}$, Palmas - Tocantins; Hospital Municipal Campo Limpo 4 , São Paulo - São Paulo.

Palavras-chave: Dermatite atópica, Adolescente, Psicodermatologia.

\section{INTRODUÇÃO}

O aumento da curva de infectados pelo Covid-19 somado ao baixo índice de testagem fez a Organização Mundial da Saúde (OMS 2020) declarar a América Do Sul como o novo epicentro do surto do novo Coronavírus, haja visto que o Brasil é o com o maior número de casos no continente (GARCOVICH S, et al., 2020). Assim, diversas consequências são observadas na atualidade, no que tange a doenças psicológicas como estresse e ansiedade, sobretudo nos adolescentes. Esses aspectos psicológicos provocados pela pandemia, associados à predisposição biológica hormonal durante o período da puberdade têm gerado o surgimento de dermatoses em especial da dermatite atópica (DOS SANTOS-SILVA C, et al., 2017).

\section{OBJETIVO}

Revisar as literaturas com finalidade de estabelecer relação entre aspectos psicológicos, sociais e biológicos em adolescentes, levando em consideração a pandemia, com o aparecimento de dermatoses demonstrada pela dermatite atópica.

\section{MÉTODO}

Trata-se de uma revisão integrativa de literatura com busca na base de dados Pubmed, utilizando os descritores "Booleanos", "Sars-Cov-2" e "Atopic dermatites". Em dezembro de 2020, foram selecionados 3 artigos científicos. Os critérios de inclusão foram trabalhos publicados em língua inglesa e os critérios de exclusão foram publicações com mais de 5 anos.

\section{REVISÂO BIBLIOGRÁFICA}

Evidências levantam a possibilidade de que o estresse psicossocial sustentado e induzido pela atual pandemia possa levar a exacerbações ou aparecimento de condições inflamatórias patológicas na pele, tanto a curto prazo quanto a longo prazo, mesmo após a resolução da pandemia (GARCOVICH S, et al., 2020). O aumento do estresse psicossocial tem um impacto no curso de muitas condições comuns da pele 'responsivas ao estresse' e, no atual contexto pandêmico, pacientes diagnosticados com dermatite atópica foram descritos com humor irritadiço, raiva, comprometimento da autoimagem e da autoestima (STEFANOVIC N, et al., 2020). Veiculado a isso, modificações fisiológicas relacionadas a puberdade favorecem um aumento da produção de adrenalina, noradrenalina entre outras substâncias facilitam o reaparecimento de prurido intenso e lesões típicas de dermatite atópica, contribuindo para que a situação pandêmica seja um agente que propicie o 
desenvolvimento de quadros clínicos dermatológicos característicos durante a adolescência (DOS SANTOSSILVA C, et al., 2017).

\section{CONSIDERAÇÕES FINAIS}

Em síntese, essas informações externam a hipótese de que o contexto atual de pandemia de COVID-19 está associado a mudanças na qualidade de vida dos pacientes com dermatite atópica, resultante da correlação entre os aspectos psicológicos, influenciando de maneira significativa em sua atividade clínica da doença.

\section{REFERÊNCIAS}

1. DOS SANTOS-SILVA C, et al. a Case Report of Patient With Atopic Dermatitis: a Biopsychosocial Approach. Psicologia, Saúde \& Doença, 2017; 18(2): 389-400.

2. GARCOVICH S, et al. Mass quarantine measures in the time of COVID-19 pandemic: psychosocial implications for chronic skin conditions and a call for qualitative studies. Journal of the European Academy of Dermatology and Venereology, 2020; 34(1): 1-2.

3. STEFANOVIC N, et al. The exposome in atopic dermatitis. Allergy: European Journal of Allergy and Clinical Immunology, 2020; 75(1): 63-74. 
RESUMO SIMPLES: Revisão Bibliográfica

Título: Descumprimento do calendário vacinal infantil e a sua relação com a ineficácia no controle da pneumonia

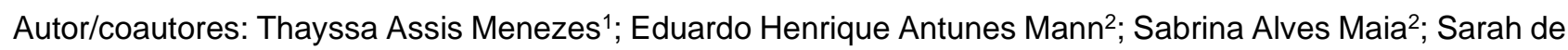
Oliveira Rosado3; Anne Gabrielle O Melo4.

Instituição: Instituto Tocantinense Presidente Antônio Carlos (ITAPAC) ${ }^{1}$, Palmas - Tocantins; Centro Universitário Atenas (UniAtenas)², Paracatu - Minas Gerais; Universidade Federal do Oeste da Bahia $(\mathrm{UFOB})^{3}$, Barreiras - Bahia; Hospital Municipal Campo Limpo4, São Paulo - São Paulo.

Palavras-chave: Vacinação, Doenças infectocontagiosas, Pneumonia adquirida na comunidade.

\section{INTRODUÇÃO}

Dentre as principais doenças com impacto na mortalidade infantil no mundo, destacam-se as infecções respiratórias agudas. A pneumonia continua a ser um problema de saúde pública pela sua alta morbimortalidade, sendo a doença que mais mata crianças entre 0 e 5 anos de idade no mundo (ARROYO LH, et al., 2016). A fim de reduzir a mortalidade causada por doenças infectocontagiosas, a Organização Mundial da Saúde (OMS 2020) promoveu a maior cobertura de vacinal com principal estratégia preventiva. Entretanto, uma preocupante diminuição na cobertura vacinal tem sido observada no Brasil, trazendo um aumento de casos de algumas doenças até então erradicadas (CALDART RV, et al., 2020).

\section{OBJETIVO}

Avaliar a importância da cobertura vacinal na prevenção de doenças infectocontagiosas, demonstrada a partir do aumento dos níveis de patologias previníveis em regiões das quais estão carentes da cobertura vacinal.

\section{MÉTODOS}

Trata-se de uma revisão integrativa de literatura com busca na base de dados Pubmed, SciELO e Uptodate, utilizando os descritores "Pneumonia", "Vacinação" e "Doenças infectocontagiosas". Em dezembro de 2020, foram selecionados 3 artigos científicos. Os critérios de inclusão foram trabalhos publicados em língua portuguesa e os critérios de exclusão foram publicações com mais de 5 anos.

\section{REVISÃO BIBLIOGRÁFICA}

A redução da imunização se mostrou heterogêneo entre os municípios brasileiros e pode ser reconhecido como um fenômeno de desigualdade, favorecendo uma disparidade na redução da mortalidade por pneumonia e outras doenças infectocontagiosas (SILVA ATP, et al., 2018). As diferenças territoriais estão relacionadas à implementação de medidas preventivas de maneira mais eficaz em regiões mais centrais do país. A má distribuição de recursos para saúde, saneamento básico precário e a baixa escolaridade da população aliada à ineficiência de medidas governamentais contribui para essa diferença (ARROYO LH, et al., 2016). As diretrizes do Programa Nacional de Imunização (PNI) apontam que a falta identificação das áreas onde as coberturas vacinais não apresentam abrangência adequada é a parte primordial para o sucesso da campanha vacinal, sendo uma das estratégias de grande eficácia os sistemas informatizados de registro de imunização (CALDART RV, et al., 2020). 


\section{CONSIDERAÇÕES FINAIS}

A imunização é a intervenção mais precoce para o controle de doenças infectocontagiosas, reduzindo a morbimortalidade e incidência de doenças preveníveis no mundo. Identificar heterogeneidades importantes é fundamental para evitar uma baixa cobertura vacinal. É necessário criar estratégias para envolver a população nas ações de imunizações, propiciando a resolução de problemas relacionados à falta de informação sobre a vacinação.

\section{REFERÊNCIAS}

1. ARROYO LH, et al. Áreas com queda da cobertura vacinal para BCG, poliomielite e tríplice viral no Brasil (2006-2016): mapas da heterogeneidade regional. Cadernos de Saúde Pública, 2020; 36: e00015619.

2. CALDART RV, et al. Fatores associados à pneumonia em crianças Yanomami internadas por condições sensíveis à atenção primária na região norte do Brasil. Jornal de pediatria, 2016; 21(5): 1597-1606.

3. SILVA ATP, et al. Cumprimento do esquema vacinal em crianças internadas por pneumonia e fatores associados. Revista de Saúde Pública, 2018; 52: 38. 
RESUMO SIMPLES: Revisão Bibliográfica

Título: Hidradenite supurativa: uma revisão acerca dos principais medicamentos utilizados no tratamento Autor/coautores: Marina Rocha Arêdes ${ }^{1}$, Nicole Assis Valadares Tavares ${ }^{1}$, Larissa Ferreira Sá1, Jassiara Soares da Silva ${ }^{1}$, Anne Gabrielle Oliveira Melo².

Instituição: ${ }^{1}$ Centro Universitário Atenas (UniAtenas), Paracatu-MG; ${ }^{2}$ Hospital Municipal Campo Limpo "Dr. Fernando Mauro Pires da Rocha", São Paulo - SP.

Palavras-chave: Dermatopatias, Dermatologia, Hidradenite Supurativa.

\section{INTRODUÇÃO}

A hidradenite supurativa (HS) é uma doença crônica inflamatória da pele, normalmente localizada nas regiões de axila, mamas e virilha. Acredita-se que decorra de uma inflamação dos folículos pilosos e/ou glândulas sudoríparas, sendo caracterizada pelo surgimento de nodulações dolorosas, que costumam evoluir com fistulização e drenagem de pus (CARDOSO AC e CARNEIRO AC, 2020). A depender do curso da doença pode resultar em cicatrizes que afetam a estética da pele (ORENSTEIN LAV, et al., 2020).

\section{OBJETIVO}

Revisar a literatura a respeito do tratamento para hidradenite supurativa e comparar os principais medicamentos empregados, bem como a eficácia desses fármacos nos diferentes níveis de classificação da doença.

\section{MÉTODO}

Trata-se de uma revisão integrativa da literatura, em que foram selecionados 20 artigos publicados nos últimos 5 anos, obtidos nas bases de dados - Pubmed e Scielo - através dos descritores "hidradenite supurativa" e "tratamento". Foram incluídos os que abordaram o assunto proposto e excluídos os que não continham informações sobre medicamentos.

\section{REVISÃO BIBLIOGRÁFICA}

O tratamento da hidradenite supurativa é baseado na gravidade da doença determinada pelo estadiamento de Hurley, pelo número de abcesso e tipo de fistulização. Não existe consenso sobre o tratamento medicamentoso, mas geralmente inicia-se com antibióticos ou terapias biológicas. Também podem ser utilizados corticoides, terapias hormonais, anticorpos e até mesmo retinoides sistêmicos (isotretinoína - muito prescrita, mas com poucas evidências de eficácia) (KURAYEV A, et al., 2016).

Em relação aos antibióticos, os principais utilizados em combinação são clindamicina e rifampicina sendo primeira linha para HS moderada a grave ou de segunda linha para doença leve. No que se refere ao primeiro, firma-se como o único antibiótico tópico com eficácia comprovada por ensaios clínicos randomizados. Ainda há as tetraciclinas orais, primeira opção na HS multifocal leve a moderada e o ertapenem intravenoso, reservado para casos graves e refratários (ORENSTEIN LAV, et al., 2020).

Dentre as terapias biológicas, destaca-se o adalimumabe, anticorpo monoclonal de necrose tumoral-a, como o primeiro medicamento aprovado especificamente para o tratamento da HS (SAUNTE DML e JEMEC GBE, 2019). 


\section{CONSIDERAÇÕES FINAIS}

A hidradenite supurativa é uma doença que interfere na qualidade de vida física e estética do paciente, e o tratamento deve ser iniciado o quanto antes. Ante a isso, faz-se necessário que haja a compreensão do uso adequado dos medicamentos, bem como a utilização desses fármacos em cada etapa da doença. Além disso, mais estudos são necessários para que haja um consenso para o tratamento da HS.

\section{REFERÊNCIAS}

1. CARDOSO AC, CARNEIRO AC. Hidradenite supurativa: relato de caso. Rev Port Med Geral Fam. 2020; 36(3): 305-310.

2. KURAYEV A, et al. Hidradenitis Suppurativa: Review of the Pathogenesis and Treatment. J Drugs Dermatol, 2016; 15(8): 1017-22.

3. ORENSTEIN LAV, et al. Medical and Surgical Management of Hidradenitis Suppurativa: A Review of International Treatment Guidelines and Implementation in General Dermatology Practice. Dermatology, 2020; 236: 393-412.

4. SAUNTE DML, JEMEC GBE. Hidradenitis Suppurativa: Advances in Diagnosis and Treatment. JAMA, 2017; 318(20): 2019-2032. 
RESUMO SIMPLES: Revisão Bibliográfica

Título: Relação entre psoríase e doenças metabólicas: uma revisão

Autor/coautores: Beatriz Carvalho Rodrigues ${ }^{1}$, Giovana Junior Pires ${ }^{1}$, Maria Eugênia Costa Casagrande ${ }^{1}$, Jassiara Soares da Silva ${ }^{1}$, Anne Gabrielle Oliveira Melo²

Instituição: ${ }^{1}$ Centro Universitário Atenas (UNIATENAS), Paracatu-MG; ${ }^{2 H o s p i t a l ~ M u n i c i p a l ~ C a m p o ~ L i m p o ~ " D r . ~}$ Fernando Mauro Pires da Rocha", São Paulo - SP.

Palavras-chave: Dermatopatias, Psoríase, Síndrome metabólica.

\section{INTRODUÇÃO}

Psoríase é uma patologia de pele crônica não contagiosa, caracterizada por manchas escamosas, secas e avermelhadas. A patogênese ainda não é totalmente esclarecida, mas sabe-se que há uma relação com fatores ambientais, genéticos e imunológicos. Acredita-se que seu desenvolvimento se dá quando linfócitos T liberam na pele substâncias inflamatórias. A obesidade tem sido muito relacionada com o desenvolvimento da psoríase devido ao estado pró-inflamatório crônico (GISONDI P, et al., 2018).

\section{OBJETIVO}

Apresentar, por meio de uma revisão, dados sobre a relação de causa e efeito entre a psoríase e as doenças metabólicas, delineando a fisiopatologia das afecções e a correlação entre ambas.

\section{MÉTODO}

Trata-se de uma revisão de literatura integrativa, confeccionada a partir de três artigos obtidos no PubMed, Scielo e Google Acadêmico, por meio dos descritores "psoríase" e "síndromes metabólicas". Os artigos incluídos foram publicados entre os anos 2017 e 2020, em língua inglesa. Foram excluídos aqueles que não contemplaram a temática e período de busca.

\section{REVISÃO BIBLIOGRÁFICA}

A relação entre obesidade e doenças metabólicas é fortemente discutida no meio científico, evidências apontam que esses distúrbios aumentam significativamente o risco do desenvolvimento de psoríase. Um estudo de coorte realizado em Taiwan mostrou que os participantes obesos apresentaram maior risco de desenvolvê-la (DA YX, et al., 2020).

No entanto, sabe-se também que a psoríase, dependendo do grau de manifestação, libera moléculas inflamatórias na corrente sanguínea (como TNF, interleucinas, entre outras). Ante a isso, há indícios de que essas moléculas - em especial citocinas, interleucinas e hormônios específicos - possam estar associadas com doenças cardiovasculares e síndromes metabólicas. Dessa forma, a psoríase é um fator de risco para o desenvolvimento dessas condições (RODRíGUEZ-CERDEIRA C, et al., 2019).

Além das moléculas inflamatórias, outro fator que deve ser levado em consideração para explicar a relação entre a psoríase e essas patologias é o fato delas possuírem fatores de pré-disposição em comum, como álcool e cigarro. Além disso, compartilham o tratamento à base de agentes imunossupressivos e drogas que alteram o perfil lipídico (VIDEIRA IFS, et al., 2017).

\section{CONSIDERAÇÕES FINAIS}


Nota-se, portanto, que existe uma relação recíproca de predisposição e agravo entre a psoríase e as síndromes metabólicas, em especial a obesidade, devido ao estado inflamatório crônico. Desse modo, é importante a conscientização do paciente sobre essa conexão, a fim de prevenir o desenvolvimento da psoríase em pacientes obesos como também o agravamento, por intermédio da obesidade, em portadores dessa dermatopatia.

\section{REFERÊNCIAS}

1. DA YX, et al. Obesity, but Not Metabolic Diseases, Is Associated with Risk of Psoriasis: A PopulationBased Cohort Study in Taiwan. Dermatology, 2020; 236 (6):521-528.

2. GISONDI P, et al. Psoriasis and the metabolic syndrome. Clin Dermatol, 2018;36(1):21-28.

3. RODRÍGUEZ-CERDEIRA C, et al. Biomarkers of inflammation in obesity-psoriatic patients. Mediators of Inflammation, 2019; 2019:1-12.

4. VIDEIRA IFS, et al. Psoríase e fatores de risco cardiovascular: estudo observacional numa população urbana da Região Norte de Portugal. Revista Portuguesa de Medicina Geral e Familiar, 2017; 33(6): 386392. 
RESUMO SIMPLES: Revisão Bibliográfica

Título: Agulhamento cutâneo e peptídeos antimicrobianos: uma alternativa para o quelóide

Autor/coautores: Hellen Kristina Magalhães Britoํㅜ, Raquel Cambraia Gomes de Melo¹, Silvano Araújo Ferreira Júnior $^{1}$, Jassiara Soares da Silva ${ }^{1}$, Anne Gabrielle Oliveira Melo²

Instituição: ${ }^{1}$ Centro Universitário Atenas (UNIATENAS), Paracatu-MG; ${ }^{2}$ Hospital Municipal Campo Limpo "Dr. Fernando Mauro Pires da Rocha", São Paulo - SP.

Palavras-chave: Dermatopatias, Procedimentos Terapêuticos, Queloide.

\section{INTRODUÇÃO}

Quelóides são lesões cutâneas fibroproliferativas em que há o crescimento dérmico excessivo (MORAVVEJ H, et al., 2020). Devido à complexidade fisiopatológica, a abordagem é um desafio (MARASCA C, et al., 2020). Em vista disso, inúmeros tratamentos são propostos, como: cirurgia, radioterapia, infiltração de corticoide, dentre outros. Porém, ainda não se obteve resultados seguros e efetivos. O que se sabe é que o tratamento quando alinhado a diferentes métodos apresenta melhor resposta terapêutica, como agulhamento associado a peptídeos antimicrobianos (MORAVVEJ H, et al., 2020).

\section{OBJETIVO}

Analisar de que forma a técnica de agulhamento cutâneo associado ao uso de peptídeos antimicrobianos (PAM) podem ser eficazes para o tratamento de quelóides, abordando seus benefícios no processo da cicatrização.

\section{MÉTODO}

Trata-se de uma revisão bibliográfica integrativa, tendo Scielo e PubMed como banco de dados, em que foram empregados os descritores: quelóide, agulhamento cutâneo e peptídeo antimicrobiano. Foram revisados 19 artigos, sendo incluídos seis: datados entre o período de 2015 a 2020, disponíveis na íntegra e em língua portuguesa e inglesa. Foram excluídos artigos duplicados, cartas, resenhas.

\section{REVISÃO BIBLIOGRÁFICA}

O agulhamento cutâneo degrada o colágeno fibrosado, promovendo a revascularização e realinhamento das fibras colágenas. Assim, há a liberação do fator de crescimento de transformação e modulação dos fatores de crescimento inflamatórios (TGF- $\beta 1$ e $\beta 2$ ). Além disso, amplia a disponibilidade de ativos clareadores cutâneos, restaura a ligação queratinócito e melanócito, normaliza a melanogênese e a comunicação celular, restabelecendo os aspectos da pele sem lesão (ALBANO RPS, et al., 2018; SANTOS ANDF, et al., 2016).

Ademais, percebeu-se nos tecidos quelóides há a diminuição expressiva de dois peptídeos: $\beta$-defensinas e catelicidina LL-37. Esses são capazes de limitar o processo inflamatório, ativar o fator de crescimento epidérmico e estimular a proliferação celular. Ainda, permitem a migração de queratinócitos, evidenciando a importância dos PAMs no reparo das lesões (MORAVVEJ H, et al., 2020; LEE HJ e JANG YJ, 2018).

Em um estudo comparativo do tratamento conjugado versus isolado, observou-se a melhora de $68 \%$ do grupo com tratamento conjugado e $52 \%$ com tratamento isolado (agulhamento), comprovando a eficácia da abordagem terapêutica conjunta (SANTOS ANDF, et al., 2016). 


\section{CONSIDERAÇÕES FINAIS}

O tratamento de cicatrizes queloidianas é complexo e de difícil resolução. Assim, a combinação entre alguns métodos é utilizada na prática clínica. Ante a isso, por mais que nenhum método seja totalmente eficaz, o tratamento conjugado de agulhamento cutâneo e peptídeos antimicrobianos tem apresentado os resultados mais satisfatórios e promissores.

\section{REFERÊNCIAS}

1. ALBANO RPS, et al. Microagulhamento - a terapia que induz a produação de colágeno - revisão de literatura. Revista Saúde em Foco, 2018; 10: 455-473.

2. LEE HJ, JANG YJ. Recent understandings of biology, proprylaxis and treatnebt strategies for hypertrophic scars and keloids. Int J Mol Sci. 2018; 19(3): 711-715.

3. MARASCA C, et al. Skin needling in combination with antimicrobial peptides for the treatment of kaloids: a novel perspective proposal and approach for skin scars. Dermatology, 2020; 236: 601-602.

4. MORAVVEJ $\mathrm{H}$, et al. Can antimicrobial peptides be repurposed as a novel therapy for keloids? Dermatology, 2020; 1: 1-3.

5. SANTOS ANDF, et al. Abordagem de cicatrizes por queimaduras com microagulhamento : revisão da literatura. Rev Bras Queimaduras, 2016; 15(2): 116-121. 
RESUMO SIMPLES: Revisão Bibliográfica

Título: Fraturas Vertebrais por Insuficiência em Idosos

Autor/coautores: Kelton de Oliveira Conceição; ${ }^{1}$ Bruno Ribeiro Leite Jardim Cavalcante; ${ }^{1}$ Taínne Gomes Lopes $^{2}$

Instituição: Centro Universitário de Brasília (UniCEUB), Brasília-Distrito Federal; Hospital das Forças Armadas, Brasília-Distrito Federal.

Palavras-chave: Fratura por Insuficiencia; Osteoporose; Idosos.

\section{INTRODUÇÃO}

As fraturas vertebrais têm grande incidência na população idosa. Considerando-se os diversos grupos etários, a prevalência aumenta com a idade. Elas podem estar relacionadas a traumas ou não, hábitos de vida e doenças pré-existentes (CONFORTIN SC, et al, 2020).

Elas têm forte impacto na vida dos idosos devido a alterações como dor crônica, incapacidade física, depressão e deformidades. Além disso, promovem deterioração da qualidade e expectativa de vida, especialmente em mulheres idosas. Essas alterações são decorrentes da baixa densidade mineral óssea (DMO) devido à osteoporose e alterações hormonais decorrentes do processo de envelhecimento (RADOMINSKI SC, et al, 2017).

\section{OBJETIVO}

Compreender o que é uma fratura vertebral por insuficiência, população afetada, a principal causa da maior incidência na população idosa, o quadro clínico característico e a correlação do processo do envelhecimento com as fraturas

\section{MÉTODO}

Revisão bibliográfica integrativa, com busca no banco PubMed Central (PMC), LILACS, Scielo e Google Acadêmico, utilizando os descritores "osteoporosis" AND "fracture" AND "insufficiency fractures". De 13 artigos, foram selecionados 6 , nacionais e internacionais, com o idioma inglês e português, publicados entre 2015 e 2020, com base nos critérios de exclusão e inclusão pré-estabelecidos pelos autores.

\section{REVISÃO BIBLIOGRÁFICA}

A fratura por insuficiência é um tipo de fratura por estresse que acomete principalmente a população idosa - com idade variando de 61 a 92 anos -, predominando no sexo feminino (85\%), estando associada a DMO. (ASTUR DC, et al., 2016)

Elas podem ocorrer em diversas regiões do esqueleto, mas são mais comuns as fraturas vertebrais. Podendo ocorrer com ou sem trauma, essas fraturas podem ser acompanhadas de dores, perda de altura, instabilidade vertebral, deformidade cifótica e deterioração da função pulmonar. (ASTUR DC, et al., 2016) (CONFORTIN SC, et al., 2020)

Essa epidemiologia está relacionada ao processo de envelhecimento, pois existe a tendência de involução do tecido ósseo, processo conhecido como osteopenia, sendo encontrada em $50 \%$ dos adultos mais velhos. À medida que esse processo se intensifica, pode-se levar a uma doença esquelética conhecida como osteoporose. (SILVA MRS, et al., 2015) (CONFORTIN SC, et al., 2020) Ademais, a incidência do sexo 
feminino está relacionada a mudança das taxas hormonais, o qual também favorece a perda óssea. (PRIOR JC, 2018).

\section{CONSIDERAÇÕES FINAIS}

As fraturas vertebrais por insuficiência vêm tendo forte aumento de incidência devido aos hábitos de vida e à crescente manifestação de osteoporose. Assim, vale ressaltar a importância de um diagnóstico e tratamento precoce da doença osteometabólica a fim de evitar fraturas futuras.

\section{REFERÊNCIAS}

1. ASTUR DC, et al. Fraturas por estresse: definição, diagnóstico e tratamento. Revista Brasileira de Ortopedia. 2016; 51(1): 3-10.

2. CONFORTIN SC, et al. Osteopenia / Osteoporose e sua associação com a sarcopenia: EpiFloripa Aging Study 2013/2014.Port J Public Health, 2020; 38(1): 15-22.

3. PRIOR JC, Progesterona para a prevenção e tratamento da osteoporose em mulheres. Climatério, 2018; 21(4): 366-374.

4. RADOMINSKI SC, et al. Diretrizes brasileiras para o diagnóstico e tratamento da osteoporose em mulheres na pós-menopausa. Revista Brasileira de Reumatologia. 2017; 57(S2): S452-S466

5. SILVA MRS, et al. Fisiopatologia da osteoporose: uma revisão bibliográfica. FEMINA, 2015; 43(6): 241244. 
RESUMO SIMPLES: Revisão Bibliográfica

Título: Fatores de Risco Envolvidos no Desenvolvimento da Síndrome do Túnel do Carpo

Autor/coautores: Taínne Gomes Lopes¹, Marcello Oliveira Barbosa, Daniel Studart Corrêa Galvão², Eduardo

Felipe Nácul 2, Pedro Miranda Vieira Bezerra ${ }^{2}$.

Instituição: Hospital das Forças Armadas, Brasília - DF 1, Centro Universitário de Brasília, Brasília-DF².

Palavras-chave: Síndrome do Túnel do Carpo, Fatores de Risco, Neuropatia Compressiva.

\section{INTRODUÇÃO}

A síndrome do túnel do carpo (STC) é a doença compressiva mais comum dos membros superiores. Causada pela compressão do nervo mediano, que controla a sensibilidade da palma e dos dedos da mão, exceto o dedo mínimo, além de controlar os impulsos para o músculo que movimenta o polegar. A STC é um transtorno geralmente debilitante comumente encontrado na atenção primária. (BURTON C, et al., 2018). O diagnóstico é baseado na eletroneuromiografia, história clínica e exclusão de outras causas (NEWINGTON L, et al., 2016). A sintomatologia é manifestada por dor, hipoestesia e parestesia no território de inervação sensitiva do nervo mediano. (WIPPERMAN J e GOERL K., 2016).

\section{OBJETIVO}

O objetivo é realizar uma revisão de literatura das fontes mais relevantes sobre o tema Síndrome do Túnel do Carpo para avaliar os fatores de risco mais relevantes na fisiopatologia de tal acometimento.

\section{REVISÃO BIBLIOGRÁFICA}

A STC é a neuropatia compressiva mais comum e possui uma causa multifatorial. Os fatores de risco estão relacionados ao histórico familiar, histórico pessoal e exposição ocupacional. A prevalência aumenta conforme a idade em ambos os sexos e é maior nas mulheres do que nos homens (3:1). Ademais, o número de casos é maior quando há histórico da doença na família. (WIPPERMAN J e GOERL K., 2016; PADUA L, et al., 2016).

Em relação ao histórico pessoal, fatores de risco amplamente conhecidos são o diabetes mellitus 1 e 2 (1,97 vezes), menopausa, hipotireoidismo, obesidade (1,5 vezes), artrite e gravidez. A gravidez, devido às alterações hormonais, pode predispor ao STC iniciando no primeiro trimestre e podendo persistir até o período pós-parto. (PADUA L, et al., 2016).

Tratando de fatores de risco ocupacionais, atividades envolvendo constantes repetições, vibrações e esforços estão correlacionadas ao desenvolvimento da doença. Metanálises também sugerem que extensão ou contração prolongada do punho correlaciona-se também como risco, somado a segurar constante de objetos, principalmente quando exigindo força. (NEWINGTON L, 2015).

\section{CONSIDERAÇÕES FINAIS}

Há consenso científico de que são diversos os fatores de risco envolvidos na STC, e a compreensão plena destes é essencial para a compreensão da fisiopatologia. Tendo em mente isto, o clínico, munido deste 
conhecimento, estará apto a orientar seus pacientes acerca das atividades cotidianas e laborais envolvidas no quadro, e intervir precocemente, evitando agravamentos e agindo em prol da qualidade de vida.

\section{REFERÊNCIAS}

1. BURTON CL, et al. Trends in the prevalence, incidence and surgical management of carpal tunnel syndrome between 1993 and 2013: an observational analysis of UK primary care records. BMJ Open. 2018; 8(6): e020166.

2. PADUA L, et al. Carpal tunnel syndrome: clinical features, diagnosis, and management. The Lancet Neurology. 2016; 15(12): 1273-1284.

3. MAGALHÃES MJS, et al. Epidemiology and Estimated Cost of Surgeries for Carpal Tunnel Syndrome Conducted by the Unified Health System in Brazil (2008-2016). Arquivos Brasileiros de Neurocirurgia: Brazilian Neurosurgery. 2017; 38(02): 086-093.

4. NEWINGTON L, et al. Carpal tunnel syndrome and work. Best Practice \& Research Clinical Rheumatology. 2015; 29(3): 440-453.

5. WIPPERMAN J, GOERL K. Carpal Tunnel Syndrome: Diagnosis and Management. American Family Physician. 2020; 94(12): 993-999. 
RESUMO SIMPLES: Revisão Bibliográfica

Título: Entorse de tornozelo: mecanismo, diagnóstico e tratamento das lesões ligamentares

Autores/coautores: Taínne Gomes Lopes¹, Ana Luiza Briere², Isabella Nascentes Tanizaki Coelho², Matheus Henrique Corado Mendonça².

Instituição: Hospital das Forças Armadas, Brasília-DF; Centro Universitário de Brasília (UniCeub), Brasília$\mathrm{DF}^{2}$.

Palavras-chave: Entorse, Tornozelo, Ligamentos.

\section{INTRODUÇÃO}

As entorses de tornozelo estão entre as principais ocorrências traumáticas no pronto-socorro e ocorrem pela eversão ou inversão do pé, sendo caracterizadas pelo alongamento ou ruptura dos ligamentos do tornozelo (PEDRO D, et al., 2020). O perfil epidemiológico demonstra maior ocorrência na população ativa, sendo mais frequentes entre atletas. O complexo ligamentar lateral é o mais comumente acometido (MACKENZIE MH, et al., 2019). Tal acometimento ocorre durante movimentos de inversão e flexão plantar, que promovem máximo estresse no ligamento talofibular anterior (LTFA), caracterizando a lesão deste ligamento como a mais frequente nas entorses de tornozelo. (FRANCISCO RLGP, et al., 2016).

\section{OBJETIVO}

Revisar a literatura científica referente aos principais pontos sobre a entorse de tornozelo e lesões ligamentares, abrangendo os mecanismos de entorse, classificação da lesão, sinais e sintomas, diagnóstico e tratamento.

\section{MÉTODO}

Revisão sistemática da literatura, tendo PubMed, SciELO e MedLine como banco de dados, em que foram empregados na busca os descritores: ("Ankle" AND "Sprain"). Foram revisados 13 artigos, sendo apenas cinco incluídos: datados entre o período de publicação 2016 a 2020, disponíveis na íntegra e em língua portuguesa e inglesa.

\section{REVISÃO BIBLIOGRÁFICA}

O mecanismo de inversão afeta os ligamentos laterais, sendo, geralmente, o LTFA o primeiro a ser lesionado devido a sua baixa resistência, porém, energias mais intensas podem levar a rupturas dos demais ligamentos, gerando grande instabilidade da articulação. (FRANCISCO RLGP, et al., 2016)

As entorses do tornozelo são classificadas do grau I ao III, de acordo com o aumento da gravidade da lesão, sendo eles: estiramento ligamentar (I), lesão ligamentar parcial (II) e lesão ligamentar completa (III). (RYAN PM e ROBROY LM, 2016)

Os sinais e sintomas são dor, edema e equimose que podem ser aparentes após a entorse. (HALABCHI F, et al., 2019)

O diagnóstico é feito por meio de um exame físico detalhado aliado à realização de exames de imagem. (PEDRO D, et al., 2020)

O tratamento de entorses varia segundo a gravidade da lesão. Nas lesões leves, opta-se pelo tratamento conservador, consistindo em órtese, terapia manual, exercícios terapêuticos progressivos e crioterapia, a 
intervenção cirúrgica é recomendada para casos que não são resolvidos com o tratamento conservador. (RYAN PM, ROBROY LM, 2016).

\section{CONSIDERAÇÕES FINAIS}

Levando em consideração os aspectos expostos, é possível observar a expressiva incidência das entorses de tornozelo na população ativa, logo, faz-se essencial a revisão dos principais pontos que permeiam tal assunto, dando enfoque no mecanismo, diagnóstico e tratamento das lesões.

\section{REFERÊNCIAS}

1. FRANCISCO RLGP, et al. Entorse lateral do tornozelo: Capacidade diagnóstica do exame objectivo e exames imagiológicos. Rev Port Ortop Traum, 2016; 24(1): 37-50.

2. MACKENZIE MH, et al. Epidemiology of Ankle Sprains and Chronic Ankle Instability. J Athl Train, 2019; 54 (6): 603-610.

3. PEDRO D, et al. Epidemiology of injuries due to ankle sprain diagnosed in na orthopedic emergency room. Einstein (São Paulo), 2020; 18: eAO4739.

4. RYAN PM, ROBROY LM. Managing ankle ligament sprains and tears: current opinion. J Sports Med. 2016; 7: 33-42.

5. HALABCHI FHM. Acute ankle sprain in athletes: Clinical aspects and algorithmic approach. World J Orthop. 2020;11(12):534-558. 
RESUMO SIMPLES: Revisão Bibliográfica

Título: A importância do rastreio precoce da toxoplasmose congênita no teste do pézinho

Autor/coautores: Ana Júlia Rodrigues Ferreira; Blenda Maria Soares de Araujo; Filippe Ferreira Morais; Mateus de Freitas Lage Santos.

Instituição: Centro Universitário Atenas (UniAtenas), Paracatu - MG.

Palavras-chave: Toxoplasmose congênita; Diagnóstico precoce; Gestante.

\section{INTRODUÇÃO}

A toxoplasmose é uma zoonose causada pelo Toxoplasma gondii caracterizada por ser umas das infecções mais frequentes no mundo. A saúde pública brasileira tem demonstrado preocupação a respeito toxoplasmose congênita, visto que é uma infecção diagnosticada tardiamente (CAMPOS FA, et al., 2017).

O teste sorológico negativo no período pré-natal não descarta $100 \%$ a doença ao nascimento. Devido ao risco para o bebê, uma adequada avaliação puerperal era necessária para evitar danos futuros ao recémnascido (DIESEL AA, et al., 2019). Dessa maneira, o Ministério da Saúde (MS) implementou o rastreio obrigatório da toxoplasmose congênita no teste do pezinho, facilitando o diagnóstico precoce, evitando complicações futuras.

\section{OBJETIVO}

Relatar a importância do rastreio precoce da toxoplasmose congênita no teste do pezinho, melhorando o prognóstico da doença e evitando manifestações clínicas tardias desta patologia em crianças e adolescentes.

\section{MÉTODO}

Realizou-se uma revisão integrativa com base nos dados da Revista Brasileira de Ginecologia e Obstetrícia e Revista Médica de Minas Gerais. Empregou-se como critério de inclusão os seguintes itens: artigos que tivessem os descritores "toxoplasmose congênita", diagnóstico precoce " e "gestante" e que fossem focados no rastreio precoce da toxoplasmose. Excluiu-se todos os materiais científicos que não constavam na bibliografia desejada.

\section{REVISÃO BIBLIOGRÁFICA}

O grau de gravidade da toxoplasmose varia muito do período de acometimento na gravidez, sendo mais grave os casos acometidos no primeiro trimestre. $80 \%$ dos neonatos infectados no último trimestre não apresentam manifestações clínicas evidentes no seu nascimento, o que retarda seu diagnóstico (DIESEL AA, et al., 2019).

Visando diminuir essa infecção materno-fetal, a triagem pré-natal por exames laboratoriais é realizada em todo o Brasil. Dessa forma, cerca de 0,3 a 1,96 por 1.000 nascidos vivos possuem o diagnóstico de toxoplasmose congênita (GONÇALVES DD, et al., 2019). Contudo, mesmo com teste sorológico negativo, por volta de 30 a $45 \%$ dessas gestantes com a doença podem ser soronegativas. 
A partir dessa perspectiva, o MS lançou um novo decreto que institucionaliza a participação do rastreio de toxoplasmose por intermédio do teste do pezinho, que visa detectar a sorologia de toxoplasmose congênita logo nos primeiros dias de vida do recém-nascido.

\section{CONSIDERAÇÕES FINAIS}

A toxoplasmose congênita pode acarretar diversos danos e é certo que a implementação do seu rastreio obrigatório no teste do pezinho vai evitar futuras complicações clínicas em crianças que serão diagnosticadas mais precocemente. Portanto, reitera a importância do rastreio e da vigilância serem mais efetivos nesta doença, favorecendo o diagnóstico precoce e proporcionando um prognóstico significativamente melhor.

\section{REFERÊNCIAS}

1. CAMPOS FA, et al. Tratar ou não crianças com toxoplasmose congênita suspeita? Contribuição de um sistema de classificação diagnóstica para decisão. Rev Med Minas Gerais, 2017; 27: 16-S24.

2. DIESEL AA, et al. Follow-up of Toxoplasmosis during Pregnancy: Ten-Year Experience in a University Hospital in Southern Brazil. Revista Brasileira de Ginecologia e Obstetrícia/RBGO Gynecology and Obstetrics, 2019; 41: 539-547.

3. GONCALVES DD, et al. Toxoplasmose congênita: estratégias de controle durante o pré-natal. Cadernos da Medicina-UNIFESO, 2019; 2. 
RESUMO SIMPLES: Revisão Bibliográfica

Título: Efeitos sistêmicos do uso de corticoides tópicos intranasais no tratamento da rinite: uma revisão bibliográfica

Autor/coautores: Stheffany Oliveira Guimarães Maciel, Ana Luisa Ferreira Vilela Marques, Gabriel Araújo

Nascimento, Rafaela Amaral Silva, Bernardo Campos Faria.

Instituição: Centro Universitário Atenas (UNIATENAS) - Paracatu - MG.

Palavras-chave: Rinite, Corticoide, Tópico nasal.

\section{INTRODUÇÃO}

Os corticoides intranasais apresentam a função de reduzir inflamação presente na mucosa nasal. Quando aplicados em doses adequadas, promovem alívio dos sintomas da rinite alérgica, podendo também diminuir eventuais complicações (BRAGA CPB, et al., 2019). O uso de corticoides tópicos inibe a atuação dos eosinófilos, reduzindo sua funcionalidade, além de auxiliar na menor liberação de citocinas quimiotáticas (PALMA-CARLOS AG, 2015). Sua absorção a nível sistêmico ocorre em pequena escala. Não são relatados efeitos colaterais a longo prazo, excetuando efeitos locais. Em crianças não foram relatadas alterações no crescimento ou no eixo hipotálamo-hipófise-adrenal, corroborando a segurança do uso (MION O, et al., 2018).

\section{OBJETIVO}

A finalidade deste estudo é revisar a literatura científica existente a respeito do uso de corticoides tópicos intranasais para o tratamento da rinite e a ocorrência de efeitos colaterais sistêmicos significativos.

\section{MÉTODO}

Para elaboração dessa revisão bibliográfica integrativa foram selecionados três artigos científicos pesquisados nas plataformas Scielo e BVS, usando os descritores "rinite", "corticóide" e "tópico nasal", relacionando corticoides tópicos intranasais, seus efeitos a nível sistêmico e o tratamento efetivo nas doenças inflamatórias da mucosa nasal e dos seios paranasais. Houve como critérios de inclusão estudos realizados nos últimos cinco anos e excluíram-se aqueles que ultrapassaram essa data.

\section{REVISÃO BIBLIOGRÁFICA}

A rinite alérgica é uma queixa frequente nos consultórios otorrinológicos. Portanto, é necessário um tratamento eficaz que ofereça melhor adesão para os pacientes. O uso de corticosteroide intranasal para o tratamento das rinites obteve um consenso quando a sua efetividade, sendo considerado tratamento padrãoouro no seu manejo (MION O, et al., 2018). Os principais efeitos adversos em crianças e adultos são semelhantes: irritação, espirros, mucosa ressecada e epistaxe.

Efeitos como perfuração septal e candidíase nasal são considerados raros. Entretanto, é possível correlacionar o uso de corticoides intranasais com aumento da pressão intraocular (BRAGA CPB, et al., 2019). $\mathrm{O}$ uso em pacientes com glaucoma requer cuidado. Em gestantes, apenas a o corticoesteroide budesonida tem recomendação nível $\mathrm{B}$ e pode ser utilizado na menor dose e pelo menor tempo possível. No geral, excetuando eventuais riscos, são considerados seguros e muito utilizados para o tratamento da rinite, melhorando a qualidade de vida dos pacientes (PALMA-CARLOS AG, 2015).

\section{CONSIDERAÇÕES FINAIS}


Os estudos analisados convergem para a hipótese de que os corticoides nasais são absorvidos sistemicamente em pequena escala, o que justifica a ausência de relatos de efeitos a nível sistêmico. Dada a alta prevalência das queixas relacionadas às rinites crônicas em unidades de atendimento geral e especializado, consideramos fundamental o conhecimento do manejo adequado dos corticoides intranasais tanto por generalistas quanto por especialistas.

\section{REFERÊNCIAS}

1. BRAGA C, et al. Consenso de rinite sob a forma de mapa conceitual. Revista Medicina Minas Gerais, 2019; 29(13): 27-32.

2. MION O, et al. Rinites: atualização. Revista Atualidades Médicas 2018, 2(3): 101-115.

3. PALMA CA. Doenças alérgicos e eosinófilos. Revista Portuguesa de Imunoalergologia, 2015, 23(1): 7-9. 
RESUMO SIMPLES: Revisão Bibliográfica

Título: Síndrome da Apnéia Obstrutiva do Sono (SAOS) em crianças: a importância do diagnóstico precoce perante suas possíveis complicações

Autor/coautores: Raquel de Oliveira Brito ${ }^{1}$; Bruna Martins Ribeiro², Guilherme Mendes Galvão3, Gustavo

Cunha Lima ${ }^{4}$, Bernardo Campos Faria ${ }^{5}$

Instituição: Centro Universitário Atenas (UNIATENAS) $)^{1,2,3,5}$, Paracatu - MG. Universidade Federal de Uberlândia (UFU) ${ }^{4}$, Uberlândia - MG.

Palavras-chave: SAOS; Apnéia do Sono; Distúrbios do Sono.

\section{INTRODUÇÃO}

A Síndrome da Apnéia Obstrutiva do Sono (SAOS) é um distúrbio respiratório do sono (DRS), acomete com frequência a população infantil, embora acredita-se que a maior parte dos casos não esteja diagnosticada. Essa patologia é caracterizada por quadros prolongados de obstrução parcial ou completa das vias aéreas superiores durante o sono. Quando não identificada e tratada corretamente, a SAOS pode ocasionar múltiplas complicações na criança, impactando negativamente na biopsicossocial do indivíduo, diminuindo consideravelmente seu bem-estar geral e elevando o risco de mortalidade relacionado as desordens cardiovasculares e metabólicas (CAMPOS D, et al., 2017).

\section{OBJETIVO}

Revisar estudos para destacar a importância do diagnóstico precoce da SAOS em crianças, a partir da perspectiva que existe um entrave quanto aos métodos de deteç̧ão da doença que persiste na atualidade.

\section{MÉTODO}

Esta revisão bibliográfica integrativa foi realizada mediante pesquisa e análise de literaturas nas bases de dados: SCIELO e GOOGLE ACADÊMICO. Foram utilizados os termos "SAOS" e "crianças". Os critérios de inclusão foram disponibilidade na íntegra, em idiomas portugueses ou inglês. Sobre o tema foram encontrados 30 artigos no total, desses foram selecionados 3 por serem mais direcionados a temática do trabalho. Filtrouse artigos publicados nos últimos 5 anos.

\section{REVISÃO BIBLIOGRÁFICA}

As pesquisas demonstraram que a SAOS é um tema de extrema relevância para a Otorrinolaringologia e Pediatria devido à suas possíveis complicações. Porém permanece um descompasso em relação a sua investigação, gerando subdiagnóstico e subtratamento da doença. Além disso, o ensino dos distúrbios respiratórios do sono na infância durante a graduação em medicina e a residência em pediatria foi insatisfatório em um estudo para 65,5\% e 38,4\% respectivamente (CORRÊA C, et al., 2017)

Assim, a polissonografia (PSG), considerada padrão ouro no diagnóstico, ainda não é conhecida por muitos profissionais, que acabam por diagnosticar a SAOS com base na sua experiência clínica, através da anamnese e exame físico, que possuem baixa especificidade para essa patologia. Apesar disso, a PSG possui alto custo e complexidade, além de estar disponível em poucos locais dificultando a sua utilização (DA SILVA C, et al., 2019).

\section{CONSIDERAÇÕES FINAIS}


A identificação precoce da SAOS na infância é o único modo de conseguir tratamento efetivo para prevenir os DRS no adulto, além de evitar as complicações relacionadas. Portanto, fica evidente a necessidade do ajuste do ensino dos DRS no curso de medicina, e nas residências de pediatria e otorrinolaringologia, visto os impactos negativos que a SAOS pode exercer nos acometidos.

\section{REFERÊNCIAS}

1. CAMPOS D, et al. Síndrome da apneia obstrutiva do sono. Rev Inspirar Mov Saúde, v. 2017; 12(1): 2936.

2. CORRÊA C, et al. Apneia obstrutiva do sono e alterações da linguagem oral. Brazilian Journal of Otorhinolaryngology, 2017; 83(1): 98-104.

3. DA SILVA C, et al. Avaliação das alterações do sono em crianças com síndrome do respirador oral. Revista Eletrônica Acervo Saúde, 2019; (24): e637. 
RESUMO SIMPLES: Revisão Bibliográfica

Título: Zumbido e Saúde Mental: o desenvolvimento de desordens psicoemocionais e fisiológicas

Autor/coautores: Raquel de Oliveira Brito; ; Gustavo Cunha Lima²; Bruna Martins Ribeiro ${ }^{3,}$ Pedro Barbosa

Gomes $^{4}$, Bernardo Campos Faria ${ }^{5}$

Instituição: Centro Universitário Atenas (UNIATENAS)1,3,4,5 Paracatu - MG. Universidade Federal de

Uberlândia (UFU)², Uberlândia - MG.

Palavras-chave: Zumbido; Tinido; Otorrinolaringologia.

\section{INTRODUÇÃO}

O zumbido consiste, sintomatologicamente, na percepção consciente de um estímulo sonoro endógeno sem que haja a sua ocorrência externa. A sensação gerada pelo sintoma geralmente está relacionada aos sons de chiado, chuva, apito ou cachoeira e pode ser distinta de pessoa para pessoa. Esse sintoma relacionase a associações emocionais negativas: indivíduos que o sentem de forma crônica geralmente apresentam dificuldade de concentração, insônia, estresse, irritabilidade, ansiedade e depressão. Essa condição incomoda muito, causa bastante desconforto para as pessoas que apresentam esse quadro e prejudica, entre outros aspectos, a saúde mental do paciente (GIBRIN P, et al., 2019).

\section{OBJETIVO}

Revisar a literatura acerca da relação do zumbido com o desenvolvimento de aspectos psicoemocionais e psiquiátricos alterados; relevância das consequências negativas geradas pelo sintoma e aumento da incidência nos centros de atendimento a nível global.

\section{MÉTODO}

Esta revisão bibliográfica integrativa foi realizada mediante pesquisa e análise de literaturas nas bases de dados: SCIELO e GOOGLE ACADÊMICO. Foram utilizados os termos "zumbido" e "saúde mental". Os critérios de inclusão foram disponibilizados na íntegra, em idiomas português ou inglês. Filtrou-se artigos publicados nos últimos 5 anos. Foram encontrados 100 artigos sobre o tema, desses foram selecionados 3 que direcionavam para a proposta do artigo.

\section{REVISÃO BIBLIOGRÁFICA}

Considerado o terceiro pior sintoma ao ser humano, o zumbido é um dos primeiros sinais de problemas auditivos. Pode ter diversas causas e sua prevalência cresce proporcionalmente ao aumento da idade. No mundo, segundo a Organização Mundial da Saúde (OMS), são 278 milhões de pessoas com o sintoma. 0 zumbido afeta de maneira direta ou indireta o indivíduo em suas atividades de rotina e lazer. Pode interferir em seus relacionamentos sociais e familiares. (BERTUOL B, et al.,2018)

As consequências negativas podem incluir isolamento, quadros de ansiedade ou depressão e, em casos extremos, tentativa de autoextermínio. Especula-se que parte dessas alterações tenham substrato orgânico, resultante da interação entre o sistema límbico e o sistema nervoso autonômico. Ao serem ativados, esses centros neurológicos trariam aumento na percepção das emoções, gerando reações emocionais negativas. Poderiam inclusive interferir na frequência cardíaca e respiratória, elevando o incômodo com o zumbido. (ROCHA G, et al.,2017)

\section{CONSIDERAÇÕES FINAIS}


As possíveis consequências trazidas pelo zumbido, principalmente as psicológicas, tornam importante melhor conhecimento do problema por parte dos profissionais que lidarão com a queixa. Além disso, é importante o desenvolvimento de meios para reduzir o incômodo causado pelo sintoma, elevando o nível de qualidade de vida dos sujeitos.

\section{REFERÊNCIAS}

1. BERTUOL B, et al. Zumbido, qualidade de vida e questões emocionais de sujeitos usuários de próteses auditivas. Distúrbios da Comunicação, 2018; 30(1): 80-89.

2. GIBRIN P, et al. O zumbido e sua relação com ansiedade e depressão em idosos: uma revisão sistemática. Revista CEFAC, 2019, 21(4): e7918.

3. ROCHA G, et al. Qualidade de vida em indivíduos portadores de zumbido com e sem perda auditiva. Revista CEFAC, 2017, 19(6): 764-772. 
RESUMO SIMPLES: Revisão Bibliográfica

Título: Síndrome de Ortner: Um desafio diagnóstico

Autor/coautores: Leticya Alves Guimarães, Rayssa Mendes de Melo, Bárbara Lopes Magalhães, Bernardo

Campos Faria.

Instituição: Centro Universtirário Atenas, Paracatu - MG.

Palavras-chave: Ortner, Cardiovocal, Laríngeo.

\section{INTRODUÇÃO}

A síndrome de Ortner ou síndrome cardiovocal, está relacionada a uma dilatação do átrio esquerdo que causa a compressão do nervo laríngeo recorrente (NLR) esquerdo contra a artéria aorta, tendo como complicação a paralisia deste nervo e um quandro clínico comum de rouquidão (CHAVES KN, et al., 2018). No entanto, existe diversas evidências mostrando a semelhança dessa síndrome com outras patologias cardiovasculares benignas, o que mostra a necessidade de realizar maiores estudos afim de definir um diagnóstico preciso e uma conduta terapêutica adequada ao paciente (DUTRA BL, et al., 2015).

\section{OBJETIVO}

Abordar por meio de uma revisão de literatura os principais diagnósticos diferenciais da síndrome de Ortner em pacientes que apresentam um acometimento do nervo laríngeo recorrente que cursam com quadros clínicos de rouquidão, em especial, aqueles que são cardiopatas.

\section{MÉTODOS}

Trata-se de uma revisão bibliográfica integrativa, com referências inglesa e portuguesa publicadas entre 2015 e 2020. Utilizou-se descritores "rouquidão", "síndrome de ortner" e "nervo laríngeo" para a pesquisa nas plataformas Scielo e PubMed. Considerou-se critérios de inclusão: publicações coerentes com o objetivo do estudo no período indicado. E de exclusão: dados incompletos e/ou desatualizados.

\section{REVISÃO BIBIBLIOGRÁFICA}

A síndrome de Ortner foi descrita em 1897, após pacientes apresentarem estenose mitral e rouquidão devido uma paralisia do nervo laríngeo recorrente (NLR) esquerdo. Foram feitos, então, estudos que evidenciaram a relação do comprometimento do NLR com outras doenças cardiovasculares, como insuficiência ventricular esquerda, defeito do septo atrial e aneurismas da aorta (LAMAS ES, et al.,2020). Assim, para que a causa seja identificada com precisão, torna-se necessário uma ampla análise médica, com exames endoscópicos da laringe e tomografia computadorizada do crânio, pescoço e tórax (DUTRA BL, et al., 2015).

O recurso terapêutico será indicado de acordo com a causa da paralisia do NLR. Além da rouquidão, outros sintomas, como tosse, disfagia e disfonia podem sugerir paralisia de prega vocal secundária a lesão do NLR. Contudo, deve-se realizar um tratamento em conjunto da doença subjacente e do fator causal, para que haja uma recuperação do nervo (CHAVES KN, et al., 2018).

\section{CONSIDERAÇÕES FINAIS}


A síndrome de Ortner é uma condição rara que pode estar relacionada a patologias cardiovasculares. Portanto, faz-se necessário uma maior abordagem clínica aos pacientes com essa sintomatologia para investigação de um possível caso de síndrome de Ortner permitindo um diagnóstico diferencial precoce de paralisia da prega vocal e a prematura definição das condutas, evitando assim, maiores agravos ao paciente.

\section{REFERÊNCIAS}

1. CHAVES KN, et al. Síndrome de Ortner ou Síndrome Cardiovocal: uma Rara Causa de Rouquidão em Paciente com Estenose Mitral. Revista Norte Nordeste de Cardiologia, 2018; 8(4): 2-4.

2. DUTRA BL, et al. Síndrome de Ortner: relato de caso e revisão da literatura. RadiolBras,2015; 48(4): 260262.

3. LAMAS ES, et al. Arterite de Células Gigantes com Envolvimento Aórtico Cursando com Síndrome Cardiovocal (Síndrome de Ortner). Arquivos Brasileiros de Cardiologia, 2020; 114(41): 16-18. 
RESUMO SIMPLES: Revisão Bibliográfica

Título: Efeitos a longo prazo do uso profilático de azitromicina contra a Covid-19

Autor/coautores: Filippe Ferreira Morais, Gabriel Araújo Nascimento¹, Anne Gabrielle O Melo².

Instituição: Centro Universitário Atenas (UNIATENAS), Paracatu-MG'; ;ospital Municipal Campo Limpo².

Financiamento: Não houve.

Palavras-chave: Resistência microbiana; Covid-19; Azitromicina.

\section{INTRODUÇÃO}

É indiscutível que a antibioticoterapia trouxe diversas facilidades e vantagens para o tratamento de doenças no que diz respeito à medicina moderna (PIMENTEL RMM, et al., 2020). Levando isso em consideração, muito se discute sobre qual seria a terapia medicamentosa mais adequada para o combate da SARS-Cov-2 (FARIÑA N, 2016). Entretanto, ainda não há um consenso entre pesquisadores e cientistas a respeito de qual é o melhor tratamento para a doença e quais são os efeitos a longo prazo do uso profilático em massa de antibióticos, como por exemplo o fármaco azitromicina

\section{OBJETIVO}

Descrever e fazer uma análise das possíveis repercussões da antibioticoterapia a base azitromicina à população, levando-se em consideração a seleção de bactérias resistentes e os mecanismos utilizados por elas para exercer tal ação.

\section{MÉTODO}

Trata-se de uma revisão integrativa de literatura na qual utilizou-se de dados da SciELO e PubMed, usando os seguintes descritores: "Resistência microbiana", "Covid-19" e "Azitromicina". Foram selecionados 3 artigos científicos mediante o estabelecimento dos seguintes critérios de inclusão: trabalhos publicados em língua portuguesa e espanhola, e os critérios de exclusão foram aqueles materiais com mais de 5 anos.

\section{REVISÃo BIBLIOGRÁFICA}

Estudos apontam que a rapidez com que surgem os microorganismos multirresistentes já iguala a velocidade com que surgem os novos medicamentos, o que confere aos profissionais de saúde uma maior dificuldade para que se tratem casos de sepse grave. Além disso, o uso inadequado de antibióticos acelera a capacidade microbiana de resistência, o que torna esse fenômeno cada vez mais observado e fazendo com que esses medicamentos venham a perder sua eficácia a longo prazo. Diminuição da permeabilidade das células microbianas aos medicamentos, alterações nos sítios receptores da porção $50 S$ do ribossomo e inativação enzimática, são adaptações desenvolvidas pelas bactérias resistentes a esses fármacos (FRANCO JMPL, et al., 2015). Visto que a azitromicina possui ações justamente relacionadas a esses mecanismos, o seu emprego profilático e terapêutico contra a covid-19 repercute diretamente na adaptação bacteriana, sendo importante a análise de como o combate ao coronavírus repercute na formação de cepas resistentes aos antibióticos (FARIÑA N, 2016).

\section{CONSIDERAÇÕES FINAIS}


Apesar de o uso de azitromicina ser protocolo de atuação médica no combate ao coronavírus, conclui-se que é importante tanto uma atenção especial por profissionais como pela própria população quanto ao uso profilático desta medicação. Por fim, é válido ressaltar que os efeitos dessa prevenção podem favorecer uma disfuncionalidade da azitromicina dentre outros efeitos adversos em longo prazo.

\section{REFERÊNCIAS}

1. FARIÑA N. Resistencia bacteriana: un problema de salud pública mundial de difícil solución. Memorias del Instituto de Investigaciones en Ciencias de la Salud, 2016; 14: 04-05.

2. FRANCO JMPL, et al. O papel do farmacêutico frente à resistência bacteriana ocasionada pelo uso irracional de antimicrobianos. Semana Acadêmica, 2015; 1:1-17.

3. PIMENTEL RMM, et al. A disseminação da covid-19: um papel expectante e preventivo na saúde global. J Hum Growth, 2020; 30: 135-140. 
RESUMO SIMPLES: Revisão Bibliográfica

Título: Sintomas otoneurológicos associados a clínica da Covid-19

Autor/coautor: Rodrigo Pereira Tiago; Bernardo Campos Faria.

Instituição: Centro Universitário Atenas (UNIATENAS), Paracatu - MG.

Palavras-chave: COVID-19, Vertigem, Zumbido.

\section{INTRODUÇÃO}

A Sindrome Respiratória Aguda Grave do Coronavírus (SARS-CoV-2) é uma doença causada pelo novo coronavírus (COVID-19), que tem se mostrado um desafio inédito para a área da saúde. As principais manifestações da doença ocorrem no Sistema Respiratório, contudo, evidências mostram achados otoneurológicos, como zumbido e vertigem. (PASQUALE V, et al., 2020). Ademais, ressalta que os sintomas respiratórios da doença podem não ser os primeiros a aparecer, os sintomas otoneurológicos, frequentemente surgem antes e são de grande importância para os profissionais da linha de frente, que devem conhecer tal sitomatologia (JACKY S, 2020).

\section{OBJETIVO}

Esta revisão bibliográfica visa reunir os achados recentes que associam sintomas otoneurológicos, como zumbido, distúrbios do equilíbrio e vertigem, com a SARS-CoV-2, e evidenciar a necessidade de mais estudos centrados nessas manifestações clínicas.

\section{MÉTODO}

Para esta revisão bibliográfica integrativa pesquisou-se os termos "Dizziness", "COVID-19" e "otoneurological symptoms" na base de pesquisa PubMed. Primeiramente 10 artigos foram selecionaos, desses 3 foram usados como base. Os critérios de inclusão foram: artigos com disponibilidade na íntegra, em idioma inglês e que apresentem coerência com a temática proposta, os de exclusão foram: falta de dos suficientes e fuga temática. Foram selecionados artigos publicados em 2020.

\section{REVISÃO BIBLIOGRÁFICA}

Nas várias regiões afetadas pelo COVID-19, observou-se manifestações otoneurológicas, como vertigem, hipoacusia e zumbido nos pacientes infectados pelo vírus, apesar da vertigem ser um sintoma inespecífico, deve-se investigar sua causa central, dentre elas otite média aguda e labirintite aguda. Além disso, a tontura é um dos achados mais prevalentes, sendo proposto que sua ocorrência se deva a potencialidade neuroinvasiva da SARS-CoV-2 (JEYASAKTHY S e JEYANTHI K, 2020).

Além da vertigem, $18 \%$ dos pacientes pesquisados apresentaram distúrbios de equilíbrio e $39,5 \%$ manifestaram zumbido recorrente. Tais alterações decorrem de dano vascular, já que devido a alta demanda energética de estruturas da orelha interna, que são sensíveis a isquemia, que pode ocorrer devido á hipercoagulabilidade sanguinea desses pacientes (PASQUALE V, et al., 2020).

Embora a tontura seja a manifestação otoneurológica mais frequente, a prevalência desses sintomas nos pacientes com COVID é reduzida. Especulam se esse fato é uma indicação de atipicidade sintomática ou se as pesquisas estavam mais centradas em sintomas mais graves (PASQUALE V, et al., 2020).

\section{CONSIDERAÇÕES FINAIS}


A literatura envolvendo a SARS-CoV-2 está se expandido bastante, apesar disso, estudos que relacionam a doença causada pelo COVID-19 com sintomas otoneurológicos ainda são limitados. Faz-se necessário de um maior número de pesquisas amplas, que procurem entender os meandros dessa sintomatologia atípica da doença.

\section{REFERÊNCIAS}

1. JACKY S. Dizziness can be an early sole clinical manifestation for COVID-19 infection: A case report. J Am Coll Emerg Physicians Open, 2020; 1(6): 1354-1356.

2. JEYASAKTHY S, JEYANTHI K. Dizziness and COVID-19. Ear Nose Throat J, 2020; 100: 29-30.

3. PASQUALE V, et al. Tinnitus and equilibrium disorders in COVID-19 patients: preliminary results. Eur Arch Otorhinolaryngol, 2020; 1-6. 
RESUMO SIMPLES: Revisão Bibliográfica

Título: Aumento de preenchimentos faciais com Ácido Hialurônico: a importância do conhecimento do protocolo de prevenção e identificação de possíveis complicações

Autor/coautores: Raquel de Oliveira Brito ${ }^{1}$; Gustavo Cunha Lima²; Kamila Simiema de Oliveira ${ }^{3}$, Frederico Silva Modes ${ }^{4}$, Talitha Araújo Faria ${ }^{5}$.

Instituição: Centro Universitário Atenas (UNIATENAS) ${ }^{1,3,4,5}$, Paracatu - MG; Universidade Federal de Uberlândia (UFU)², Uberlândia-MG.

Palavras-chave: Ácido Hialurônico; Preenchedores dérmicos; Harmonização facial.

\section{INTRODUÇÃO}

O uso de ácido hialurônico $(\mathrm{AH})$ injetável tem sido muito utilizado no tratamento de rugas, sulcos, e volumização facial tornando-se um procedimento consagrado. $\mathrm{O}$ aumento do uso de HA pode ser explicado devido à sua biocompatibilidade e boa margem de segurança em relação a efeitos adversos. Além disso, no Brasil, houve um aumento no número de profissionais com permissão para executar esses procedimentos, contribuindo para elevar a quantidade de procedimentos que utilizam HA. Apesar do uso de preenchedores cutâneos serem considerados seguros, eventos adversos podem ocorrer. (BRASIL P, et al., 2016)

\section{OBJETIVO}

Revisar a literatura afim de ressaltar a importância da preparação do profissional executor do procedimento com HA em saber prevenir e, reconhecer e tratar em tempo hábil possíveis complicações advindas do seu uso.

\section{MÉTODO}

Esta revisão bibliográfica integrativa foi realizada mediante pesquisa e análise de literaturas nas bases de dados: SCIELO e GOOGLE ACADÊMICO. Foram utilizados os termos: "Ácido Hialurônico" "Complicações com preenchedores cutâneos". Os critérios de inclusão foram disponibilizados na íntegra, em idiomas português ou inglês. Filtrou-se artigos publicados nos últimos 5 anos. Foram encontrados 138 artigos sobre 0 tema, desses foram selecionados 3 que direcionavam para a proposta do artigo.

\section{REVISÃO BIBLIOGRÁFICA}

Com o aumento do uso de HA em procedimentos espera-se por consequência que a prevalência de todas as complicações relacionadas ao seu uso também aumente. Aquelas que são classificadas como precoce aparecem em um período de horas a dias, sendo as mais comuns entre elas o edema, dor, hiperemia e equimose. Essas reações geralmente são autolimitadas e não exigem grandes intervenções. Entretanto, uma complicação precoce infrequente, porém temida, são as vasculares uma vez que estas podem resultar em perda de visão e necrose tecidual. Portanto requerem maior atenção e acompanhamento. (DE CASTRO M, et al., 2020)

Esses efeitos adversos na atualidade são relacionados principalmente à técnica de aplicação e inadequada higienização da pele. Para evitar intercorrências, também é fundamental que haja uma avaliação cuidadosa do paciente, investigando o histórico de distúrbios hemorrágicos, doenças autoimunes, gravidez, herpes, alergias, tendência à formação de queloides, procedimentos prévios, e uso de medicamentos, tais como anticoagulantes. (BERNARDES L, et al., 2018)

\section{CONSIDERAÇÕES FINAIS}


Apesar de pouco comuns, as complicações relacionadas ao uso de ácido hialurônico podem ser graves e irreversíveis. Assim há a necessidade de o profissional executor aperfeiçoar a técnica de infiltração e estar preparado para reconhecer de forma precoce alguma complicação evitando sequelas a longo prazo.

\section{REFERÊNCIAS}

1. BERNARDES I, et al. Prenchimento com Ácido Hialurônico-Revisão de Literatura. Revista saúde em foco, 2018; (10): 603-612.

2. BRASIL $P$, et al. Manejo de complicações de preenchedores dérmicos.Surgical \& Cosmetic Dermatology, 2016; 08(4): 342-351.

3. DE CASTRO M, et al. Efeitos adversos no uso do ácido hialurônico injetável em preenchimentos faciais. Brazilian Journal of Health Review, 2020, 3(2): 2995-3005. 
RESUMO SIMPLES: Revisão Bibliográfica

Título: O uso do ácido tranexâmico na abordagem inicial ao trauma

Autor/coautores: Larissa Ferreira Sá ${ }^{1}$; Natalia Maria de Lima Peres ${ }^{1}$; lara Santos Rodrigues'; Sabrina Alves

Maia'; Anne Gabriele O Melo².

Instituição: Centro Universitário Atenas (UniAtenas), Paracatu, MG'; Hospital Municipal Campo Limpo "Dr.

Fernando Mauro Pires da Rocha².

Palavras-chave: Ácido tranexâmico, Sangramento, Trauma.

\section{INTRODUÇÃO}

A lesão traumática é responsável por $10 \%$ das mortes no mundo, sendo parte causadas por sangramento e posterior coagulopatia, sendo as causas evitáveis mais comuns em pacientes traumatizados, especialmente nas primeiras 24 horas (CABALLERO J e MIRANDA JJ, 2017). O TXA (Ácido tranexâmico) é um antifibrinolítico, sintético do aminoácido lisina, apresenta baixo custo comercial e tem seu uso associado às operações eletivas, metrorragia e prevenção de sangramento em extrações dentárias. O mecanismo de ação ocorre pela adesão do TXA aos sítios de ligação da lisina, na molécula de plasminogênio, dessa forma, evita a formação de plasmina, principal agente responsável pela fibrinólise (PINTO MA, et al., 2016).

\section{OBJETIVO}

Revisar o conhecimento acumulado em estudos realizados com o uso de ácido tranexâmico em pacientes traumatizados, a fim de reduzir a mortalidade geral ligada a quadros de hemorragia e responder às questões mais importantes à prática clínica que ainda desencadeiam discussão.

\section{MÉTODO}

Feito uma revisão sistemática a partir de artigos científicos indexados na base de dado Scielo, priorizando os estudos mais recentes (2015 a 2020), sobre o uso do ácido tranexâmico no trauma. O estudo CRAHS-2, foi um ensaio clínico randomizado. Já o estudo CRASH-3, foi um estudo internacional, multicêntrico, radomizado e controlado por placebo dos efeitos do ácido tranexâmico na morte e incapacidade em pacientes TCE.

\section{REVISÃO BIBLIOGRÁFICA}

Foi realizado um ensaio clínico randomizado, do tipo duplo-cego, com mais de 20.000 pacientes, e demonstrou o benefício do uso de ácido tranexâmico para reduzir a mortalidade total relacionado à hemorragia em pacientes vítimas de trauma. O estudo revelou que a administração precoce de ácido tranexâmico reduz a mortalidade de pacientes com hemorragia traumática em $32 \%$ se administrado dentro da primeira hora e $21 \%$ nas primeiras 3 horas (PINTO MA, et al., 2016).

Já o CRASH-3, realizado posteriormente (2012 a 2019), estudou a utilização do ácido tranexâmico em pacientes com trauma cranioencefálico (TCE), mostrou que o risco de morte relacionada à lesão na cabeça reduziu com TXA em pacientes com traumatismo craniano leve a moderado quando administrado nas três primeiras horas. Com isso, a indicação do TXA se apresenta como opção para as vítimas de trauma com quadro clínico de sangramento ou em risco de sangramento, bem como casos de TCE e coagulopatias (CRASH T, 2019).

\section{CONSIDERAÇÕES FINAIS}


A análise concluiu que o TXA é seguro no controle de sangramento na abordagem inicial ao trauma; e que o tratamento em até $3 \mathrm{~h}$ após a lesão reduz a morte relacionada ao TCE. Os pacientes devem ser tratados o mais rápido após a lesão.

\section{REFERÊNCIAS}

1. CABALLERO J, MIRANDA JJ. Tranexámico: evidencia científica y su traducción en la práctica clínica. Revista chilena de cirugía, 2017; 69(1): 99-100.

2. CRASH T. Effects of tranexamic acid on death, disability, vascular occlusive events and other morbidities in patients with acute traumatic brain injury (CRASH-3): a randomised, placebo-controlled trial. The Lancet, 2019; 394(10210): 1713-1723.

3. PINTO MA, et al. Uso de ácido tranexâmico no trauma: uma análise e custo-efetividade para o uso no Brasil. ABCD Arq Bras Cir Dig, 2016; 29(4): 282-286. 
RESUMO SIMPLES: Revisão Bibliográfica

Título: Lúpus Eritematoso Sistêmico (LES): a importância da detecção precoce das possíveis complicações cardiovasculares desencadeadas pela síndrome

Autor/coautores: Raquel de Oliveira Brito, Bianca Franco Correa Barbosa, Victor de Souza Nascimento, Talitha Araújo Faria.

Instituição: Centro Universitário Atenas (UNIATENAS), Paracatu - MG.

Palavras-chave: Doença cardiovascular; Lúpus eritematoso sistêmico; Técnicas de diagnóstico cardiovascular.

\section{INTRODUÇÃO}

Lúpus eritematoso sistêmico (LES) é uma condição autoimune crônico-degenerativa, de processo fisiopatológico complexo, que envolve fatores genéticos, ambientais e provavelmente infecciosos. Possui maior ocorrência no gênero feminino, podendo afetar pessoas de qualquer idade.Os principais componentes do sistema imune inato e adaptativo, celular e humoral têm influência sobre a doença, e pode acometer de forma variada diversos órgãos como rins, pulmão e coração, além de tecidos. Com o progresso da doença, o acometimento miocárdico se inicia, e a identificação precoce permitirá abordar a doença miocárdica melhorando o desfecho por morbimortalidade cardiovascular (MOCARZEL L, et al.,2015).

\section{OBJETIVO}

Revisar a literatura para ressaltar a importância do diagnóstico precoce do acometimento cardiovascular desencadeado pela LES afim de reduzir a morbimortalidade e aumentar a qualidade de vida dos pacientes.

\section{MÉTODO}

Esta revisão bibliográfica integrativa foi realizada mediante pesquisa e análise de literaturas nas bases de dados: PUBMED e GOOGLE ACADÊMICO. Foram utilizados os descritores "Lúpus Eritematoso" e "Complicações cardiovasculares". Os critérios de inclusão foram disponibilizados na íntegra, em idiomas português ou inglês. Filtrou-se artigos publicados nos últimos 5 anos. Foram encontrados 100 artigos sobre 0 tema, desses foram selecionados 3 que havia coerência com proposta do artigo.

\section{REVISÃO BIBLIOGRÁFICA}

O acometimento cardíaco no LES pode ocorrer isoladamente em qualquer fase de evolução da doença, como um dano isolado ou de forma concomitante a outras manifestações clínicas, sendo a principal a nefropatia. A doença cardiovascular representa a maior causa de morbimortalidade nos pacientes portadores da LES. Acredita-se que pelo menos metade dos pacientes com LES possuam anormalidades cardíacas, e desses a maioria são oligossintomáticas mas detectáveis quando investigadas a partir de métodos de diagnóstico diferencial. (COSTI L, et al., 2017)

O índice SLICC (Systemic Lupus International Collaborating Clinics,2012) é utilizado para o acompanhamento ambulatorial dos pacientes com LES a fim de contabilizar o dano cumulativo ocasionado pela doença. Por essa classificação, o comprometimento cardiovascular é determinado pela presença de $s$ sinais e sintomas como a hipertensão pulmonar, histórico de angina,e infarto prévio. Apesar dessa importância, não há critérios cardiológicos estabelecidos dentro da classificação dos critérios SLICC, enfatizando assim a necessidade de percepção clínica pelo médico para detectar em tempo hábil as complicações cardiovasculares (SOUSA G, et al., 2018). 


\section{CONSIDERAÇÕES FINAIS}

A suspeição clínica precoce do acometimento cardiovascular no LES é de extrema importância. A abordagem apropriada e a solicitação de exames complementares para desenvolver um diagnóstico diferencial podem reduzir a morbimortalidade e contribuir para a qualidade de vida desses pacientes.

\section{REFERÊNCIAS}

1. COSTI L, et al. Mortalidade por lúpus eritematoso sistêmico no Brasil: avaliação das causas de acordo com o banco de dados de saúde do governo. Revista brasileira de reumatologia, 2017; 57(6): 574-582.

2. MOCARZEL L, et al. Lúpus eritematoso sistêmico: revisão das manifestações cardiovasculares. Int $\mathrm{J}$ Cardiovasc Sci, 2015; 28(3): 251-261.

3. SOUSA G, et al. Complicações do Lúpus Eritematoso Sistêmico e o comprometimento da qualidade de vida. Revista de Enfermagem da FACIPLAC, 2018; 2(2): 01-09. 


\section{AGRADECIMENTOS}

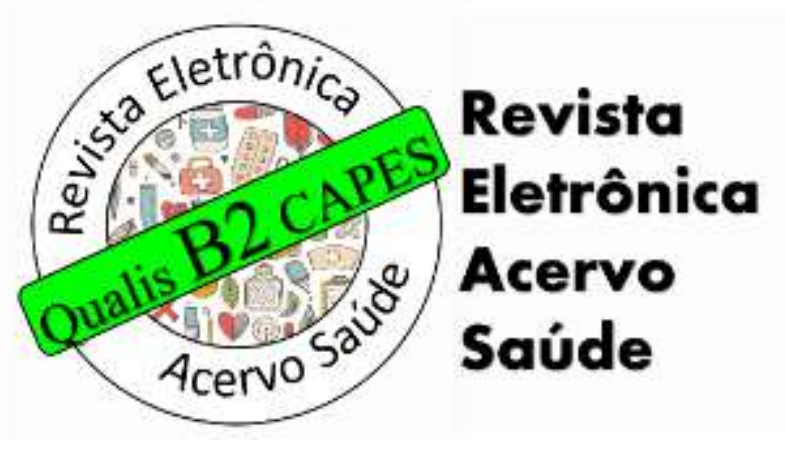

